\title{
Neurotrophic factors and their receptors
}

\author{
Vimal Parkash \\ Research Program in Structural Biology and Biophysics \\ Institute of Biotechnology, University of Helsinki
}

Department of Biological and Environmental Sciences, Faculty of Biosciences Division of Biochemistry, University of Helsinki

and

Viikki Graduate School in Biosciences

University of Helsinki

\begin{abstract}
ACADEMIC DISSERTATION
To be presented for public examination with the permission of the faculty of Biosciences of the University of Helsinki, in the lecture hall 1041 (Auditorium)

at Viikki Biocenter 2, Helsinki

on October 16, 2009 at 12 noon
\end{abstract}

Helsinki 2009 
Supervised by

Research Director Adrian Goldman

Structural Biology and Biophysics

Institute of Biotechnology

University of Helsinki, Finland

Reviewed by

Docent Tuomo Glumoff

Department of Biochemistry

University of Oulu, Finland

And

Professor Kari Keinänen

Institute of Biotechnology

Department of Biological and Environmental sciences

University of Helsinki, Finland

\section{Opponent}

Professor Joel Sussman

Department of Structural Biology

Weizmann Institute of science, Rehovot, Israel

Custos

Professor Carl G. Gahmberg

Faculty of Biosciences

Department of Biological and Environmental sciences

Division of Biochemistry

University of Helsinki, Finland

ISBN 978-952-10-5738-0 (pbk.)

ISBN 978-952-10-5736-6 (PDF)

ISSN 1795-7079

Helsinki University press

Helsinki 2009 
To my beloved family 


\section{Table of Contents}

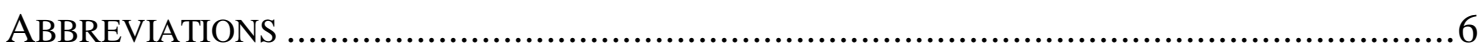

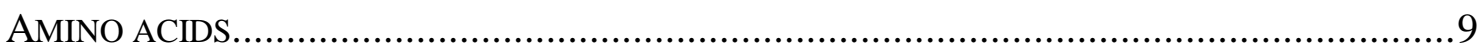

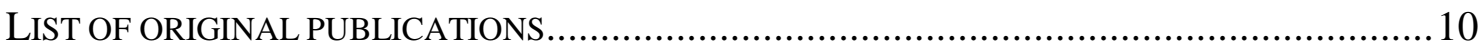

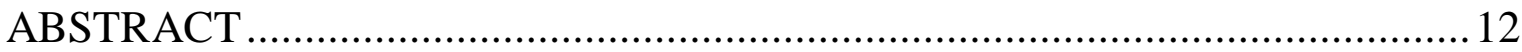

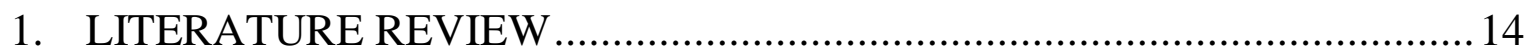

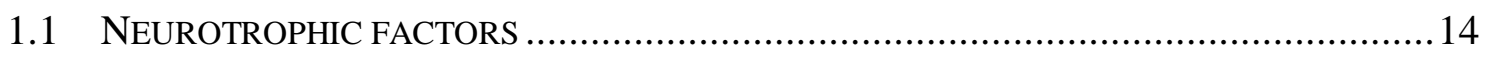

1.2 THE GDNF FAMILY OF NEUROTROPHIC FACTORS ……...................................... 17

1.3 THE GDNF FAMILY RECEPTORS AND SIGNALLING …….....................................20

1.3.1 Ligand Binding Coreceptor......................................................................21

1.3.2 Receptor tyrosine kinase RET ................................................................22

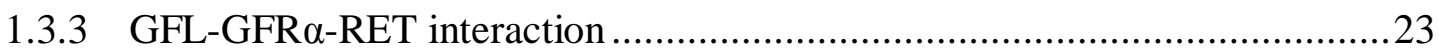

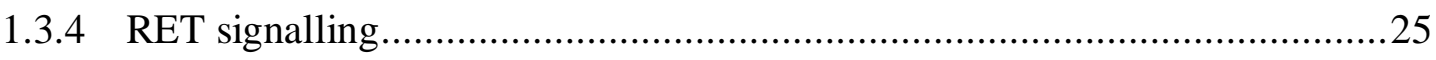

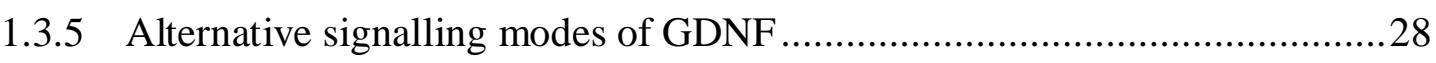

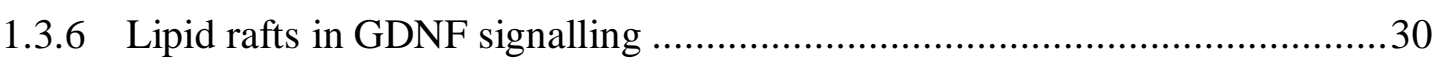

1.3.7 Heparan sulphate in GDNF signalling ........................................................30

1.4 MANF AND CDNF FAMILY OF NEUROTROPHIC FACTORS ......................................33

1.4.1 MANF as a neurotrophic factor..................................................................

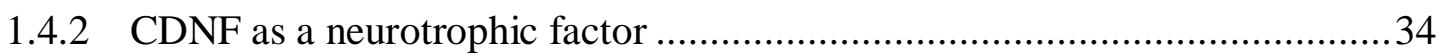

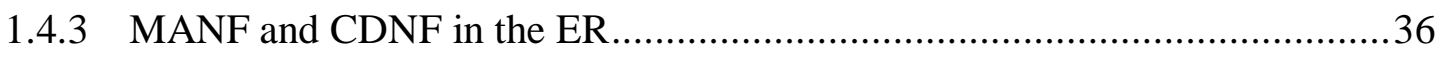

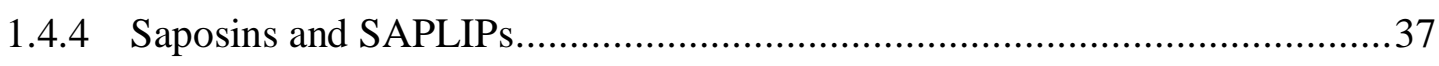

1.5 DISEASES RELATED TO GDNF-RET SIGNALLING AND MANF/CDNF .....................39

1.5.1 Knockout studies in GDNF-GFR $\alpha 1-R E T$ system ............................................39

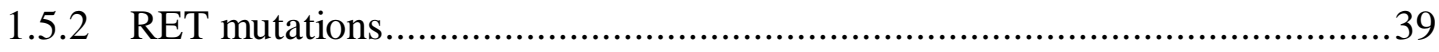

1.5.3 GDNF in Parkinson's disease ……………………………………........

1.5.4 MANF/CDNF in Parkinson's disease ……………………………….......43

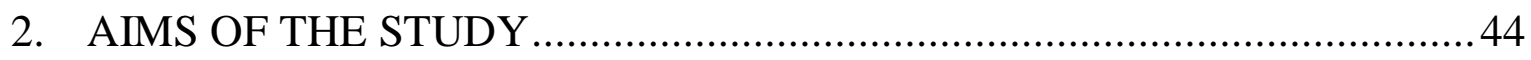

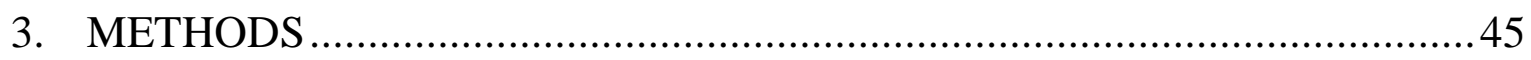

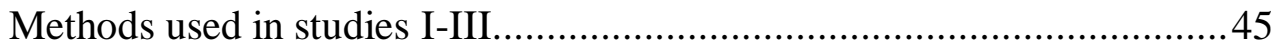




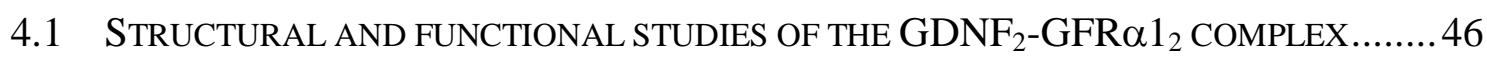

4.1.1 The crystal structure of the $\mathrm{GDNF}_{2}$-GFR $\alpha 1_{2}$ complex (Study I) ...................46

4.1.2 Insights into heparin- and RET-binding (Study I) ........................................4 48

4.1.3 Comparison between $\mathrm{GDNF}_{2}-\mathrm{GFR}_{\alpha} 1_{2}$ and $\mathrm{ARTN}_{2}-{\mathrm{GFR} \alpha 3_{2} \ldots \ldots \ldots \ldots \ldots \ldots \ldots . . .51}^{2}$

4.1.3.1 Structural basis of ligand specificity....................................................

4.1.3.2 Structural difference between GFLs indicates novel ways of signalling. 55

4.1.4 Analysis of GFL structural variation (Study III) .........................................56

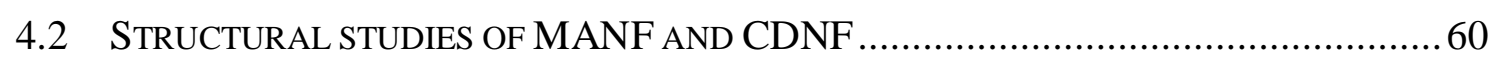

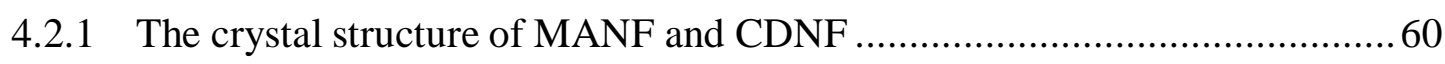

4.2.1.1 The closed saposin fold of N-termini of MANF and CDNF ..................61

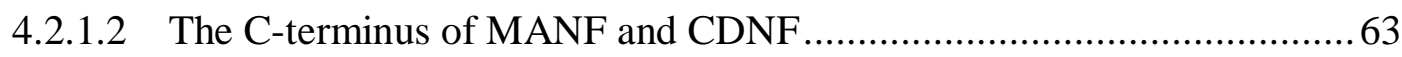

4.2.2 Functional implications from MANF and CDNF structures ............................64

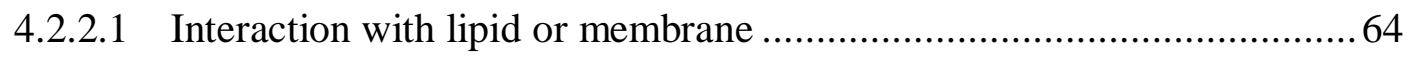

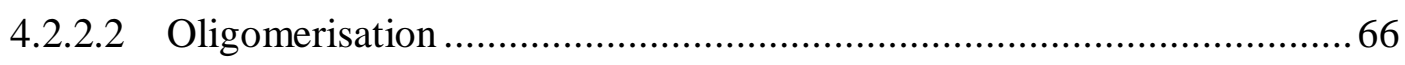

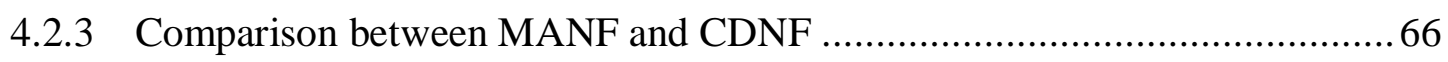

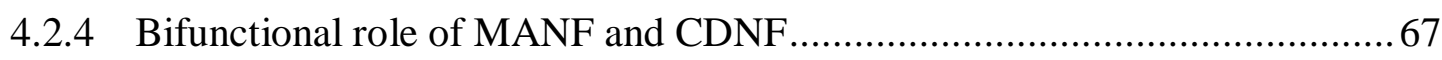

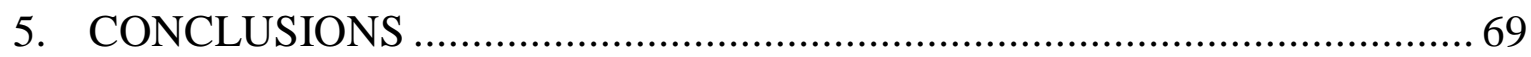

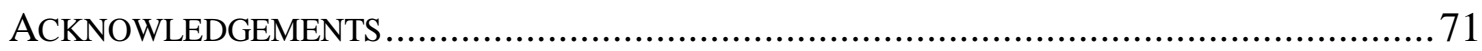

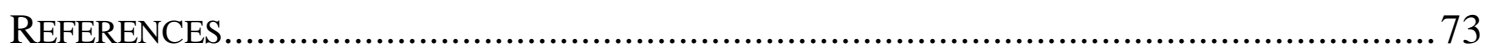

Cover Figure: The structures of the $\mathrm{GDNF}_{2}-\mathrm{GFR} \alpha 1_{2}$ complex, and the MANF and CDNF proteins in cartoon representation (Study I and II). 


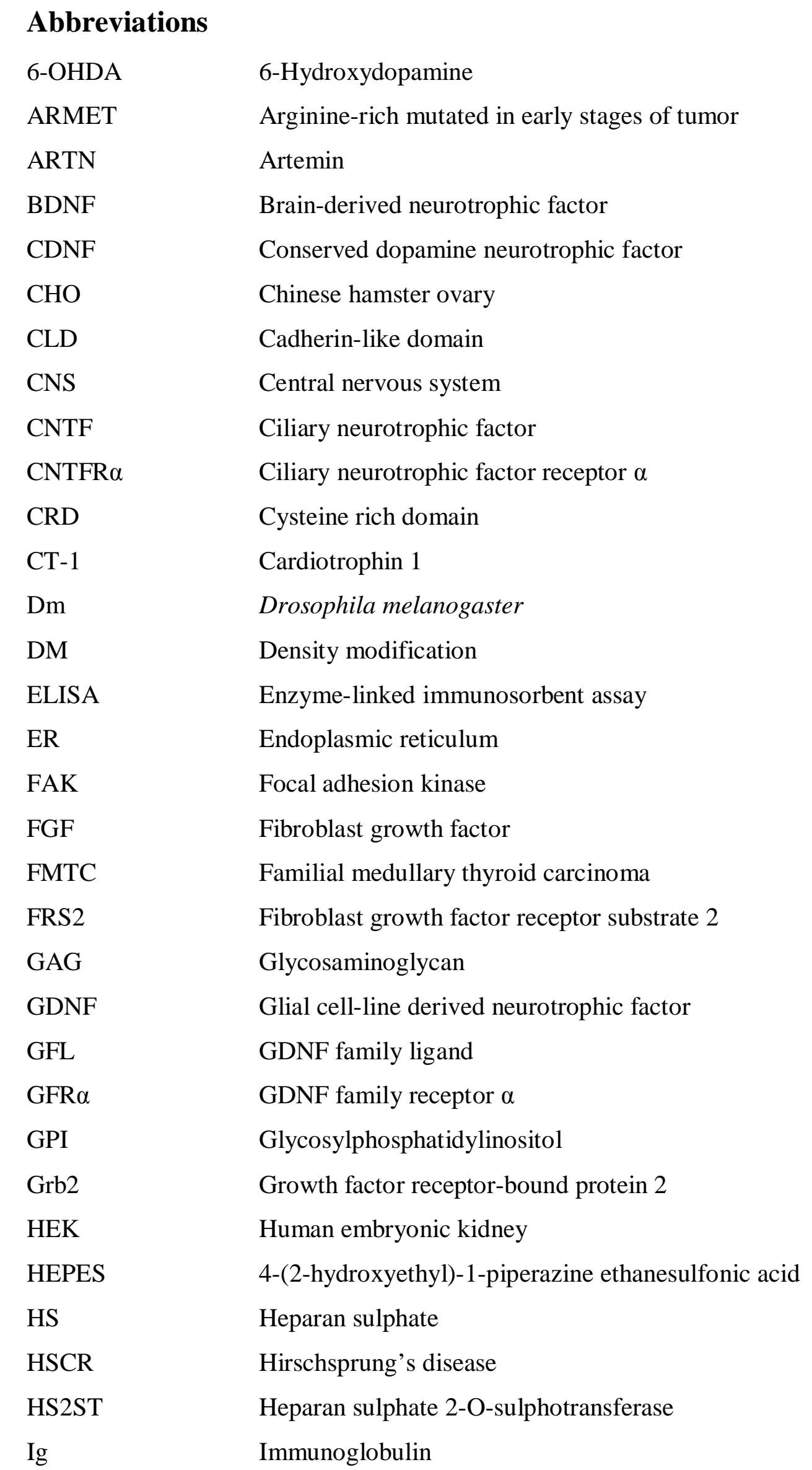


IGF

IL

IRS

JAK/STAT

JNK

$\mathrm{kDa}$

LIF

MAD

MANF

MAPK

MEN2A

MES

MME-PEG

MPTP

MTC

NCAM

NCS

NGF

NK-lysin

NRTN

NT

PAS

PD

PDI

PEG

PI3K

PLC- $\gamma$

PM

PNS

PSPN

RAS/ERK

RET

RMSD
Insulin-like growth factor

Interleukin

Insulin receptor substrate

Janus kinase/signal transduction and activator of transcription

Jun N-terminal kinase

Kilo dalton

Leukaemia inhibitory factor

Multiple anomalous diffraction

Mesensephalic astrocyte-derived neurotrophic factor

Mitogen-activated protein kinase

Multiple endocrine neoplasia type 2A

2-(N-morpholino) ethanesulfonic acid

Monomethyl ether polyethylene glycol

1-methyl-4 phenyl-1,2,5,6-tetrahydropyridine

Medullary thyroid carcinoma

Neural cell adhesion molecule

Non-crystallographic symmetry

Nerve growth factor

Natural killer-cell lysin

Neurturin

Neurotrophin

Plasmid achromobacter secretion

Parkinson's disease

Protein disulphide isomerase

Polyethylene glycol

Phosphatidylinositol-3 kinase

Phospholipase C- $\gamma$

Plasma membrane

Peripheral nervous system

Persephin

Rat sarcoma oncogene/extracellular signal-regulated kinase

Rearranged during transfection

Root mean square deviation 
SAD

SAPLIP

SCOP

SDS

SeMet

SH2

SOS

SPR

TGF

$\mathrm{TH}$

TK

Trk

UPR

$w t$
Single-wavelength anomalous diffraction

Saposin-like protein

Structural classification of proteins

Sodium dodecyl sulphate

Selenomethionine

Src homology 2

Sucrose octasulphate

Surface plasmon resonance

Transforming growth factor

Tyrosine hydroxylase

Tyrosine kinase

Tropomyosin-related kinase

Unfolded protein response

Wild-type 


\section{Amino acids}

$\begin{array}{lll}\text { A } & \text { Ala } & \text { Alanine } \\ \text { C } & \text { Cys } & \text { Cysteine } \\ \text { D } & \text { Asp } & \text { Aspartate } \\ \text { E } & \text { Glu } & \text { Glutamate } \\ \text { F } & \text { Phe } & \text { Phenylalanine } \\ \text { G } & \text { Gly } & \text { Glycine } \\ \text { H } & \text { His } & \text { Histidine } \\ \text { I } & \text { Ile } & \text { Isoleucine } \\ \text { K } & \text { Lys } & \text { Lysine } \\ \text { L } & \text { Leu } & \text { Leucine } \\ \text { M } & \text { Met } & \text { Methionine } \\ \text { N } & \text { Asn } & \text { Asparagine } \\ \text { P } & \text { Pro } & \text { Proline } \\ \text { Q } & \text { Gln } & \text { Glutamine } \\ \text { R } & \text { Arg } & \text { Arginine } \\ \text { S } & \text { Ser } & \text { Serine } \\ \text { T } & \text { Thr } & \text { Threonine } \\ \text { V } & \text { Val } & \text { Valine } \\ \text { W } & \text { Trp } & \text { Tryptophan } \\ \text { Y } & \text { Tyr } & \text { Tyrosine }\end{array}$




\section{List of original publications}

This thesis is based on the following publications.

Study I Vimal Parkash, V-M Leppänen, H. Virtanen, J. M. Jurvansuu, M. M. Bespalov, P. Runeberg-Roos, M. Saarma, Adrian Goldman (2008) The structure of the glial cell line-derived neurotrophic factor-coreceptor complex: Insights into RET signalling and heparin binding. J. Biol. Chem., 284, 35164-172.

Study II Vimal Parkash, P. Lindholm, J. Peränen, N. Kalkkinen, E. Oksanen, M. Saarma, V-M Leppänen and Adrian Goldman (2009) The structure of the conserved neurotrophic factors MANF and CDNF explains why they are bifunctional. PEDS, 22 , 233-241.

Study III Vimal Parkash and Adrian Goldman (2009) Comparison of GFL-GFR $\alpha$ complexes: further evidence relating GFL bend angle to RET signalling. Acta Cryst. F65, 551-558.

The articles have been reprinted with the permission of the copyright holders. 


\section{ABSTRACT}

GDNF family ligands (GDNF, neurturin, artemin and persephin), and mesencephalic astrocyte-derived neurotrophic factor (MANF) and conserved dopamine neurotrophic factor (CDNF) protect midbrain dopaminergic neurons that degenerate in Parkinson's disease. Each of the four homodimeric GDNF ligands binds a specific coreceptor GDNF family receptor $\alpha(\mathrm{GFR} \alpha)$, leading to the formation of a heterotetramer complex, which then interacts with receptor tyrosine kinase RET, the signalling receptor. The structure of the GDNF monomer has cystine knot topology, consisting of the heel and the finger domain. However, MANF and CDNF form a novel neurotrophic factor family with eight conserved cysteines, the receptors for which have not been identified. The present thesis describes the structural and biochemical characterization of the $\mathrm{GDNF}_{2}-\mathrm{GFR} \alpha 1_{2}$ complex and the MANF and CDNF proteins.

The crystal structure of the $\mathrm{GDNF}_{2}-\mathrm{GFR} \alpha 1_{2}$ complex shows that ion-triple and hydrophobic interactions between the GDNF finger domain and the domain 2 of GFR $\alpha 1$ are responsible for the complex formation, as in the $\operatorname{artemin}_{2}-\mathrm{GFR} \alpha 3_{2}$ structure. Previous and current mutation data and comparison between GDNF-GFR $\alpha 1$ and artemin-GFR $\alpha 3$ binding interfaces show that $\mathrm{N} 162^{\mathrm{GFR} \alpha 1}, \mathrm{I} 175^{\mathrm{GFR} \alpha 1}, \mathrm{~V} 230^{\mathrm{GFR} \alpha 1}, \mathrm{Y} 120^{\mathrm{GDNF}}$ and $\mathrm{L} 114^{\mathrm{GDNF}}$ are the specificity determinants among different ligand-coreceptor pairs.

As heparin or heparan sulphates have been suggested to influence GDNF signalling, the crystal structure of the $\mathrm{GDNF}_{2}-\mathrm{GFR} \alpha 1_{2}$ complex was solved in the presence of the heparin mimic, sucrose octasulphate (SOS). The structure suggests that heparin interacts with a region R190-K202 within domain 2 of GFR $\alpha 1$, consistent with previous predictions. Mutating these residues on the GFR $\alpha 1$ surface, which are not in the GDNF binding region, affected RET phosphorylation. I could thus identify a putative RET binding region in domain 2 and 3 of GFR $\alpha 1$. The mutant and structural data suggest that the heparin and RET binding sites within GFR $\alpha 1$ overlap.

The structural comparison of the $\mathrm{GDNF}_{2}-\mathrm{GFR} \alpha 1_{2}$ and $\operatorname{artemin}_{2}-\mathrm{GFR} \alpha 3_{2}$ complexes shows a difference in bend angle between the ligand monomers. This variation in bend angle of the ligand may affect the kinetics of RET phosphorylation. To confirm that the difference is not due to crystallization artefacts, I crystallized the $\mathrm{GDNF}_{2}-\mathrm{GFR} \alpha 1_{2}$ complex without 
SOS in different cell dimensions. The structure of the second $\mathrm{GDNF}_{2}-\mathrm{GFR} \alpha 1_{2}$ complex is very similar to the previous one, suggesting that the difference between the $\operatorname{artemin}_{2}$ GFR $\alpha 3_{2}$ and $\mathrm{GDNF}_{2}-\mathrm{GFR} \alpha 1_{2}$ complexes are intrinsic, not due to crystal packing. From the comparison of eleven GDNF and artemin structures, $\mathrm{GDNF}_{2}$ seems to be more bent and more flexible than $\operatorname{artemin}_{2}$, and this may be related to RET signalling. The differences appear to be due to increased curvature of the artemin fingers, which both increases the buried surface area in the monomer-monomer interface and changes the intermonomer bend angle.

Finally, MANF and CDNF are bifunctional proteins with extracellular neurotrophic activity and ER resident cytoprotective role. The crystal structures of MANF and CDNF are presented here. Intriguingly, the structures of both the neurotrophic factors do not show structural similarity to any of previously known growth factor superfamilies; instead they are similar to saposins, the lipid-binding proteins. The N-terminal domain of MANF and CDNF contain conserved lysines and arginines on its surface, which may interact with negatively charged head groups of phospholipids, as saposins do. Thus MANF and CDNF may provide neurotrophic activities by interacting with a lipo-receptor. The structure of MANF shows a CXXC motif forming internal disulphide bridge in the natively unfolded C-terminus. This motif is common to reductases and disulphide isomerases. It is thus tempting to speculate that the CXXC motif of MANF and CDNF may be involved in oxidative protein folding, which may explain its cytoprotective role in the ER. 


\section{LITERATURE REVIEW}

\subsection{Neurotrophic factors}

Neurotrophic factors are small proteins that provide trophic (derived from the Greek $\tau \rho o \phi \eta$, meaning "to nourish") events in neuronal cells. These secreted neurotrophic factors act by binding to the specific cell surface receptor(s) that signal the neuron to survive. Neurotrophic factors are important in the developing and mature nervous system. They influence cell proliferation, survival, differentiation, migration, axon and dendritic growth and synaptic plasticity. They play critical roles in complex behaviors including anxiety, depression (Vaidya and Duman, 2001), and learning (Mangina and Sokolov, 2006). Neurotrophic factors may provide treatment for a variety of neurological diseases including Alzheimer's disease, Parkinson's disease, Huntington's disease, epilepsy and neuropathies. They can be given exogenously as pure proteins or through gene therapy (Lawlor and During, 2004), to prevent nerve cell death caused by various insults including nerve injury, brain trauma, and exposure to toxins.

A number of trophic factors that exert survival-promoting effects in experimental models of nervous system injury and neurodegenerative diseases can be grouped into families based on homology of the trophic factors, receptors, and common transduction pathways. There are currently four families of trophic factors that are specific to the nervous system (Figure 1.1). Three of them, which include neurotrophins, neuropoietic cytokines and glial cell line-derived neurotrophic factor (GDNF) family, have been well characterized (for a review, see Butte, 2001). The fourth one consisting of mesencephalic astrocyte-derived neurotrophic factor (MANF, Petrova et al., 2003) and conserved dopamine neurotrophic factor (CDNF, Lindholm et al., 2007) has recently shown to have potent neurotrophic effects. These neurotrophic factor families promote the survival of dopaminergic neurons, and provide protective and restorative effects against neurodegeneration. The neurotoxins 6-hydroxydopamine (6-OHDA) (Simon et al., 1974) and 1-methyl-4 phenyl-1,2,5,6tetrahydropyridine (MPTP) (Heikkila et al., 1984) are used in neurodegenerative models of rats and monkeys. To observe neuroprotective effects, trophic factor is injected before the toxin; whereas in neurorestoration, it is injected after the lesion is induced. A number of 
other trophic factors also have survival promoting, protective and restorative effects on dopamine neurons in vitro and in vivo (Table 1).

\section{Neurotrophic Factors}

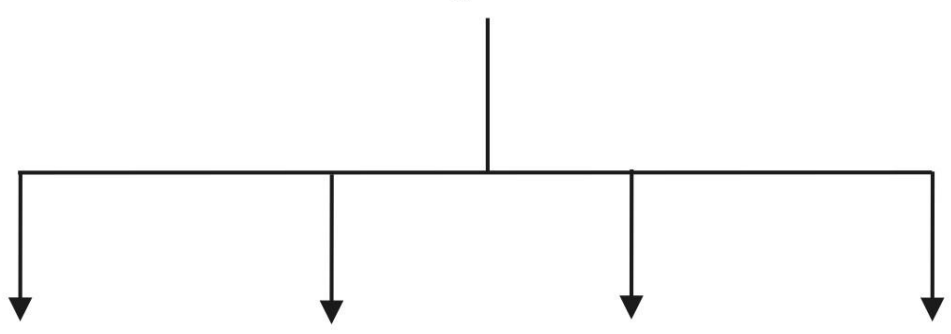

\begin{tabular}{llll} 
Neurotrophins & Cytokines & \multicolumn{1}{c}{ GFLs } & MANF family \\
1. NGF & 1. CNTF & 1. GDNF & 1. MANF \\
2. BDNF & 2. IL-6 & 2. NRTN & 2. CDNF \\
3. NT-3 & 3. CT-1 & 3. ARTN & \\
4. NT-4/5 & & 4. PSPN &
\end{tabular}

Figure 1.1 Neurotrophic factors. Abbreviations: NGF, nerve growth factor (neurotrophin-1); BDNF, brain-derived neurotrophic factor (neurotrophin-2); NT, neurotrophin; CNTF, ciliary neurotrophic factor; IL-6, interleukin-6; CT-1, cardiotrophin-1; GDNF, glial cell line-derived neurotrophic factor; GFL, GDNF family of ligands; NRTN, neurturin; ARTN, artemin; PSPN, persephin; MANF, mesencephalic astrocyte derived neurotrophic factor; CDNF, conserved dopamine neurotrophic factor.

The most studied neurotrophic factors form the neurotrophin family, consisting of nerve growth factor (NGF), brain-derived neurotrophic factor (BDNF), neurotrophin-3 (NT-3), and neurotrophin-4/5 (NT-4/5) (Reichardt, 2006). Neurotrophins support various neuronal populations in the peripheral nervous system and the central nervous system (Huang and Reichardt, 2001). Nerve growth factor promoted the neurite growth of sympathetic neurons in chicken (Levi-Montalcini and Hamburger, 1951). BDNF was the first neurotrophin described to promote the survival and dopamine uptake of embryonic midbrain dopaminergic neurons in vitro (Hyman et al., 1991). It prevented neuronal death caused by 6-OHDA (Spina et al., 1992). Later other neurotrophins including NT-3 and NT-4 also showed survival promoting effects in dopaminergic neurons. Neurotrophins can bind two unrelated receptors: tropomyosin-related kinase (Trk A, Trk B, Trk C) and a common neurotrophin receptor p75NTR (Reichardt, 2006). Trks are tyrosine kinase receptors that stimulate the mitogen-activated protein kinase (MAPK) pathway, while p75NTR is a tumor necrosis factor receptor, and signals through an intracellular death domain to activate the cellular apoptosis machinery. Ligand binding is selective to different Trks, whereas all neurotrophins bind to p75NTR. 
Table 1. Other growth factors with effects on dopaminergic neurons.

\begin{tabular}{|c|c|c|c|}
\hline Trophic Factor & $\begin{array}{l}\text { Reference (for } \\
\text { trophic activities) }\end{array}$ & $\begin{array}{l}\text { Neuroprotection } \\
\text { model (Ref.) }\end{array}$ & $\begin{array}{l}\text { Neurorestoration model } \\
\text { (Ref.) }\end{array}$ \\
\hline Erythropoietin (EPO) & Studer et al., 2000 & $\begin{array}{l}\text { 6-OHDA rat (Xue } \\
\text { et al., 2007) } \\
\text { MPTP mice (Genc } \\
\text { et al., 2001) }\end{array}$ & $\begin{array}{l}\text { MPTP-mice (Puskovic et } \\
\text { al., 2006) } \\
\text { 6-OHDA rat (Xue et al., } \\
\text { 2007) }\end{array}$ \\
\hline $\begin{array}{l}\text { Insulin-like growth } \\
\text { factor (IGF1/2) }\end{array}$ & Knusel et al., 1990 & $\begin{array}{l}\text { 6-OHDA rat } \\
\text { (Quesada and } \\
\text { Micevych, 2004) }\end{array}$ & $\begin{array}{l}\text { 6-OHDA rat (Ebert et al., } \\
\text { 2008) }\end{array}$ \\
\hline $\begin{array}{l}\text { Fibroblast growth } \\
\text { factor (bFGF/FGF-2) }\end{array}$ & $\begin{array}{l}\text { Engele and Bohn, } \\
1991\end{array}$ & $\begin{array}{l}\text { 6-OHDA rat } \\
\text { (Shults et al., } \\
\text { 2000) }\end{array}$ & $\begin{array}{l}\text { MPTP monkey (Fontan et } \\
\text { al., 2002) }\end{array}$ \\
\hline $\begin{array}{l}\text { Vascular endothelial } \\
\text { growth factor (VEGF) }\end{array}$ & $\begin{array}{l}\text { Silverman et al., } \\
1999\end{array}$ & $\begin{array}{l}\text { 6-OHDA rat } \\
\text { (Yasuhara } \text { et al., } \\
\text { 2004) }\end{array}$ & $\begin{array}{l}\text { 6-OHDA rat (Yasuhara et } \\
\text { al., 2004; Yasuhara et al., } \\
\text { 2005) }\end{array}$ \\
\hline $\begin{array}{l}\text { Platelet-derived growth } \\
\text { factor (PDGF) }\end{array}$ & $\begin{array}{l}\text { Nikkhah et al., } \\
1993\end{array}$ & ND & $\begin{array}{l}\text { 6-OHDA rat (Mohapel et } \\
a l ., \text { 2005) }\end{array}$ \\
\hline $\begin{array}{l}\text { Transforming growth } \\
\text { factor } \alpha \text { (TGF- } \alpha \text { ) }\end{array}$ & $\begin{array}{l}\text { Alexi and Hefti, } \\
1993\end{array}$ & ND & $\begin{array}{l}\text { 6-OHDA rat } \\
\text { (Fallon } \text { et al., 2000) }\end{array}$ \\
\hline $\begin{array}{l}\text { Transforming growth } \\
\text { factor } \beta \text { (TGF- } \beta \text { ) }\end{array}$ & $\begin{array}{l}\text { Krieglstein and } \\
\text { Unsicker, } 1994\end{array}$ & $\begin{array}{l}\text { MPTP mouse } \\
\text { (Schober et al., } \\
\text { 2007) }\end{array}$ & ND \\
\hline $\begin{array}{l}\text { Bone morphogenetic } \\
\text { protein (BMP) }\end{array}$ & Jordan et al., 1997 & $\begin{array}{l}\text { 6-OHDA rat } \\
\text { (Harvey et al., } \\
\text { 2005) }\end{array}$ & ND \\
\hline
\end{tabular}

The neuropoietic cytokine family (also known as neurokines) include ciliary neurotrophic factor (CNTF), interleukin 6 (IL-6) and leukaemia inhibitory factor (LIF), interleukins 11 (IL-11), cardiotrophin 1 (CT-1), and oncostatin M (OSM) (Sleeman et al., 2000). Of these, IL-6, CNTF and CT-1 mostly affect nervous system development, and IL-6 and CNTF show trophic effects on midbrain dopaminergic neurons (Heinrich et al., 2003). CNTF was originally considered as a neurotrophin because of its survival-promoting actions on parasympathetic neurons from chick ciliary ganglia. Later cloning and sequencing revealed that it does not belong to neurotrophins. CNTF has shown trophic and differentiating effects on different types of peripheral and central neurons (Sleeman et al., 2000). CNTF signalling involves its association with CNTFR $\alpha$, GP130 and LIF-receptor. Formation of this complex leads to activation of the Janus kinase/signal transducer and activator of transcription (JAK/STAT) signalling pathway. 
The following sections review previous studies of the GDNF ligands and their receptors, and the MANF/CDNF family.

\subsection{The GDNF family of neurotrophic factors}

First isolated from glial cell line B49, GDNF showed survival-promoting effects in embryonic midbrain culture of dopaminergic neurons by regulating tyrosine hydroxylase (TH) expression and dopamine uptake (Lin et al., 1993). GDNF is also a potent survival factor of motor neurons (Henderson et al., 1994) and other neuronal subpopulations in the central nervous system (CNS) and the peripheral nervous system (PNS). In the CNS, GDNF prevented 6-OHDA-induced degeneration of noradrenergic neurons (Arenas et al., 1995) and, in the PNS, it regulates the differentiation of sympathetic, parasympathetic, sensory and enteric neurons (Taraviras et al., 1999; Young et al., 2001; Natarajan et al., 2002; Gianino et al., 2003). These potent effects in the nervous system mean that GDNF can be beneficial for the treatment of Parkinson's disease (see section 1.5.3). Since GDNF knockout mice have severe renal agenesis at the time of birth, GDNF signalling is essential for kidney morphogenesis (Costantini and Shakya, 2006). In addition, GDNF is important for spermatogonia development (Hofmann, 2008). This wide range of neuroprotective and therapeutic roles of GDNF makes it an interesting molecule for study.

Three other homologous proteins, neurturin (NRTN), artemin (ARTN) and persephin (PSPN), have been characterized with neurotrophic and neuroprotective actions. NRTN has been shown to support survival and proliferation of several neuron populations in the central and peripheral nervous system (Kotzbauer et al., 1996; Klein et al., 1997; Heuckeroth et al., 1998; Rossi et al., 1999; Golden et al., 2003). Like GDNF, NRTN promotes the survival of dopaminergic neurons in vitro and in vivo (Horger et al., 1998). It has protective and restorative effects on mesencephalic dopaminergic neurons in animal models of Parkinson's disease (Rosenblad et al., 1999). It also regulates the development of most of the parasympathetic neurons (Rossi et al., 1999). In addition, NRTN can induce branch initiation in kidney development (Davies et al., 1999).

ARTN is a survival factor for sympathetic and sensory neurons in vitro (Baloh et al., 1998; Enomoto et al., 2001). In vivo, it protects rodent nigrostriatal dopamine neurons 
(Rosenblad et al., 2000). It also regulates sensory neurons, and is therefore considered for the treatment of chronic pain (Wang et al., 2008). PSPN, the fourth GDNF-like protein, promotes the survival of ventral midbrain dopaminergic neurons in culture and in vivo after sciatic nerve axotomy and, like GDNF, promotes ureteric bud branching in vitro (Milbrandt et al., 1998; Åkerud et al., 2002). PSPN promotes the survival of embryonic basal forebrain cholinergic neurons in vitro (Golden et al., 2003). However, PSPN does not seem to support any peripheral neurons (Milbrandt et al., 1998; Åkerud et al., 2002). PSPN has also been shown to promote both survival and neuritogenesis of midbrain dopamine neurons and thus it has been suggested that PSPN, like GDNF and NRTN, might have therapeutic potential in the treatment of Parkinson's disease (Åkerud et al., 2002).

These neurotrophic factors together form a family named GDNF family of ligands (GFLs).

\section{Structural features of the GDNF ligands}

GFLs are biologically active covalently linked homodimers, in which each monomer has a "cystine knot" topology. The cystine knot is a covalent ring formed by two cystines and the connecting polypeptide chain, through which a third cystine is passed. It confers structural stability, and is characteristic of many growth factor families with less than $20 \%$ sequence identity (Sun and Davies, 1995). Cystine knot growth factors include TGF- $\beta$ s, neurotrophins, platelet-derived growth factor family, and glycoprotein hormones (Sun and Davies, 1995). These growth factors are dimeric proteins, and some have an intermonomer disulphide bridge in addition to the cystine knot. GFLs are more closely related to TGF- $\beta \mathrm{s}$ than other cystine knot growth factors. Like TGF- $\beta$ s, GFLs contain seven conserved cysteines in each monomer; six of those form cystine knot (Figure 1.2A), while the seventh one forms the intermonomer cystine bridge. Neurotrophins and glycoprotein hormone families dimerize by noncovalent interactions without the interchain disulphidebridge (McDonald et al., 1991; Holland et al., 1994). The overall sequence identity between GFLs and the TGF- $\beta$ superfamily is less than $20 \%$, which makes them a distant member of the TGF- $\beta$ superfamily. 


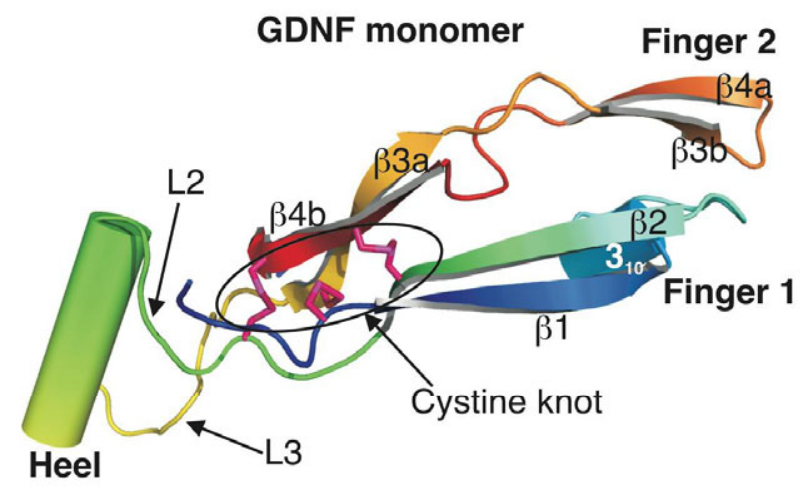

B GDNF homodimer
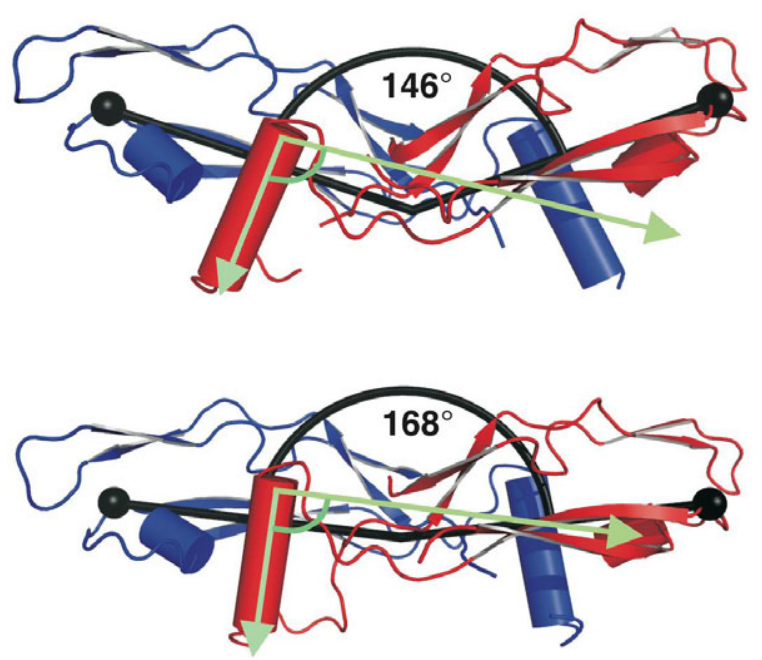

C

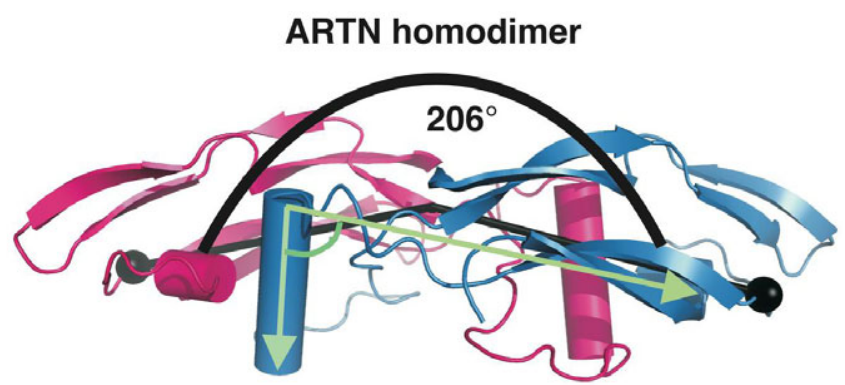

Figure 1.2 The GDNF and ARTN structures. A) Structural details of the GDNF monomer (1AGQ; chain $\mathrm{D}$ ). The cartoon is coloured from blue to red. $\beta 1$ and $\beta 2$ form finger 1 , and $\beta 3$ and $\beta 4$ form finger 2. Magenta sticks show the characteristic 'cystine-knot'. B) Bend angle in the GDNF homodimer structures (1 AGQ). Top figure shows the bend angle between chain A and B (in red and blue), while bottom one is between chain $\mathrm{C}$ and $\mathrm{D}$ (in the same colours). The light green arrows mark the hinge angle between the finger domain and the heel. The structure is symmetric about the vertical two-fold axis. The lines (black) drawn from the intermonomer $S_{\gamma}$ of Cys101 to E61- $C_{\alpha}$ and E61- $\mathrm{C}_{\alpha}{ }^{\prime}$ (black sphere) describes the bend angle (see Methods in Study III). C) The ARTN homodimer structure (2GH0, in light blue and magenta) showing the bend angle between the monomers. 
GDNF is expressed as a prepro-protein, from which the signal peptide (pre) is cleaved upon secretion. An enzymatic cleavage of the pro-GDNF results in a mature secreted form containing 134 residues, which is functional as a disulphide-bonded homodimer. The rat GDNF structure (1AGQ; Eigenbrot and Gerber, 1997) is comprised of four $\beta$-strands and an $\alpha$-helix, called the 'heel' (Figure 1.2A). The $\beta$-strands of GDNF form a finger domain consisting of two 'fingers', finger 1 and finger 2.

The two monomers form a head-to-tail dimer with the residues on the heel packed against the finger domain. In the GDNF crystal, the asymmetric unit contained two independent covalent homodimers (chain $\mathrm{AB}$ and $\mathrm{CD}$ ) that differ in the hinge angle between the finger domain and the heel in the monomer structure (Figure 1.2B). Superposing the homodimers gives a root mean square deviation (RMSD) of $2.6 \AA$.

Of the GFLs, ARTN is the only other ligand in the family whose structure has been solved (2ASK; Silvian et al., 2006). Its amino acid sequence is more similar to NRTN and PSPN than to GDNF. The ARTN structure is similar to GDNF (1AGQ) with the same cystine knot topology. The superposition of GDNF on ARTN gives a RMSD of $2.9 \AA$ for the monomer structure but over $4 \AA$ for the homodimer. Silvian and co-workers (2006) measured the hinge angle between the heel and the finger domain by calculating the angle between the helical axis and a line drawn perpendicular to the disulphide bonds of the cystine knot. The hinge angle is $83^{\circ}$ in ARTN, and approximately $90^{\circ}$ in each of the two independent GDNFs. There is intermonomer bend angle in the GFL homodimer, which is measured as the angle between the fingertips from the center of the intermonomer cystine bridge (see Methods, Study III). The bend angles for both the dimeric GDNFs are $146^{\circ}$ and $168^{\circ}$ (Figure 1.2B), and $206^{\circ}$ for $\mathrm{ARTN}_{2}$ (Figure 1.2C). Unlike $\mathrm{GDNF}_{2}$, the bend angle is same in all the six $\mathrm{ARTN}_{2}$ structures (codes $2 \mathrm{ASK}, 2 \mathrm{GYR}, 2 \mathrm{GH} 0,2 \mathrm{GYZ}$ ), which superimpose to an RMSD value of less than $1 \AA$. The bend angle could impart different receptor specificities by altering receptor interactions or conformations.

\subsection{The GDNF family receptors and signalling}

GFLs require two independent receptor subunits to exert their biological effects: a ligand binding GDNF family receptor $\alpha(\mathrm{GFR} \alpha)$, and a common signalling receptor tyrosine 
kinase RET (Durbec et al., 1996; Trupp et al., 1996). In GDNF signalling, RET delivers the intracellular signal but cannot bind ligand on its own. The coreceptor binds the ligand but does not signal in the absence of RET. GFL signalling is thus different from other members of the TGF- $\beta$ family, where a heterotetramer complex is formed with the ligand binding receptor of a transmembrane serine/threonine kinase (Massague and Weis-Garcia, 1996).

\subsubsection{Ligand Binding Coreceptor}

GFR $\alpha 1$, first described as GDNFR- $\alpha$ (Jing et al., 1996; Treanor et al., 1996), was identified as a GDNF-binding receptor in RET signalling (Durbec et al., 1996; Trupp et $a l ., 1996)$. It is glycosylphosphatidylinositol (GPI)-anchored to the cell surface. Likewise, other GFLs also signal through RET by binding a preferred GFR $\alpha$ (Figure 1.3): NRTN binds GFRa2 (Baloh et al., 1997; Buj-Bello et al., 1997; Jing et al., 1997; Klein et al., 1997; Sanicola et al., 1997); ARTN, GFRa3 (Baloh et al., 1998), and PSPN, GFR $\alpha 4$ (Enokido et al., 1998; Lindahl et al., 2001).

The ubiquitous in vivo expression of GFR $\alpha$ compared to RET suggested that the GPIanchor of GFRas could be cleaved to release soluble GFR $\alpha$ s from the cell surface, which may subsequently bind to a GFL and activate RET on another cell in trans (Baloh et al., 1997; Trupp et al., 1997; Yu et al., 1998). It has been demonstrated that endogenous soluble GFR $\alpha 1$ is released from cultured gut cells (Worley et al., 2000) and Schwann cells (Paratcha et al., 2001). This is analogous to other GPI-anchored receptors, such as the CNTF receptor $\alpha(\mathrm{CNTFR} \alpha)$, which are also released from cells and act as soluble mediators of the biological activities of their ligands (Davis et al., 1993).

Each GFR $\alpha$ consists of three homologous cysteine-rich domains (D1, D2 and D3) with a C-terminal extension (Figure 1.3). The conserved cysteine pattern and sequence similarity (>60\%) among D1, D2 and D3 of the coreceptor suggest alikeness in their three dimensional structures. The role of D1 is unclear, but it is not necessary for RET binding to GFR $\alpha 1$ (Scott and Ibáñez, 2001; Virtanen et al., 2005) and is absent in GFRa4 (Lindahl et al., 2001). Leppänen and co-workers (2004) solved the first crystal structure of GFR $\alpha 1$ D3, revealing a novel fold consisting of five $\alpha$-helices connected with five disulphide bridges, which was used to build a homology model of GFR $\alpha 1$ D2. 


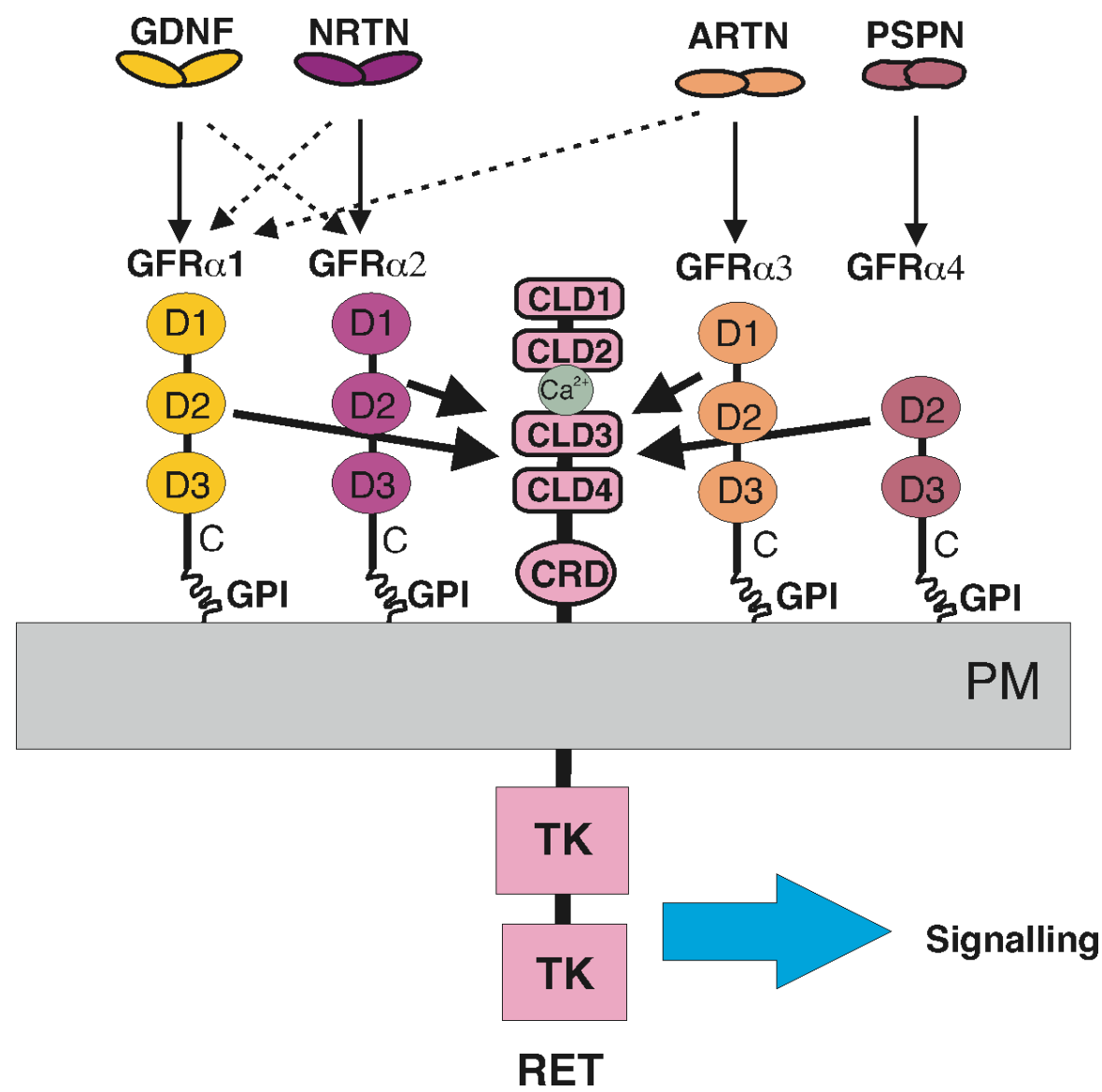

Figure 1.3 GFLs, GFR as and RET. GFLs (GDNF, NRTN, ARTN and PSPN) bind a specific coreceptor (GFR $\alpha 1$, GFR $\alpha 2$, GFR $\alpha 3$ and GFR $\alpha 4$ ), and activate the common signalling receptor RET (in light pink). The promiscuity of GFR $\alpha 1$ is shown with dotted arrows. PM, plasma membrane; TK, tyrosine kinase domain; GPI, glycosylphosphatidylinositol. Reprinted with permission from Acta Cryst. sect. F (Study III) copyrights 2009.

\subsubsection{Receptor tyrosine kinase RET}

Receptor tyrosine kinases are transmembrane spanning receptors, which are activated by ligand. Receptor tyrosine kinase RET was originally discovered in a gene rearrangement and transfection assay using a fibroblast cell line (Takahashi et al., 1985). In 1996, it was identified as a signalling receptor for GDNF (Durbec et al., 1996; Trupp et al., 1996). The natural alternative splicing of the RET gene results in the production of three different isoforms of the protein. RET51, RET43 and RET9 contain 51, 43 and 9 amino acids in their C-terminal tail, respectively. RET51 (1114 residues) and RET9 (1072 residues) are the predominant isoforms in which RET occurs. Each isoform of RET is composed of an 
extracellular region, followed by a single pass transmembrane segment and a cytoplasmic tyrosine kinase (TK) domain.

The extracellular region in RET is significantly different from other receptor tyrosine kinases (Anders et al., 2001). It contains four cadherin like domains (CLD1-4) and a cysteine rich domain (CRD) (Figure 1.3). The $\mathrm{Ca}^{2+}$ binding site between CLD2 and CLD3 is essential for folding, secretion, as well as signal transduction (Nozaki et al., 1998; Anders et al., 2001). Although no structure is yet available for any of the extracellular domains of RET, each of the CLDs of RET was modeled using the crystal structures of the epithelial and the neural cadherins (Anders et al., 2001). On the other hand, the structure of the intracellular RET-TK has been solved (see section 1.3.4).

\subsubsection{GFL-GFR $\alpha$-RET interaction}

The details of the activation mechanisms behind $\mathrm{GFL}_{2}-\mathrm{GFR}_{2}-\mathrm{RET}_{2}$ signalling are poorly understood. In the original model, it was suggested that dimeric GDNF first binds GFR $\alpha 1$, and forms the $\mathrm{GDNF}_{2}-\mathrm{GFR} \alpha 1_{2}$ complex (Jing et al., 1996). It then binds two molecules of RET, forming the $\mathrm{GDNF}_{2}-\mathrm{GFR} \alpha 1_{2}-\mathrm{RET}_{2}$ complex. Formation of the complex leads to the transphosphorylation of the tyrosine kinase domains of RET. In cell-based studies, Schlee and co-workers (2006) proposed a new model in which ARTN first binds to a monomer of GFR 33 , followed by sequential recruitment of one RET molecule and then additional molecules of GFR $\alpha 3$ and RET. The crystal structure of the ARTN $\mathrm{A}_{2}-\mathrm{GFR} \alpha 3_{2}$ complex is symmetric (Wang et al., 2006), which suggests that the heterohexamer complex with RET is symmetric too, but it does not provide any information on the details of the activation mechanism.

The ligand coreceptor binding was studied by a number of groups. GFR $\alpha 1$ was originally described as a high affinity $(\sim 2 \mathrm{pM})$ coreceptor for GDNF in the absence of RET in kidney cell line (Jing et al., 1996; Treanor et al., 1996). Later, radioligand cell-based binding assay showed a high affinity binding of $11 \mathrm{pM}\left(K_{\mathrm{d}}\right)$ between GDNF and GFR $\alpha 1$ only in the presence of RET (Cik et al., 2000). The authors observed low levels of RET mRNA in HEK293 cells, and suggested that this low level expression of RET might have influenced the affinity of GDNF in previous studies by Jing et al. (1996). 
In cell-based binding assays, the GDNF finger loop residues E61, L114 and Y120 were identified as critical for GFR $\alpha 1$ binding (Eketjäll et al., 1999), but only mutation E61A led to more than ten-fold reduction in RET activation. The mutations L114A and Y120A, with insignificant GFR $\alpha 1$ binding affinity, still phosphorylate RET in a GFR $\alpha 1$ dependent manner. The authors suggested that these mutations interact with a binding site formed by a pre-associated GFR $\alpha 1-$ RET complex. The mutations L118A and I122A also showed a more than five-fold reduction in coreceptor binding. These observations gave the first evidence that the coreceptor-binding site was in the GDNF finger domain.

On the GFR $\alpha$ side, Scott and Ibáñez (2001) constructed chimeric GFR $\alpha$, mapped GDNF binding to the central region of GFR $\alpha 1$ (D23 ${ }^{145-348}$ ), and identified two triplets, ${ }^{224} R_{R R}{ }^{226}$ and ${ }^{211} \mathrm{MLF}^{213}$, that are critical for the ligand binding. Based on a homology model of GFRa1 D23, a number of residues (F213, R217, I219, R224, R225, R226, R240, Y254/I255, R257/R259, D262/E280 and E323/D324) surrounding these triplets were mutated, and binding affinity was measured using radioligand cell-based binding and scintillation proximity assays (Leppänen et al., 2004). Four critical residues (F213, R224, R225 and I229) significantly affected the GDNF binding affinity. Nonetheless, these mutations still mediated GDNF-dependent RET phosphorylation, which suggests that GDNF-GFR $\alpha 1$ interactions can largely be compromised without losing GDNF-induced RET activation (Leppänen et al., 2004).

The crystal structure of the $\mathrm{ARTN}_{2}-\mathrm{GFR} \alpha 3_{2}$ complex contained domain 2 and 3 (D23) of GFR 3 3, where D3 stabilizes D2 (Wang et al., 2006). The structure showed that the ARTN fingers insert into the center of the triangular $\alpha$-spiral of GFR $\alpha 3$ D2, and a salt bridge is formed at the binding interface between E61 ${ }^{\mathrm{ARTN}}$, R171 ${ }^{\mathrm{GFR} \alpha 3}$ and R224 ${ }^{\mathrm{GFR} \alpha 3}$ (GDNF and GFR $\alpha 1$ numbering).

Like GDNF, NRTN and ARTN can also signal through RET-GFR $\alpha 1$ (Creedon et al., 1997; Cik et al., 2000; Carmillo et al., 2005). On the other hand, GDNF can also phosphorylate RET via GFRa2, though it is less effective than NRTN (Jing et al., 1997). These in vitro results suggest the existence of cross talk among GFL-GFR $\alpha$ pairs, with GFR $\alpha 1$ being the most promiscuous coreceptor for GDNF, NRTN and ARTN (Figure 1.3) (Airaksinen et al., 1999). However, PSPN cannot signal through GFRa1-RET even in 
vitro (Enokido et al., 1998). The biological relevance of cross talk signalling is poorly understood, and the structural basis of specificity among GFLs is unclear.

In the absence of ligand, GFR $\alpha$ s (GFR $\alpha 1$ and GFR $\alpha 2$ ) associate with RET in coimmunoprecipitation experiments (Treanor et al., 1996; Klein et al., 1997). However, the GFR $\alpha$-RET interaction is weak (Sanicola et al., 1997), and ligand stabilizes the association between GFR $\alpha 1$ and RET (Treanor et al., 1996; Klein et al., 1997). Therefore, it is thought that RET binds a composite surface formed over the ligand-coreceptor complex. Homologue scanning mutagenesis studies of RET extracellular domains suggested that the first domain of RET, CLD1, may be involved in interacting with GDNF-GFR $\alpha 1$ (Kjær and Ibáñez, 2003a). However, cross-linking and mass spectrometry experiments indicated that the CLD4-CRD interacts with the ligand-coreceptor complex (Amoresano et al., 2005). Making the assumption that RET binds to the same region in different GFRas, Wang et al. (2006) proposed that the conserved GFR $\alpha$ residues N164, R169, K202, L255, R257, R259, E280, Q281, N320, E323, E324, N335 (GFR 1 numbering) form the RET binding surface.

\subsubsection{RET signalling}

Receptor tyrosine kinases contain a cytoplasmic TK domain. The structure of the TK of both receptor tyrosine kinase and non-receptor tyrosine kinase is similar. It has a twodomain architecture comprised of a smaller $\mathrm{N}$-terminal lobe ( $\sim 90$ residues) connected by a linker to a larger C-terminal lobe ( 200 residues) (Knowles et al., 2006). Based on the crystal structure of the insulin- $\beta$ receptor, Hubbard et al. (1994) proposed that the activation loop (A-loop) in the TK interferes with ATP or substrate binding, thus giving rise to cis-autoinhibition. The phosphorylation of tyrosine(s) within this A-loop, conserved in most tyrosine kinases, induces a structural change that is required to expose the A-loop, which allow substrate and ATP binding. The same is true for most non-receptor tyrosine kinases, like Src (see Benati and Baldari, 2008).

Five tyrosine residues $\operatorname{Tyr}^{905}, \mathrm{Tyr}^{981}, \mathrm{Tyr}^{1015}, \mathrm{Tyr}^{1062}$ and $\mathrm{Tyr}^{1096}$ in the RET-TK have been studied for their role in downstream signalling activities. $\mathrm{Tyr}^{900}$ and $\mathrm{Tyr}^{905}$ are in the Aloop structure, and mass spectrometry analysis identified both tyrosines as autophosphorylation sites. Phosphorylated $\mathrm{Tyr}^{905}$ stabilizes the active conformation of the 
TK domain, which in turn results in autophosphorylation of the other tyrosines mainly located in the C-terminus tail region of the molecule critical for kinase activity (Kawamoto et al., 2004). However, the crystal structures of the RET-TK showed that the A-loop structure in both phosphorylated and non-phosphorylated states have the same conformation (Knowles et al., 2006). The phosphorylation of $\mathrm{Tyr}^{905}$ showed only a three to four fold increase in its catalytic activity in vitro (Knowles et al., 2006), unlike the kinases present in other receptors that show a 10-200-fold change (Cheetham, 2004). RET-TK thus has an active A-loop conformation, which rules out the cis-inhibitory mechanism utilized by most tyrosine kinases (see above). Based on the crystallographic dimers in the TK and juxtamembrane-TK structures, an alternative trans-inhibited model of dimeric TK was suggested (Knowles et al., 2006), which required a large conformational change to relieve this trans-inhibition. The conformational change is driven by its binding to the $\mathrm{GFL}_{2}-\mathrm{GFR} \alpha_{2}$ complex.

Docking of adaptor molecules invokes intracellular signalling cascades that ultimately lead to biological responses like cell proliferation, survival, differentiation, and neurite outgrowth (Schlessinger, 2003). Phosphorylated Tyr ${ }^{905}$ binds to Grb7/10 adaptors, Tyr ${ }^{981}$ to Src and $\mathrm{Tyr}^{1015}$ to phospholipase C- $\gamma$ (PLC- $\gamma$ ) (Pandey et al., 1995; Borrello et al., 1996; Hayashi et al., 2000; Encinas et al., 2004). Tyr ${ }^{1096}$ and $\mathrm{Tyr}^{1062}$ lie in the C-terminus tail region of RET; therefore signalling via $\mathrm{Tyr}^{1096}$, required binding to Grb2, is seen only for the longest isoform of RET, RET51. Phosphorylated Tyr ${ }^{1062}$ binds to variety of adaptor proteins including SHC (Src homologous and collagen-like protein), FRS2 (fibroblast growth factor receptor substrate 2), Dok1/4/5, IRS1/2 and Enigma (Pützer and Drosten, 2004). These adaptor proteins lead to RAS/ERK, phosphatidylinositol-3-kinase (PI3K)/AKT, mitogen-activated protein kinase (MAPK), and Jun N-terminal kinase (JNK) pathways (Figure 1.4) (Ichihara et al., 2004; Kodama et al., 2005). 


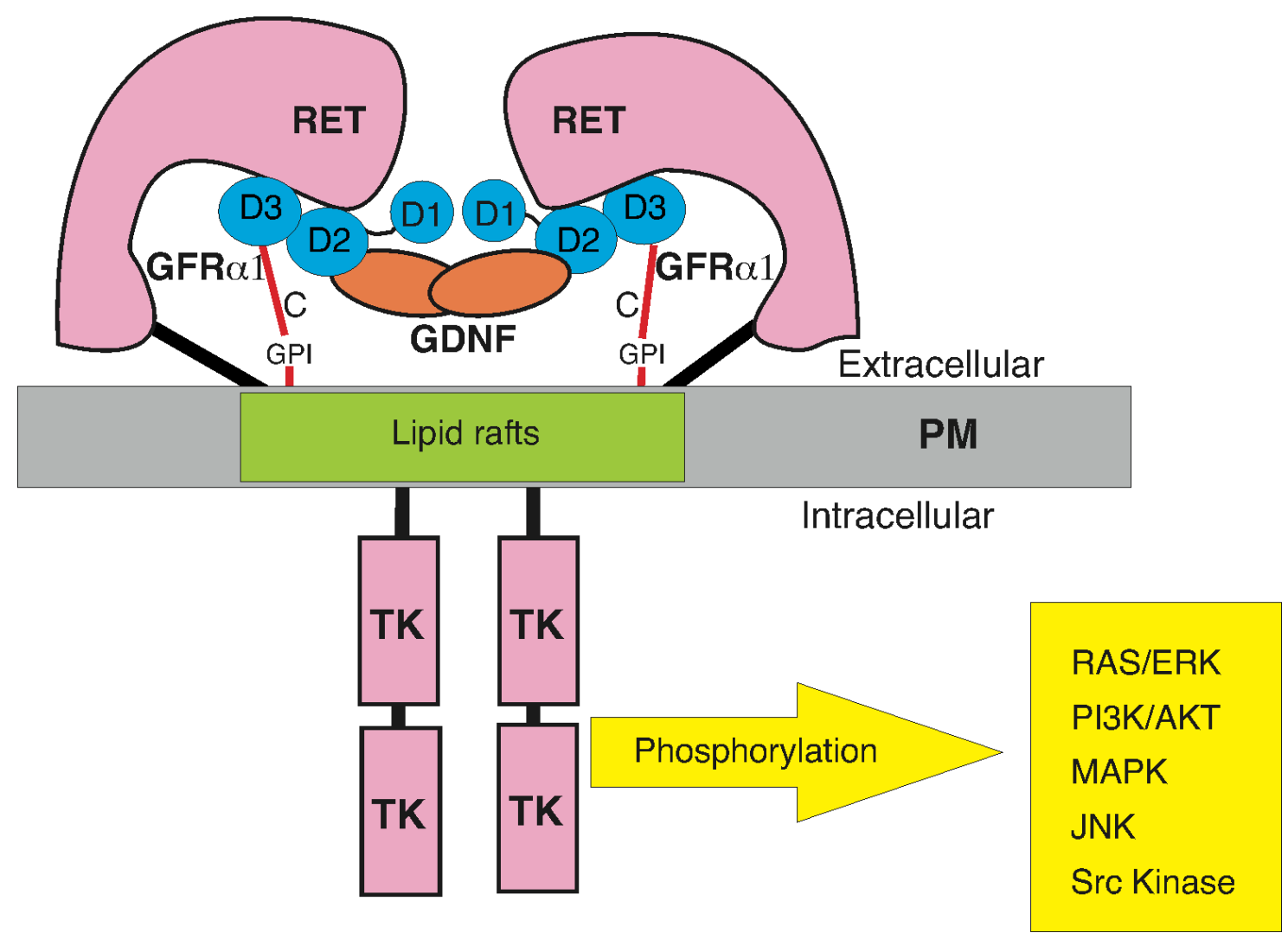

Figure 1.4 RET-GDNF signalling. In the extracellular region, the GDNF homodimer (orange) binds two molecules of GFR $\alpha 1$ (blue). RET (light pink), dimerizes by binding to the $\mathrm{GDNF}_{2}-$ GFR $\alpha 1_{2}$ heterotetramer, and phosphorylates intracellular tyrosines leading to various signalling pathways. The pathways activated by Tyr1062 are listed here. PM, plasma membrane.

Signalling via $\mathrm{Tyr}^{1062}$ has been shown to be important for GDNF mediated neuronal survival and differentiation (Coulpier et al., 2002). For instance MAPK and PI3Ksignalling pathways contribute to neurite growth and neuronal survival (Besset et al., 2000; Encinas et al., 2001; Natarajan et al., 2002; Srinivasan et al., 2005). It was shown that knock-in mice with mutated $\mathrm{Tyr}^{1062}$ had severe defects in the development of the enteric nervous system and the kidney (Jijiwa et al., 2004). The PLC- $\gamma$ signalling pathway regulates the intracellular level of $\mathrm{Ca}^{2+}$ ions by increasing the level of inositol $(1,4,5)$ triphosphate (IP3), but the cellular effects of this pathway following activation by GFL action are poorly understood (Mason, 2000). Finally, GDNF-mediated RET signalling can also activate Src-family kinases, eliciting optimal neurite outgrowth and neuronal survival (Oatley et al., 2007).

Since each GFL has a specific GFR $\alpha$ to activate the common signalling receptor RET, it is possible that different GFLs activate RET differently. The signalling could differ because 
of different tyrosine phosphorylation, or differences in the duration of phosphorylation. The signalling of GFLs via their specific GFRas did not show any significant differences in the phosphorylation of the four key tyrosines (Y905, Y1015, Y1062 and Y1096) in the RET-TK (Coulpier et al., 2002). However, Lee and co-workers (2006b) showed that there were differences in the phosphorylation profile in a neuroblastoma cell line that expressed GFR $\alpha 1$ when it was stimulated with GDNF and NRTN. In addition, NRTN - but not GDNF - induced neurite outgrowth of the same cells, while GDNF (not NRTN) promoted their survival. Therefore, it is likely that GFLs differ in their signalling via RET.

\subsubsection{Alternative signalling modes of GDNF}

The nervous system does not express equal amounts of the two GFL signalling receptors, as GFR $\alpha$ receptors are much more widely expressed than RET (Trupp et al., 1997; Ylikoski et al., 1998; Kokaia et al., 1999). As mentioned before, one possibility is that GPI-anchors of GFRas can be cleaved off and become solubilized and bind GFLs in different cell populations to activate RET. On the other hand, GFL together with GFR $\alpha$ may signal via other alternative receptors (Sariola and Saarma, 2003). For instance, GDNF triggers Src family kinase activation and phosphorylation of ERK/MAPK and PLC- $\gamma$ in RET-deficient cell lines and primary neurons (Poteryaev et al., 1999; Trupp et al., 1999).

Paratcha and co-workers (2003) demonstrated that neural cell adhesion molecule (NCAM) functions as an alternative signalling receptor for GFLs. The three main isoforms of NCAM vary only in their cytoplasmic region. These are: GPI-anchored (120 kDa), short$(140 \mathrm{kDa})$ and long-cytoplasmic domain $(180 \mathrm{kDa})$ forms. The extracellular region of NCAM consists of five N-terminal immunoglobulin ( $\mathrm{Ig}$ ) domains followed by two fibronectin-like domains. NCAM signalling is involved in neurite outgrowth (Hansen et al., 2008). Both GFR $\alpha 1-$ and NCAM-knockout mice showed similar defects in migration of neuronal precursors in the rostral migratory stream, a migratory pathway that delivers cells from the subventricular zone to the olfactory bulb during postnatal and adult life, while no such phenotype was observed in mice lacking RET (Paratcha et al., 2003). In association with GFR $\alpha 1$, NCAM binds GDNF with high affinity $\left(K_{\mathrm{d}}=1.1 \mathrm{nM}\right)$, and activates Fyn (Src like kinase) and FAK (Focal adhesion kinase) in the cytoplasm (Paratcha et al., 2003). Unlike RET, NCAM can interact directly with GDNF, and NCAM deletion constructs and site-directed mutagenesis studies identified the third Ig domain of 
NCAM as necessary for its interaction with GDNF (Sjöstrand et al., 2007). Recent cellbased cross-linking experiments showed that D1 of GFR $\alpha 1$ interacts with the fourth Ig domain of NCAM (Sjöstrand and Ibáñez, 2008).

GDNF is also shown to signal via another receptor tyrosine kinase MET, the signalling receptor for hepatocyte growth factor. GDNF induces MET phosphorylation in RETdeficient/GFR $\alpha 1$-positive cells, and GFR $\alpha 1 /$ RET co-expressing cell lines (Popsueva et al., 2003). In RET-deficient/GFR $\alpha 1$-positive cells, GDNF stimulates branching but not chemotactic migration. On the other hand, GFR $\alpha 1 /$ RET co-expressing cells showed both branching and chemotaxis, which mimics the effects of hepatocyte growth factor signalling through MET. However, GDNF does not immunoprecipitate MET, which indicates no direct involvement of GDNF/GFR $\alpha 1$ and MET.

In addition to transmembrane receptor mediated signalling, GDNF seems to utilize novel signalling modes which lead to synapse development and maturation in ventral midbrain dopaminergic neurons and spinal cord motorneurons (Bourque and Trudeau, 2000; Wang et al., 2002). Investigation of homophilic interactions between GFR $\alpha 1$ s showed that GDNF triggers binding between microspheres coated with GFR $\alpha 1$ and cells expressing GFR $\alpha 1$ (Ledda et al., 2007). These experiments suggested that there is GDNF dependent but RET independent - trans-homophilic binding between GFR $\alpha 1$ molecules and cell adhesion between GFR $\alpha 1$ expressing cells. The localization of GFR $\alpha 1$ to both pre- and post-synaptic compartments in hippocampal neurons, and the reduced number of presynaptic sites formed during synaptogenesis of GDNF heterozygous mice suggests an important role of GDNF and GFR $\alpha 1$ in synaptogenesis (Ledda et al., 2007). On the other hand, several cell adhesion molecules, including cadherins, protocadherins, integrins, NCAM, L1, SynCam and neurexin-neuroligin, have been found to be involved in controlling synaptic development (Yamagata et al., 2003). Other than cell adhesion molecules, secreted growth factors, such as BDNF, have also been implicated in synapse formation and plasticity (Schinder and Poo, 2000), but the mechanism by which GDNF and GFR $\alpha 1$ contribute to this processs is unique, as it combines features of both membrane bound and soluble signals (Ledda et al., 2007).

However, RET-independent GDNF signalling mechanisms are quite unclear. 


\subsubsection{Lipid rafts in GDNF signalling}

Lipid rafts are dynamic assemblies of cholesterol and sphingolipids in the membrane bilayer. Src family kinases, GPI-anchored and other signalling proteins in the intracellular regions are localized in lipid rafts. It was thus suggested that rafts might be essential signalling compartments in the cell membrane (Paratcha and Ibáñez, 2002). GPI-anchored GFR $\alpha$ s are also positioned in lipid rafts. Cholesterol depletion with methyl- $\beta$-cyclodextrin reduces GDNF-dependent activation of MAPK and AKT kinases (Tansey et al., 2000). Furthermore, interaction of RET with Src family kinases required its localization in lipid rafts. Therefore, it was suggested that RET signalling occurs in lipid rafts (Tansey et al., 2000; Encinas et al., 2001).

Paratcha and co-workers (2001) showed that stimulation of RET-expressing cells with GDNF and soluble GFR $\alpha 1$ also recruits RET to lipid rafts, and potentiates the survival and differentiation of motor neurons. However, the recruitment of RET to lipid raft through soluble GFR $\alpha 1$ was delayed compared to that of GPI-GFR $\alpha 1$. During trans signalling, therefore RET may first be activated outside rafts and is then recruited into the rafts. In this model, the $\mathrm{GDNF}_{2}$-GFR $1_{2}-\mathrm{RET}_{2}$ complex is associated with soluble SHC, and RET is then recruited to lipid rafts through a direct or indirect association with FRS2 (Paratcha et al., 2001; 2002). Intriguingly, both adaptor molecules (FRS2 and SHC) bind to the same phosphotyrosine residue $\mathrm{Tyr}^{1062}$ (Paratcha et al., 2001).

\subsubsection{Heparan sulphate in GDNF signalling}

Heparan sulphate (HS) is localized on the cell surface and the extracellular matrix, and is synthesized as a proteoglycan composed of a protein core with multiple glycosaminoglycan (GAG) chains. The biosynthesis of HS involves post incorporation modifications of hexoses in the nascent polysaccharide chains. Such modifications include the epimerization of glucuronate residues to iduronate and their possible subsequent $\mathrm{O}$ sulphation at the C-2 position (reviewed in Lindahl, 1994), which is catalyzed by a specific HS 2-O-sulphotransferase (HS2ST). Heparan sulphate is required for development of renal collecting ducts in vivo and in culture (Bullock et al., 1998). Mice homozygous for disruption of the HS2ST gene exhibit a variety of developmental defects, 
but the most striking phenotype is the absence of kidneys, which is very similar to that of GDNF, RET and GFR $\alpha 1$ gene knockouts (Bullock et al., 1998).

GDNF was originally purified using a heparin-sepharose column (Lin et al., 1993). Heparin promoted the GDNF-induced upregulation of tyrosine-hydroxylase mRNA (Tanaka et al., 2002). It indicated that membrane bound GAGs are involved in GDNF signalling. Barnett and co-workers (2002) showed that heparinase III treatment or the addition of exogenous heparin inhibits RET phosphorylation in kidney cell line, and suggested that heparan sulphate GAGs mediate a direct interaction between GDNF and its receptors. Rickard and co-workers (2003) also showed that GDNF binds highly sulphated heparan sulphates. Using enzyme-linked immunosorbent assay (ELISA), the interaction between GDNF and heparin was shown to be dependent on the 2O-sulphate moieties of the GAG chains (Davies et al., 2003; Rickard et al., 2003).

Hileman et al. (1998) studied a number of GAG-protein interactions, and described a consensus sequence, which brings basic amino acids into proximity. Using this criterion, Barnett and co-workers (2002) suggested that the N-terminus of GDNF and a region of residues 188-196 in D2 of GFR 1 are probable binding sites for heparin. Alfano et al. (2007) confirmed that the N-terminus of GDNF binds heparin, and showed by deleting the $\mathrm{N}$-terminus of the GDNF that heparin neither promotes nor inhibits GFR $\alpha 1$ binding to GDNF. Also, the authors suggested that GFR $\alpha 1$ did not bind to heparin column. Other GFLs, except PSPN, also have a heparin binding sequence: NRTN seems to have a positively charged arginine rich region in its N-terminus, while ARTN has positively charged residues in its $\mathrm{N}$-terminus and the pre-helix region. Mutagenesis showed that the latter region binds heparin (Silvian et al., 2006). Both affinity chromatography and ELISA showed that heparin affinity increases in the order GDNF $<$ NRTN $<$ ARTN (Alfano et al., 2007). However, the in vivo role of heparin or heparan sulphate in GDNF signalling is still unclear.

There are two predominant ways in which GAGs might facilitate signalling by growth factors. One possible role for GAGs, which are borne by abundant proteoglycans associated with the plasma membrane, is to bind quantities of growth factor with relatively low affinity and thereby increase the local concentration of growth factor at the plasma membrane where its high affinity receptor is situated. Like other growth factors, GFLs can 
bind to heparan sulphate side chains of extracellular-matrix proteoglycans, which might restrict their diffusion and raise their local concentration (Hamilton et al., 2001). Another possibility is that heparan sulphates mediate signalling by receptor dimerization, as seen in many cytokines. For instance, heparan sulphates dimerize FGF-2 and subsequently dimerize and activate the receptor tyrosine kinase (Rapraeger et al., 1991; Yayon et al., 1991). The interaction of heparan sulphates in GDNF cannot be responsible for GDNF dimerization, as it is a covalent homodimer. However, it may stabilize the interaction between GDNF and GFR $\alpha 1$, or GDNF-GFR $\alpha 1$ and RET. 


\subsection{MANF and CDNF family of neurotrophic factors}

Like GDNF, two new neurotrophic factors, mesencephalic astrocyte-derived neurotrophic factor (MANF, Petrova et al., 2003) and conserved dopamine neurotrophic factor (CDNF, Lindholm et al., 2007) also support the survival of midbrain dopaminergic neurons. These proteins with eight cysteines form the first family of neurotrophic factors, which are also found in invertebrates. The spacing between the cysteines is strictly conserved from vertebrates to invertebrates (Figure 1.5). Since MANF/CDNF do not have cystine-knot pattern, their sequences are dissimilar to GFLs and neurotrophins. However, these novel proteins are secreted growth factors that exist as monomers. In addition to its role as a neurotrophic factor, MANF has been shown as an ER soluble protein with a cytoprotective role (Mizobuchi et al., 2007; Apostolou et al., 2008). The mechanisms behind the neuroprotective and cytoprotective functions of MANF and CDNF have not been discovered yet; there is not even a putative receptor for these neurotrophic factors.

\subsubsection{MANF as a neurotrophic factor}

MANF, a novel secreted neurotrophic factor of $18 \mathrm{kDa}$ (158 amino acids), was first identified from a rat mesencephalic astrocyte cell-line (Petrova et al., 2003). MANF is also known as ARMET (arginine-rich mutated in early stage of tumors), because it was originally discovered as a human gene highly mutated in a number of cancers (Shridhar et al., 1996). The name ARMET is misleading as it refers to an arginine-rich region in the $\mathrm{N}$ terminus, which is not part of the mature protein. MANF supported the survival of specific embryonic midbrain dopaminergic neurons in vitro, but showed no effects on serotonergic or GABAergic neurons (Petrova et al., 2003). The presence of MANF mRNA and protein in the midbrain of embryonic mouse suggested that MANF might have a role in embryonic development of dopaminergic neurons (Lindholm et al., 2008). Further in situ hybridization and immunohistochemistry experiments showed that MANF is widely expressed in neuronal and non-neuronal tissues in developing and adult mouse (Lindholm et al., 2008). In the brain, relatively high levels of MANF were detected in the cerebral cortex, hippocampus and cerebellar Purkinje cells (Lindholm et al., 2008).

MANF also showed neuroprotection and neurorestoration in a 6-OHDA model of PD (Voutilainen et al., 2009). An intrastriatal MANF injection six hours before a striatal 6- 
OHDA injection was able to prevent the degeneration of nigral dopaminergic neurons. In neurorestoration experiments, four weeks after the 6-OHDA lesions, MANF induced functional recovery of the mesencephalic dopaminergic system (Voutilainen et al., 2009). MANF administration into the cerebral cortex of adult rats before middle cerebral artery occlusion significantly reduced the volume of infarction as measured after two days, and reduced apoptosis in ischemic cortex (Airavaara et al., 2009). MANF pre-treatment also improved motor recovery after stroke, although with some delay (Airavaara et al., 2009). Adding recombinant MANF to the culture medium of cardiac myocytes prevented cell death induced by stimulated ischemia (Tadimalla et al., 2008).

Despite the existence of neurotrophic principles and interactions in the Drosophila nervous system, no neurotrophic factors so far have been described (Jaaro et al., 2001). However, Drosophila melanogaster (Dm) and Caenorhabditis elegans (C. elegans) also express a protein, which is more than $45 \%$ identical to human MANF. Based on high homology between vertebrate MANF/CDNF and invertebrate MANF sequences, it was predicted that invertebrate MANF is also a neurotrophic factor (Lindholm et al., 2007). Recently, human MANF rescued a Dm-MANF gene knockout lethality, which suggested that Dm-MANF is a functional ortholog of mammalian MANF (Palgi et al., 2009).

\subsubsection{CDNF as a neurotrophic factor}

CDNF is a vertebrate specific paralog of MANF. It is also known as ARMET-like 1 protein. It has been characterized as a trophic factor for dopaminergic neurons in vivo (Lindholm et al., 2007), and it protects and repairs these neurons in vivo in a rat 6-OHDA model of PD (Lindholm et al., 2007). Injecting CDNF, before 6-OHDA, into the striatum significantly reduced amphetamine-induced ipsilateral turning behaviour and almost completely rescued dopaminergic $\mathrm{TH}$-positive cells in the substantia nigra. In the neurorestorative experiments, CDNF was injected into the striatum four weeks after the lesion. After eight weeks of the CDNF injection, significant recovery of motor function was noticed. These protective and restorative effects were comparable to those induced by GDNF (Lindholm et al., 2007). Like MANF (Lindholm et al., 2008), CDNF is also expressed in different human and mouse tissues, including the brain (Lindholm et al., 2007). In line with the observed neurotrophic activities, MANF and CDNF have been shown to be secreted proteins (Lindholm et al., 2007; 2008). 


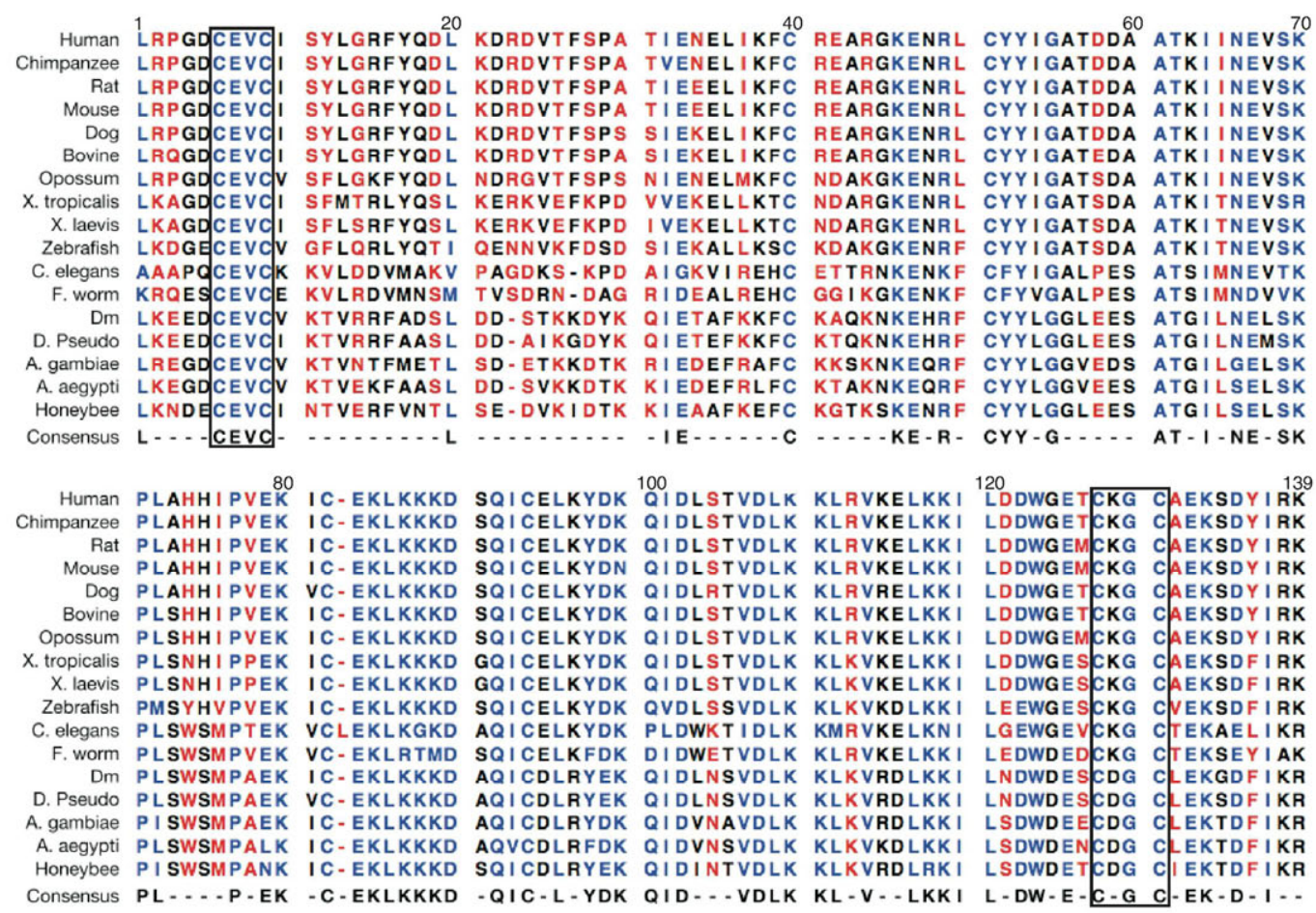

CDNF sequence alignment

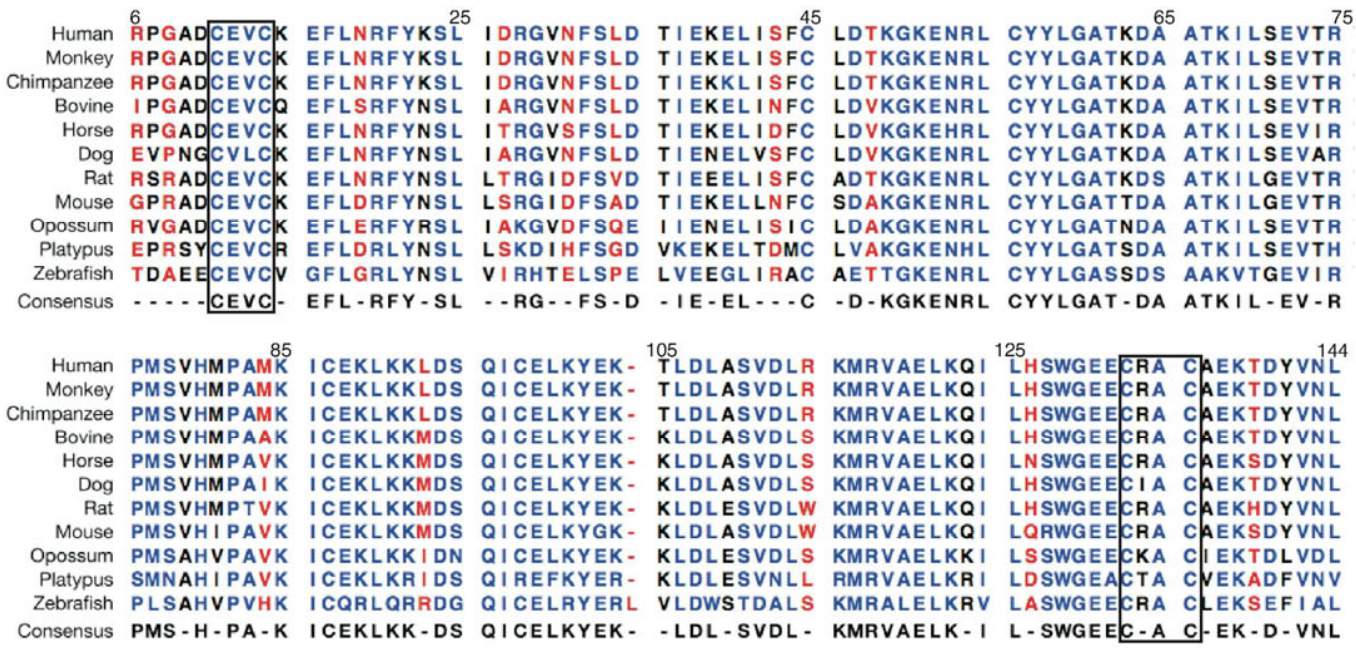

Figure 1.5 Multiple sequence alignment of MANF and CDNF homologues. 17 MANF and 11 CDNF sequences were selected for alignment. Separate multiple alignments from MANF and CDNF sequences, omitting the signal sequence, were produced using the CLC sequence viewer. The first five residues from the mature CDNF sequences and the last 19 residues in MANF-C (17 in CDNF-C) are not shown in the alignment. All cysteines and the two CXXC motifs (boxed) are conserved in both MANF and CDNF. The residues are coloured on the basis of conservation: conserved residues (>80\% identity) in blue, semi-conserved (60-80\% identity) in black and other $(<60 \%$ identity) in red. The consensus is shown in the bottom row with conserved residues $(>80 \%$ identity) in uppercase and all others as ' - '. X. tropicalis, Xenopus tropicalis; X. leaevis, Xenopus leaevis; C. elegans, Caenorhabditis elegans; F. worm, Filarial worm; Dm, Drosophila melanogaster; D. pseudo, Drosophila pseudoobscura; A. gambiae, Anopheles gambiae; A. aegypti, Aedes aegypti. Modified and reprinted with permission from PEDS (Study II) copyrights 2009. 
In addition, several non-neuronal tissues of embryonic and adult rats show similar expression of MANF and CDNF (Lindholm et al., 2007; 2008). In the tissue samples analyzed, high levels of MANF mRNA and protein were detected in the liver and testis, whereas CDNF mRNA and protein levels were relatively high in skeletal muscle, heart and testis (Lindholm et al., 2007; 2008).

\subsubsection{MANF and CDNF in the ER}

In addition to neurotrophic functions as a secreted protein, MANF is localized in the ER, and is upregulated by ER stress (Mizobuchi et al., 2007; Apostolou et al., 2008). It was first shown to be upregulated by tunicamycin treatment (Lee et al., 2003). Other reagents that cause ER stress, such as expressing incorrectly folded insulin, showed MANF upregulation in the pancreatic $\beta$ cells (Mizobuchi et al., 2007). Apostolou and co-workers (2008) have shown that MANF plays an important role in protecting cells against tunicamycin and thapsigargin-induced cell death. In rat, MANF was upregulated by cerebral ischemia, which is again an ER stress inducer (Apostolou et al., 2008). In addition, myocardial infarction in mouse heart leads to overexpression of MANF (Tadimalla et al., 2008). Thus, MANF can function as an ER stress responsive gene in the heart and the brain. KDEL-like sequences at the C-terminus also indicate that MANF and CDNF are expressed into the ER lumen (Mizobuchi et al., 2007). However, using Brefeldin A assay, which inhibited the trafficking from the ER to the Golgi, Apostolou et al. (2008) showed that MANF and CDNF secrete via classical ER-golgi pathway (Apostolou et al., 2008). Therefore, MANF is ER-resident protein, which is secreted also.

It was proposed that MANF and CDNF might facilitate the removal of misfolded proteins from the ER by degradation and/or enhancing protein folding or controlling the activation of ER stress sensors (Apostolou et al., 2008). However, CDNF expression was not regulated in upon ER stress, so it must have a constitutive role in the ER (Apostolou et al., 2008).

In normal physiology, ER stress is ultimately caused by the accumulation of misfolded proteins in the ER, which initiates unfolded protein response (UPR) (Marciniak and Ron, 2006). By UPR, the protein folding capacity and degradation of misfolded proteins is increased inside the cell, and molecular chaperones function to refold proteins, and ER 
associated protein degradation removes misfolded proteins. As MANF and presumably CDNF are involved in cytoprotection in the ER, they might function in protein folding.

\subsubsection{Saposins and SAPLIPs}

The MANF and CDNF structures solved in this study have a similar fold to saposins (see section 4.2.1.1). Saposins (sphingolipid activator proteins) A, B, C and D are derived from a single precursor, prosaposin, from which they are proteolytically cleaved (Kishimoto et $a l ., 1992)$. These small heat-stable glycoproteins (12-14 kDa) have identical pattern of six cysteines residues. Saposins are required for the lysosomal hydrolysis of a variety of sphingolipids (reviewed in Vaccaro et al., 1999). Each of the four saposins promotes the degradation of particular sphingolipids. Functional deficiencies of saposins lead to sphingolipid storage diseases, which are characterized by accumulation of lipid aggregates within the lysosomes. Prosaposin knockout mice die shortly after birth due to accumulation of glycosphingolipids in cells and neurodegeneration (Fujita et al., 1996). The neurodegeneration in prosaposin knockout studies indicated that prosaposin is a trophic factor for neurons. Consistent with this, prosaposin promoted the survival of cultured hippocampal neurons and the regeneration of sciatic nerve (Kotani et al., 1996). Also, prosaposin and saposin C promote neurite outgrowth (O'Brien et al., 1994). A peptide sequence of about 18 residues from the $\mathrm{N}$-terminus of saposin $\mathrm{C}$ was shown to rescue dopaminergic neurons in a mouse MPTP-model of PD (Liu et al., 2001). However, the signalling mechanism of prosaposin and saposins is unclear. Recent in vitro experiments showed that prosaposin signalling occurs through lipid rafts (Sorice et al., 2008).

The structure of saposins consists of four to five $\alpha$-helices connected by three disulphide bridges (Figure 1.6A). Saposins exist in two conformations: 'closed' and 'open' (Ahn et al., 2003; 2006; Hawkins et al., 2005). In the closed state, the helices are packed to form a 'folded-leaf' structure so that a hydrophobic core is formed. In the open state, this hydrophobic core is exposed out. This conformational change in saposins is dependent on $\mathrm{pH}$ and presence of lipids (see below). For instance, saposin B was crystallised as a homodimer with the hydrophobic core opened out to bind lipids (Ahn et al., 2003) (Figure $1.6 \mathrm{~B})$. 
A number of proteins have been found with saposin-like fold in a globular conformation. These saposin-like proteins (SAPLIPs) (SCOP; Murzin et al., 1995) include surfactant protein B (SP-B) (Johansson et al., 1991), NK-lysin (Liepinsh et al., 1997), granulysin (Anderson et al., 2003), amoebapores (Zhai and Saier, 2000; Hecht et al., 2004), prophytepsin (Kervinen et al., 1999) and domains of acid sphingomyelinase (Schuchman et al., 1991) and acid acyloxyacyl hydrolase (Hagen et al., 1991). Like saposins, SP-B is generated from a larger precursor that contains, in addition to SP-B, two other similar domains (Zaltash and Johansson, 1998). SP-B lowers surface tension at the liquid-gas interface in the lung. NK-lysin and granulysin are produced by natural killer cells and cytotoxic T-lymphocytes, and function as antimicrobial proteins. Amoebapores form ion channels in the membrane of a target cell by oligomerisation, which leads to cell death (Zhai and Saier, 2000; Hecht et al., 2004).

A

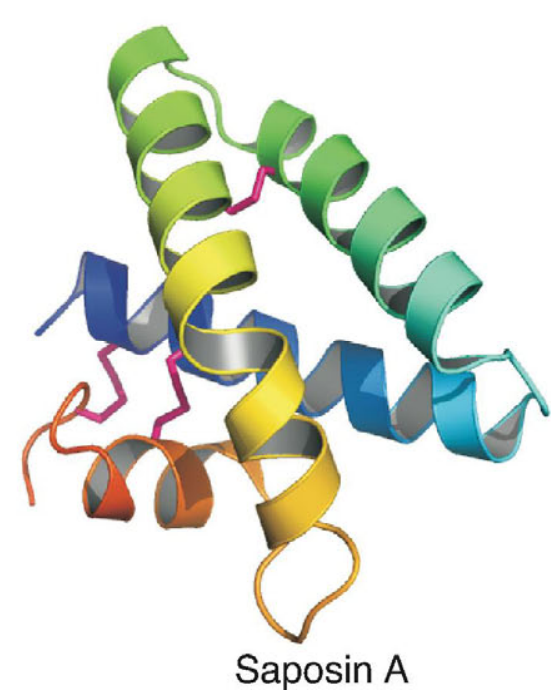

B

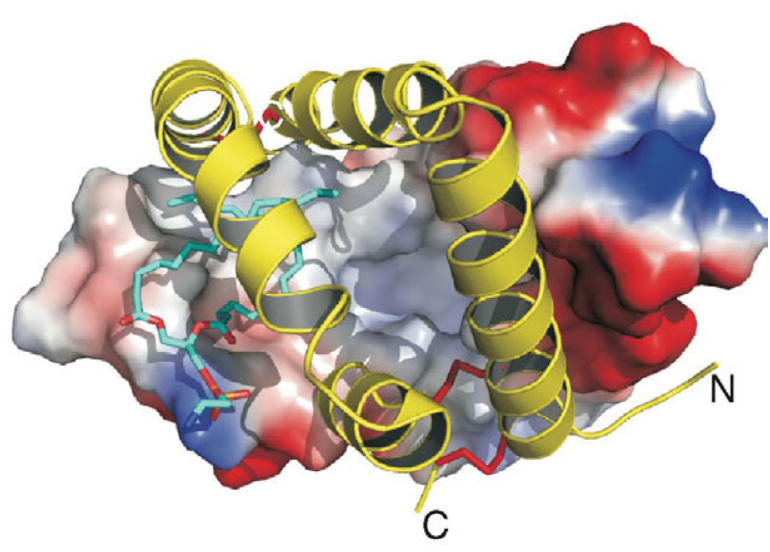

Saposin B

Figure 1.6 Saposins A and B in monomeric and dimeric conformations, respectively. (A) Saposin A structure (PDB 2DOB) showing 'folded-leaf' saposin fold in closed conformation coloured as rainbow. Disulphide bridges are in dark pink. (B) Saposin B (PDB 1N69) as homodimer. One monomer is in cartoon (yellow), and the other one is shown in electrostatic surface representation. Bound phspholipid is shown as cyan sticks. Colour scheme in surface representation: blue, positive; red, negative and white, hydrophobic residues.

Saposins and SAPLIPs have a wide range of functions, but all seem to interact with membranes or lipids (Bruhn, 2005). Saposins A-D are lysosomal proteins that bind galactosyl- and glucosyl-ceramides (Vaccaro et al., 1999). Saposins are acidic proteins with isoelectric points around four to five, and the dimeric saposin B structure suggests that conformational changes in the saposin structure may facilitate the extraction of target 
lipids from the membrane (Ahn et al., 2003). SP-B and amoebapore peptides also bind to negatively charged headgroup of lipids (Vaccaro et al., 1999). Lipid binding by the SAPLIP domain is required for vacuolar targeting of prophytepsin, a plant aspartic protease (Kervinen et al., 1999). NK-lysin and granulysin are basic proteins, and the positively charged lysines and arginines on their surface may be required for membrane binding and lysis (Miteva et al., 1999; Sánchez-Barrena et al., 2003). Molecular dynamics simulations and site-directed mutagenesis experiments suggested that the lysine residues in helices $\alpha 1$ and $\alpha 5$ at saposin $\mathrm{C}$ provide a base for membrane anchoring by interacting with the anionic phospholipids (Liu et al., 2005).

\subsection{Diseases related to GDNF-RET signalling and MANF/CDNF}

\subsubsection{Knockout studies in GDNF-GFRa1-RET system}

Mice lacking RET, GDNF, or GFR $\alpha 1$ all die soon after birth and share similar phenotype of kidney agenesis and absence of enteric neurons (Schuchardt et al., 1994; Moore et al., 1996; Pichel et al., 1996; Sánchez et al., 1996; Cacalano et al., 1998; Enomoto et al., 1998). In RET-/- and GFR $\alpha 1-/-$ homozygotes, the animals show renal abnormalities (Schuchardt et al., 1994; Enomoto et al., 1998). However, unlike the GDNF+/- mice, where up to $30 \%$ of the animals have kidney abnormalities (Sánchez et al., 1996), GFR $\alpha 1+/$ - and RET+/- mice have normal kidneys compared to the wild type animals (Schuchardt et al., 1994; Enomoto et al., 1998). In addition to role in kidney development, GDNF induced cell signalling also regulates the spermatogonial self-renewal and differentiation in GDNF transgenic mice (Meng et al., 2000; 2001; Kubota et al., 2004). On the other hand, the NRTN-/-, GFR $22-/-$ (Garces et al., 2000), ARTN-/- and GFR $\alpha 3-/-$ mice (Honma et al., 2002), unlike the GDNF-/-, GFR $\alpha 1-/-$ and RET-/- mice, are viable and fertile.

\subsubsection{RET mutations}

The proto-oncogene RET has attracted considerable clinical interest because of the range of mutations found in diverse conditions that include Hirschsprung's (HSCR) disease and 
a variety of cancers involving the thyroid gland. The mutations in its gene are spread throughout the coding sequence. Diseases associated with RET mutations can be grouped into two classes according to its gain-of-function or loss-of-function. Loss-of-function mutations in RET impair its phosphorylation, and causes HSCR disease or aganglionic megacolon (Plaza-Menacho et al., 2006). Patients with HSCR disease suffer from a variable lack of neurons in the distal segments of the enteric nervous system, which leads to intestinal obstruction or chronic constipation (Lantieri et al., 2006). These mutations, which were scattered all over the RET, are found in up to $50 \%$ of the familial and $15 \%$ of the sporadic cases (Hofstra et al., 2000). Mutations in the RET extracellular region leading to unfolded or incorrectly folded RET affects its binding to the ligand-coreceptor complex and inhibits downstream pathway (Kjær and Ibáñez, 2003b). Loss-of-function in RET could also be caused by mutations in the TK domain which adversely affects its stability or activity (Carlomagno et al., 1996; Iwashita et al., 1996). Other mutations of critical tyrosines in the RET-TK affect the binding of the adaptor molecules, which inactivates the signalling (Geneste et al., 1999).

On the other hand, gain-of-function mutations of RET that induce constitutive dimerization or constitutive kinase activation causes multiple endocrine neoplasia type 2 (MEN2), an inherited cancer syndrome characterized by medullary thyroid carcinoma (MTC) (Kodama et al., 2005). The disease has three clinically distinct subtypes, ranging from the later onset, less severe, familial medullary thyroid carcinoma (FMTC), to more severe MEN2A, characterized by MTC, pheochromocytoma and parathyroid hyperplasias. MEN2B, which is characterized by MTC and pheochromocytoma, as well as by an array of developmental abnormalities including marfanoid habitus, mucosal neuromas, and myelinated corneal nerves, is the most aggressive form of MEN2.

Six well-characterized cysteine mutations in CRD (C609, C611, C618, C620, C630 and C634) are associated with MEN2 syndromes (Mulligan et al., 1995). The mutations C630 and C634 are related to the MEN2A and FMTC phenotypes. MEN2A is associated most frequently with C634R mutation, which leads to its partial misfolding due to formation of abnormal cystine bridges between the two RET molecules. Other mutations (C609, C611, C618, C620) are associated not only with the MEN2A and FMTC phenotypes, but also with the HSCR disease. 
The most aggressive oncogenic phenotype, MEN2B, has been linked to M918T. This mutation does not cause the dimerization of the protein, but alters the substrate specificity of the kinase; therefore, it affects the downstream signalling pathways (Santoro et al., 1995; Eng and Mulligan, 1997). Different types of mutations underlie the papillary thyroid carcinomas (PTC). Patients with PTC mostly harbour a chromosomal rearrangement in which the TK domain of RET is fused at its N-terminus to a soluble protein (Nikiforov, 2002). It spontaneously forms cytoplasmic dimers, which in turn phosphorylate the TK domain, as shown by the constitutive phosphorylation of $\mathrm{Tyr}^{1015}$ and $\mathrm{Tyr}^{1062}$ in RET/PTC chimeric protein (Salvatore et al., 2000). The constitutive phosphorylation in PTC variants of RET differ from the transmembrane MEN2 variants of RET in their subcellular localization.

\subsubsection{GDNF in Parkinson's disease}

Parkinson's disease (PD) is a neurodegenerative disorder characterized by the impairment of motor function due to loss of dopaminergic neurons in the nigrostriatal system (Calne, 1984). As mentioned before, the neurotoxins 6-OHDA (Simon et al., 1974), MPTP (Heikkila et al., 1984) and methamphetamine have been used to create PD model in monkeys and rats. A neurotrophic factor can be considered beneficial for PD if it prevents the degeneration of dopaminergic neurons exposed to toxins and other insults, and/or it provides a therapeutic effect of restoring the function of dopamine neurons (i.e. the capacity to synthesize and release dopamine).

Since GDNF prevents embryonic midbrain dopaminergic neurons from degeneration (Lin et al., 1993) and protects them against 6-OHDA and methamphetamine (Cass, 1996; Shults et al., 1996), it has been considered as a potential therapeutic agent for treatment of PD. In rodent and primate models of PD involving selective degeneration of dopamine neurons, GDNF has been shown to be neuroprotective, and its delivery into the cerebral ventricles or directly into striatum or substantia nigra improves motor functions (Tomac et al., 1995; Gash et al., 1996; Bjorklund et al., 1997). The toxic effects of 6-OHDA are related to oxidative stress, mitochondrial dysfunction and apoptotic cell death (Schober, 2004). Therefore, it is possible that the neuroprotective effects of GDNF may result from a reduction in oxidative stress induced by 6-OHDA (Smith and Cass, 2007). 
The positive results obtained using intracerebroventricular administration of GDNF in monkeys (Gash et al., 1996; Zhang et al., 1997) prompted clinical trials in patients with PD. Gill and co-workers (2003) infused GDNF directly into putamen via implanted catheters in five PD patients in an open trial in Bristol, UK. A marked improvement in PD patients was observed, which allowed a randomized, double-blind, placebo-controlled trial of bilateral GDNF infusion in 34 subjects with moderately advanced PD, sponsored by Amgen (Newbury Park, CA) (Lang et al., 2006). In this study, GDNF did not seem to have any impact on the symptoms and three patients produced a neutralizing GDNF antibody. It was suggested that GDNF might not have reached putamen and substantia nigra, the target tissues. Dr. Slevin and co-workers (2005) administered GDNF into the putamen and found considerable improvement in patients. Several adverse effects including nausea, loss of appetite, hallucinations and depression have been found in some studies (Nutt et al., 2003).

Alternative techniques like GDNF gene therapy with the use of three viral vector systems, adenovirus, adeno-associated virus and lentivirus, have been considered, which have been found effective against neurodegeneration and have shown restorative effects in monkey and rat models of Parkinson's disease (Choi-Lundberg et al., 1997; Gash et al., 1998; Bjorklund et al., 2000; Kordower et al., 2000). NRTN has also been shown to enhance the survival of dopaminergic neurons in rodent and monkey models of PD (Horger et al., 1998; Rosenblad et al., 1999). In addition, gene transfer of NRTN protects nigral dopaminergic neurons in rats (Peterson and Nutt, 2008). However, it produced conflicting results in clinical trials, as phase II study failed to induce any beneficial effects in PD patients (Peterson and Nutt, 2008).

Although RET (Schuchardt et al., 1994), GDNF (Moore et al., 1996; Pichel et al., 1996; Sánchez et al., 1996), or GFRa1 (Cacalano et al., 1998; Enomoto et al., 1998) knock-out mice died at birth due to absence of kidney, no significant differences in substantia nigra compared to that of wild-type mice was observed. To study the postnatal survival of dopaminergic neurons, Granholm and co-workers (2000) transplanted fetal neural tissues from GDNF-/-, GDNF+/-, and wild-type mice into the brain of adult wild-type mice and showed that survival of ventral mesencephalic dopaminergic neurons is dependent on GDNF. Further studies of GDNF-GFR $\alpha 1-$ RET signalling in adult mice nervous system using selective RET ablations which allow postnatal survival showed that deficiency of 
RET causes progressive and late loss of dopamine neurons in the substantia nigra pars compacta (Kramer et al., 2007). It also led to degeneration of dopamine nerve terminals in striatum and reduced levels of evoked dopamine release. Furthermore, the similar phenotype to PD of aged mice suggested that RET is important for the maintenance of adult nigrostriatal dopamine system. In contrast, Jain and co-workers (2006) showed that RET is not required for survival of midbrain dopaminergic neurons in adult mice. In addition, GDNF-RET signalling in relation to PD in humans has not been confirmed yet, and no association between HSCR and PD has been found (Lücking et al., 2008). Therefore, the importance of GDNF-GFR $\alpha 1$-RET signalling in the nervous system is unclear.

\subsubsection{MANF/CDNF in Parkinson's disease}

Since clinical trials of GDNF and NRTN in PD patients have not been fully successful, other neurotrophic factors such as MANF and CDNF have been investigated for their neuroprotective and neurorestorative effects in 6-OHDA or MPTP model of PD. After its discovery as a survival factor for mesencephalic dopamine neurons in vitro (Petrova et al., 2003), MANF showed both neuroprotective and neurorestorative effects in 6-OHDAlesioned mesencephalic dopaminergic system. Recent neuroprotective and neurorestorative studies of CDNF in the rat model of PD showed that CDNF is as potent as GDNF (Lindholm et al., 2007). It is intriguing that the structurally unrelated CDNF and GDNF protect and restore nigral dopaminergic neurons. Unlike GDNF, the putative receptor for CDNF and MANF and their signalling mechanism are unknown. 


\section{AIMS OF THE STUDY}

The aim of my thesis was to obtain structural and functional information on RET-GDNFGFR $\alpha 1$ system, and to characterize two novel neurotrophic factors: MANF and CDNF. My specific goals were:

1) To structurally characterize the $\mathrm{GDNF}_{2}-\mathrm{GFR} \alpha 1_{2}$ complex.

a) To express and crystallize the $\mathrm{GDNF}_{2}-\mathrm{GFR} \alpha 1_{2}$ complex.

b) To identify other GFR $\alpha 1$ residues involved at the GDNF binding interface.

c) To explore the role of heparin in GDNF signalling.

d) To identify the structural determinants of ligand specificity.

2) To find a RET binding site within GFR $\alpha 1$.

a) To identify residues involved in RET binding.

3) To structurally characterize the MANF and CDNF proteins.

a) To solve the crystal structure of MANF and CDNF.

b) To learn the structure-function relationship of MANF and CDNF. 


\section{METHODS}

\section{Methods used in studies I-III}

Detailed description of materials and methods used can be found in the original publications I-III, and the methods used in each study are listed in Table 1.

Table 1 Methods used in the original publications.

\begin{tabular}{clc}
\hline \multicolumn{1}{c}{ Method } & & Study \\
\hline Molecular biology & & \\
& DNA sequencing & I, III \\
& PCR & I, III \\
& Cloning & I, III \\
& Protein expression & I, III \\
& Protein purification & I, III \\
& Site-directed mutagenesis & I \\
& & \\
Protein characterization & & \\
& & Bradford assay \\
& Western blot & I, III \\
& SDS-PAGE & I, III \\
& Size exclusion chromatography & I, III \\
& Ion-exchange chromatography & I, III \\
& Sequence comparison & I, II, III \\
& & \\
& & \\
Crystallography & Sitting-drop vapour diffusion/crystallization & I, II, III \\
& Data collection & III \\
& Data processing & I, II, III \\
& Molecular replacement & I, II, III \\
& Se-MAD & II \\
& Model building & I, II, III \\
& Refinement & I, II, III \\
& Structural alignment & I, II, III \\
\hline & &
\end{tabular}




\section{RESULTS AND DISCUSSION}

\subsection{Structural and functional studies of the $\mathrm{GDNF}_{2}-\mathrm{GFR} \alpha 1_{2}$ complex}

The results presented in this section are based on Study I and Study III.

\subsubsection{The crystal structure of the $\mathrm{GDNF}_{2}-\mathrm{GFR} \mathbf{1}_{2}$ complex (Study I)}

The $\mathrm{GDNF}_{2}-\mathrm{GFR} \alpha 1_{2}$ complex was co-expressed in insect cells and purified using Niaffinity and size-exclusion chromatography. Domain 1 of GFR $\alpha 1$ was not included, as it is not needed for ligand binding (Virtanen et al., 2005). The complex (3mg/ml) was crystallized at $+4^{\circ} \mathrm{C}$ in a well solution of $100 \mathrm{mM}$ HEPES, $\mathrm{pH} 7.5,10 \%$ polyethylene glycol 8000, and 8\% ethylene glycol. The crystals belong to space group C2 with single molecule of GDNF-GFR $\alpha 1$ per asymmetric unit. The structure was solved by molecular replacement using human GFR $\alpha 3$ (domain 2 and 3; D23) from ARTN-GFR $\alpha 3$ (code 2GH0; Wang et al., 2006) and rat GDNF (code 1AGQ; Eigenbrot and Gerber, 1997) as search models with Phaser. The flexible N-terminal region (33 residues) of GDNF and the GFR $\alpha 1$ C-terminal extension (76 residues) were not visible in the electron density. The final model containing GFR $1-\Delta \mathrm{D} 1^{150-349}$ and $\mathrm{GDNF}^{34-134}$ was refined to $\mathrm{R}_{\text {work }} 18.1 \%$ $\left(R_{\text {free }} 23.7 \%\right)$. In the structure of the complex, each of D2 and D3 of GFR $\alpha 1$ consists of the triangular spiral of five $\alpha$-helices folded with five cystine bridges (Figure 4.1). The heparin mimic, sucrose octasulphate (SOS), was also bound to D2 of GFR $\alpha 1$.

The biological heterotetrameric complex is formed by the unique crystallographic twofold axis (Figure 4.1). Each monomer in the GDNF homodimer binds GFR $\alpha 1$ on its fingertips. At the GDNF-GFR $\alpha 1$ binding interface, the finger domain of GDNF binds GFR $\alpha 1$ through the centre of the "triangular helix spiral" formed by $\alpha$-helices $\alpha 1, \alpha 2$ and $\alpha 5$ in D2 (Study I). The key interaction at the interface is the formation of the ion triple $\mathrm{R} 171^{\mathrm{GFR} \alpha 1}-\mathrm{E} 61^{\mathrm{GDNF}}-\mathrm{R} 224^{\mathrm{GFR} \alpha 1}$ (Figure 4.2). Of the other residues in the same region, $\mathrm{N} 162^{\mathrm{GFR} \alpha 1}$ buttresses the ion triple interaction by positioning E61 ${ }^{\mathrm{GDNF}}$ and R171 ${ }^{\mathrm{GFR} \alpha 1}$. It does so by forming hydrogen bonds between the amide group of $\mathrm{N} 162^{\mathrm{GFR} \alpha 1}$, the carboxyl group of E61 ${ }^{\mathrm{GDNF}}$ and the guanidine group of R171 ${ }^{\mathrm{GFR} \alpha 1}$ (Figure 4.2). 


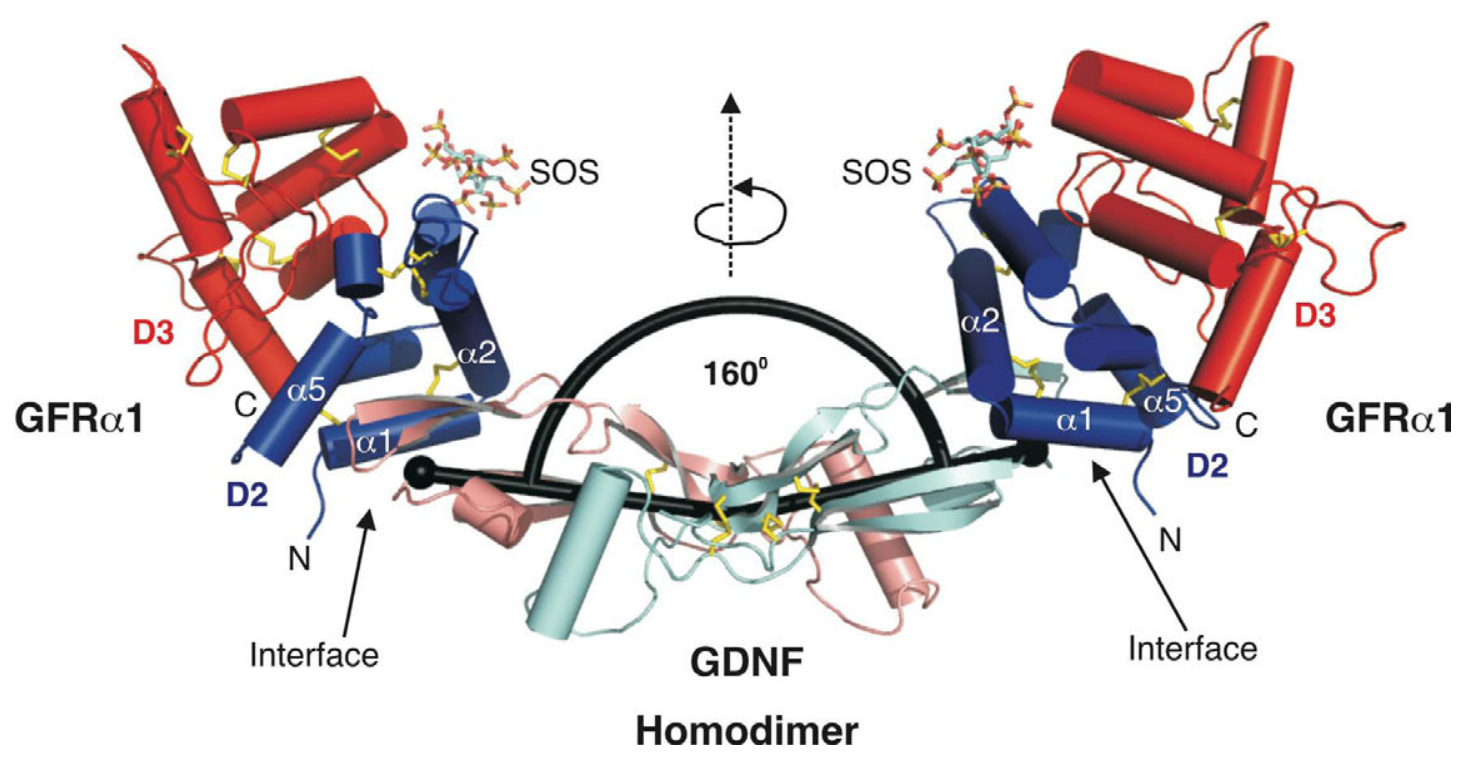

Figure 4.1 The $\mathrm{GDNF}_{2}-\mathrm{GFR} \alpha 1_{2}$ heterotetrameric complex. GFR $\alpha 1$ (D2, blue, and D3, red) and the GDNF homodimer (in light pink and cyan) are shown in cartoon. The complex is symmetric and the two heterodimers are related by the two-fold vertical axis. SOS is bound to GFR $\alpha 1$ D2. It is shown as sticks with colour coding: sulphur, yellow; oxygen, red; nitrogen, blue; carbon, cyan. Disulphide bridges are shown as yellow sticks. The lines (black) drawn from the intermonomer $\mathrm{S}_{\gamma}$ of Cys101 to the E61- $\mathrm{C}_{\alpha}$ and E61- $\mathrm{C}_{\alpha}{ }^{\prime}$ describes the bend angle. Modified and reprinted with permission from J. Biol. Chem. (Study I) copyrights 2008.
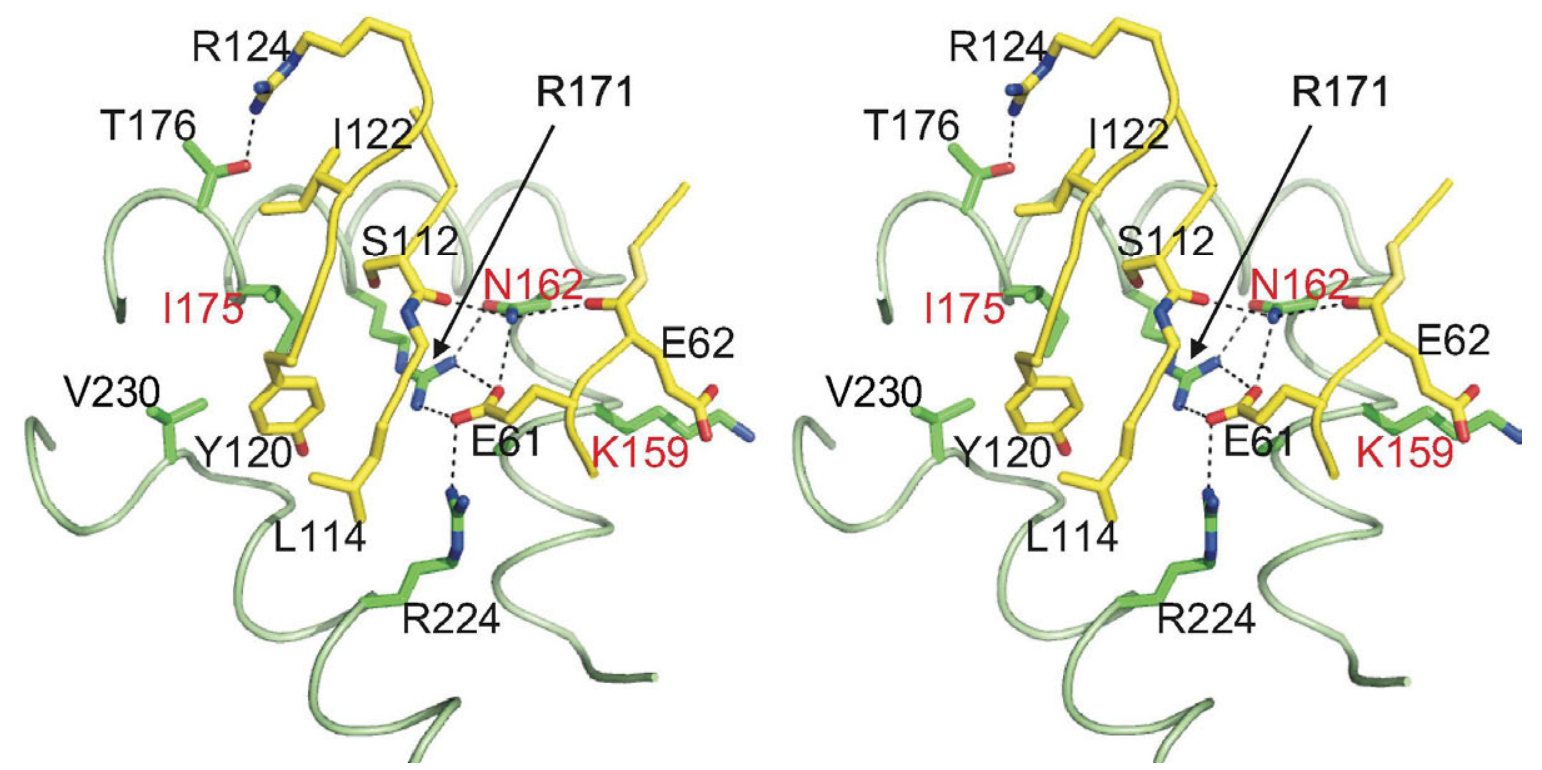

Figure 4.2 The GDNF-GFR $\alpha 1$ binding interface. Stereo view of the GDNF-GFR $\alpha 1$ binding interface (code 2V5E). The triangular helix spiral of GFR $\alpha 1$ is shown in pale green, and the GDNF loops are in yellow. The important binding interface residues are shown in sticks. Colour coding: carbon, green (GFR $\alpha 1$ ), yellow (GDNF); nitrogen, blue and oxygen, red. The interface residues mutated in Study I are marked with red labels. 
On the other side of the ion triple, the hydrophobic interactions involve the packing of $\mathrm{Y} 120^{\mathrm{GDNF}}$ between $\mathrm{L} 114^{\mathrm{GDNF}}, \mathrm{I} 175^{\mathrm{GFR} \alpha 1}$ and $\mathrm{V} 230^{\mathrm{GFR} \alpha 1}$. At the periphery of the binding interface, $\mathrm{I} 122^{\mathrm{GDNF}}$ is packed between $\mathrm{I} 175^{\mathrm{GFR} \alpha 1}$ and $\mathrm{T} 176^{\mathrm{GFR} \alpha 1}$ (Figure 4.2).

\subsubsection{Insights into heparin- and RET-binding (Study I)}

Here GFR $\alpha 1$, the high affinity GDNF receptor polypeptide, was examined for its affinity to heparin (Study I). Both $w t$-GFR $\alpha 1$ and GFR $\alpha 1-\Delta \mathrm{D} 1$ bind to the heparin column, but $w t$ GFR $\alpha 1$ elutes at a higher $\mathrm{NaCl}$ concentration $(\sim 1 \mathrm{M})$ than GFR $\alpha 1-\Delta \mathrm{D} 1$, which elutes at about $0.5 \mathrm{M} \mathrm{NaCl}$. The reduced binding affinity of GFR $\alpha 1-\Delta \mathrm{D} 1$ to the heparin column suggests that D1 of GFR $\alpha 1$ binds heparin (Study I, Figure 3). This is in contrast to previous heparin binding experiments where Alfano and co-workers (2007) do not see GFR $\alpha 1$ binding to the heparin column. In addition to heparin binding experiments, the crystals of the $\mathrm{GDNF}_{2}-\mathrm{GFR} \alpha 1_{2}$ complex were grown in the presence of SOS. The structure of the complex showed SOS bound to the GFR $\alpha 1$ residues R190, K194, R197, Q198 and K202 in domain 2 which is consistent with the previously predicted heparinbinding sequence (see section 1.3.7). Taking into account the biological importance of 2Osulphation, I docked a heparin pentasaccharide into the SOS-binding region by keeping the 2O-sulphates in a similar orientation to that of SOS. Thus affinity chromatography shows that GFR $\alpha 1$ binds heparin, and the modelling and SOS binding in the crystal structure provide a region of residues involved in heparin binding (Study I, Figure 3).

As GDNF is also shown to bind heparin, and Alfano et al. (2007) showed that a 40-residue stretch at the N-terminus of GDNF is involved in heparin binding. Deleting this region does not affect the interaction between GDNF and GFR $\alpha 1$, and so the heparin-binding site in GDNF is distinct from the GFR $\alpha 1$ binding site (Alfano et al., 2007). The N-terminus of GDNF was disordered in the previous crystal structure (Eigenbrot and Gerber, 1997). Here also only a partial N-terminus (residues 34-40) of GDNF in the structure of the complex is ordered (Study I). Intriguingly, residues Q34, R35, K37, R39 in this N-terminus region interact with SOS, and therefore SOS mediates interaction between GDNF and GFR 1 . One side binds D2 of GFR $\alpha 1$ while the other side interacts with the N-terminus of a symmetry-related GDNF (Study I, Figure 3). It thus forms a SOS-linked arrangement of the $\mathrm{GDNF}_{2}-\mathrm{GFR} \alpha 1_{2}$ complexes in the crystal. A similar interaction is possible in my second crystal structure of the $\mathrm{GDNF}_{2}-\mathrm{GFR} \alpha 1_{2}$ complex, where two NAG residues 
attached to $\mathrm{N} 49^{\mathrm{GDNF}}$ bind to the SOS-binding region in GFR $\alpha 1$ (Study III). The two complex structures of $\mathrm{GDNF}_{2}-\mathrm{GFR} \alpha 1_{2}$ thus indicate that polysaccharide can mediate interaction between the heterotetrameric $\mathrm{GDNF}_{2}-\mathrm{GFR} \alpha 1_{2}$ complexes. They thus may explain how the $\mathrm{GDNF}_{2}-\mathrm{GFR} \alpha 1_{2}$ complex is involved in synapse formation (Ledda et al., 2007); long chains of heparan sulphates attached to the cell surface may link two $\mathrm{GDNF}_{2}-$ GFR $\alpha 1_{2}$ complexes on different cells, thereby inducing synaptic interactions between the cells (Figure 4.3).

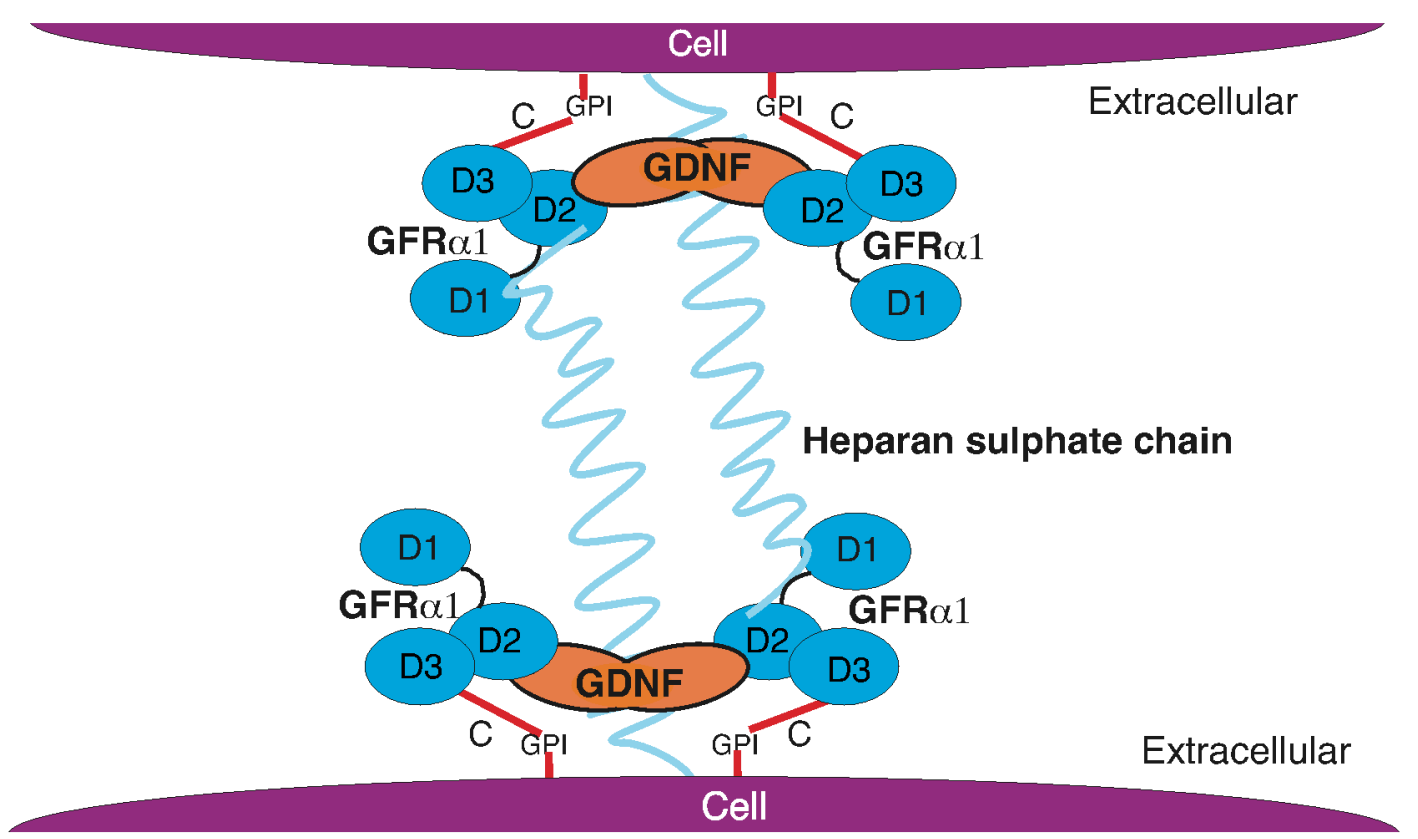

Figure 4.3 Schematic diagram of how heparin might create $\mathrm{GDNF}_{2}-\mathrm{GFR} \alpha 1_{2}$ "dimer of tetramers" between cells. The GDNF homodimer is orange and GFR $\alpha 1$ is coloured blue. Heparan sulphate chain (cyan) on the cell surface connects GDNF from one $\mathrm{GDNF}_{2}-\mathrm{GFR} \alpha 1_{2}$ complex to GFR $\alpha 1$ on a different cell, which might lead to trans signalling.

To identify the RET binding site within GFR $\alpha 1$, a number of surface residues were mutated in GFR $\alpha 1$ D2 and D3 including the SOS-binding residues (Study I): D164, R190, K194, R197, Q198, K202, R217, R240, R257 and R259. In addition, I purified the previously mutated E323 and D324 (Leppänen et al., 2004). These soluble mutants were tested for their ability to phosphorylate RET in ELISA using RET-expressing cells. Interestingly, R190A/R197A， K194A， Q198A/K202 and R257A/R259A showed 
significant reduction in RET phosphorylation and these mutations lie on the SOS-binding surface (Figure 4.4).

\section{A}

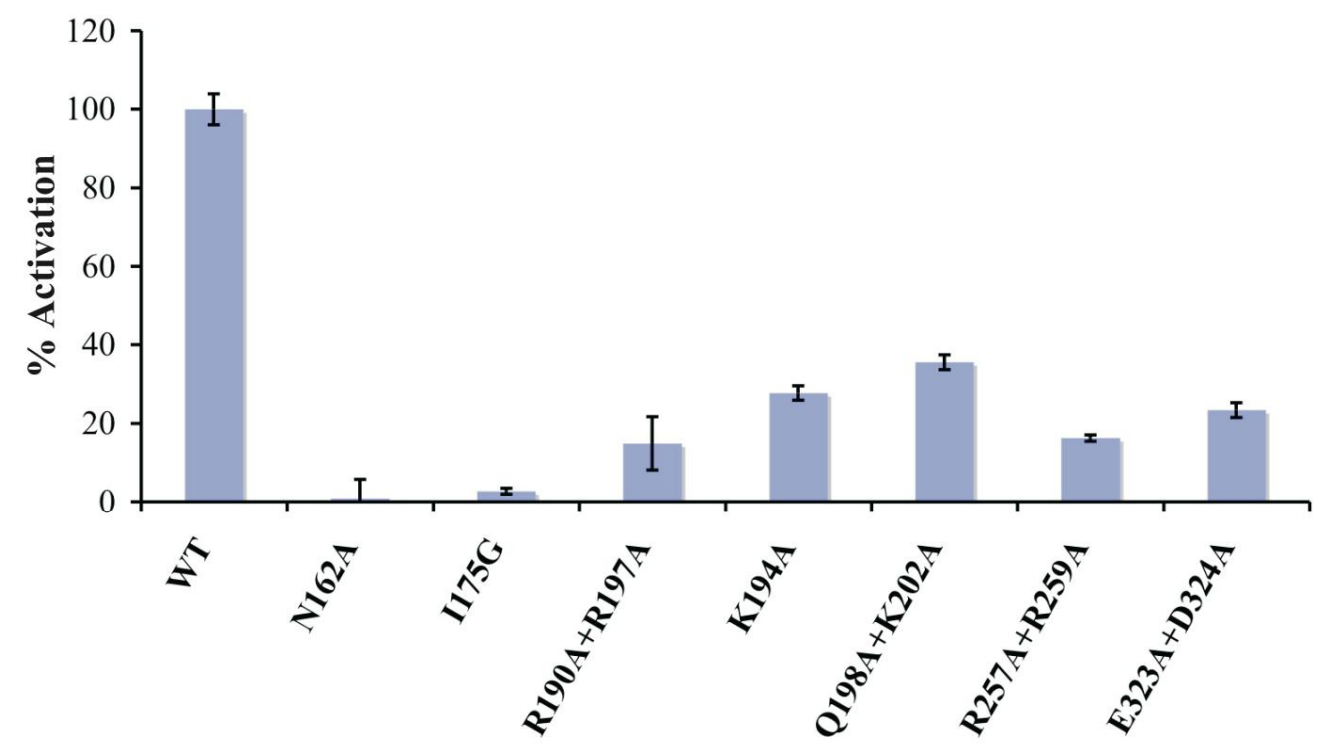

B

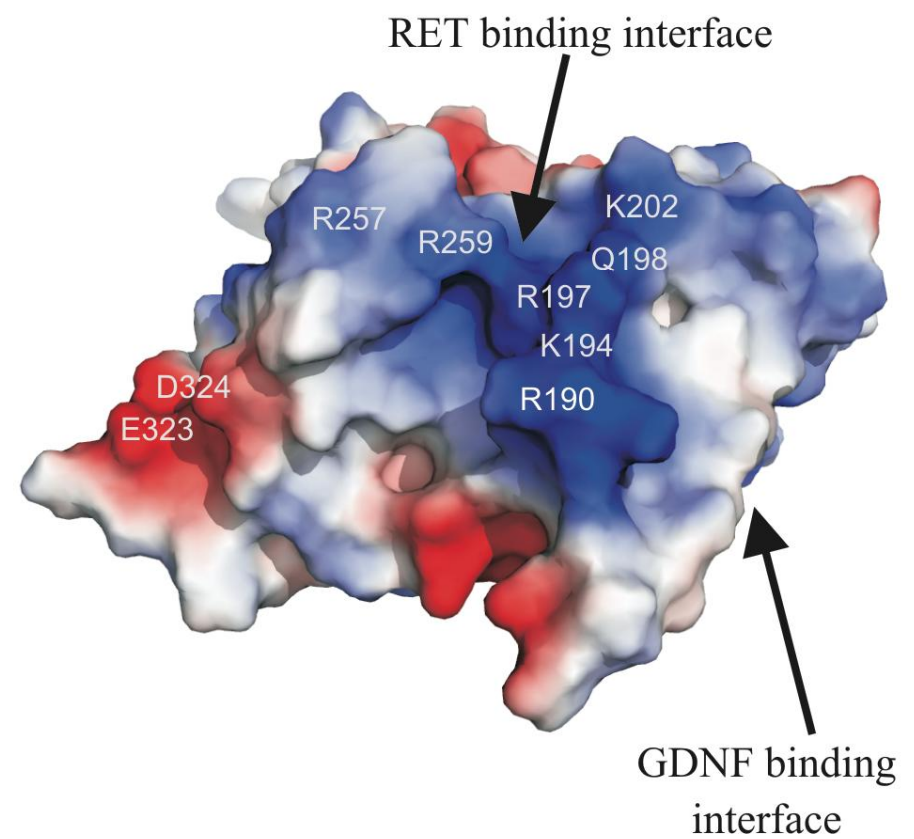

Figure 4.4 RET phosphorylation assay and the RET binding surface. A) Relative activation in ELISA assays $(w t=100 \%)$. MG87-RET cells were used and $1 \mu \mathrm{g} / \mathrm{ml}$ of soluble $w t$ - or mutant GFR $\alpha 1$ was added in the presence or absence of $0.1 \mu \mathrm{g} / \mathrm{ml}$ of soluble GDNF. Percentage stimulation values were obtained by subtracting the individual respective control values, and then the percentage stimulation with respect to $w t$-GFR $\alpha 1$ was calculated. B) Electrostatic surface view of GFR $\alpha 1$ D23 showing the proposed RET binding surface. Probable RET-interacting residues are marked. Arrows point to the RET and GDNF binding interfaces. Reprinted with permission from J. Biol. Chem. (Study I) copyrights 2008. 
The E323A/D324A double mutant also affects the RET phosphorylation. As none of these mutants are on the GDNF binding site, these GFR $\alpha 1$ residues appear to be involved in RET binding. Furthermore, RET and heparin binds to the same region in GFR $\alpha 1$ (Figure 4.4B). It may explain how exogenous heparin inhibited RET signalling (Barnett et al., 2002); heparin could bind to the $\mathrm{R}^{190}-\mathrm{K}^{202}$ region in GFR $\alpha 1$, thereby inhibiting the RET binding.

\subsubsection{Comparison between $\mathrm{GDNF}_{2}-\mathrm{GFR \alpha 1} \mathrm{1}_{2}$ and $\mathrm{ARTN}_{2}$-GFR $\alpha 3_{2}$}

Of the four $\mathrm{GFL}_{2}-\mathrm{GFR} \alpha_{2}$ complexes, the crystal structures of $\mathrm{GDNF}_{2}-\mathrm{GFR} \alpha 1_{2}$ (Study I \& III) and $\mathrm{ARTN}_{2}-\mathrm{GFR} \alpha 3_{2}$ (Wang et al., 2006) have been determined. The structures of GDNF-GFR $\alpha 1$ (codes 2V5E) and ARTN-GFRa3 (code 2GH0) contained only the two binding domains in GFR $\alpha$. GFR $\alpha 1$ and GFR $\alpha 3$ are highly similar with a root mean square deviation of $0.89 \AA$ for $166 \mathrm{C}_{\alpha}$ atoms. From both the crystal structures and previous mutagenesis (Eketjäll et al., 1999; Scott and Ibáñez, 2001; Leppänen et al., 2004), it is clear that the GFL fingertips bind D2 of the coreceptor. The binding interface in both the complexes form an ion triple R224 ${ }^{\text {coreceptor }}$-E61 ${ }^{\text {ligand }}-\mathrm{R} 171^{\text {coreceptor }}$ that is conserved in other GFL-GFR $\alpha$ pairs too (Figure 4.5). Mutations R224A ${ }^{\text {GFR } \alpha 1}$ and E61A ${ }^{\text {GDNF }}$ showed a significant loss in GDNF-GFR $\alpha 1$ binding (Eketjäll et al., 1999; Leppänen et al., 2004), which suggests that loss of the ion triple interaction significantly affects the binding, and $\mathrm{R} 171^{\mathrm{GFR} \alpha 1}$ may be as important as R224 ${ }^{\mathrm{GFR} \alpha 1}$ and E61 ${ }^{\mathrm{GDNF}}$. The ion triple thus appears to be the key interaction required for all the ligand-coreceptor complexes. What is the basis of GFL-GFR $\alpha$ specificity?

\subsubsection{Structural basis of ligand specificity}

Besides the conserved ion triple, the ligand-coreceptor binding interface in different GFLcoreceptor complexes contained non-conserved residues that contribute differently at the interface (Figure 4.5). The ARTN-GFR $\alpha 3$ binding interface involves the packing of $\mathrm{W} 120^{\mathrm{ARTN}}$ in a hydrophobic cavity composed of $\mathrm{G} 175^{\mathrm{GFR} \alpha 3}, \mathrm{M} 114^{\mathrm{ARTN}}$ and A230 ${ }^{\mathrm{GFR} \alpha 3}$ (Figure 4.5B). The equivalent $\mathrm{Y} 120^{\mathrm{GFR} \alpha 1}$ binds to a slightly smaller but deeper pocket at the GDNF-GFR $\alpha 1$ interface (see section 4.1.1). Since mutations of Y120 and L114 to Ala affect coreceptor binding (Eketjäll et al., 1999), the packing of Y120 is important. It appears that the contact residues $\mathrm{I} 175^{\mathrm{GFR} \alpha 1}$ and $\mathrm{V} 230^{\mathrm{GFR} \alpha 1}$ are also important. To find 
specificity determinants, I mutated $\mathrm{I} 175^{\mathrm{GFR} \alpha 1}$ to glycine, so that it forms a GFR $\alpha 3$-like pocket. This resulted in a more than 20-fold reduction in RET phosphorylation (Study I, Table 3). This can be explained because the Ile175 $\rightarrow$ Gly mutation increases the size of the hydrophobic cavity around $\mathrm{Y} 120^{\mathrm{GDNF}}$, thereby influencing the complementary binding interface.

A

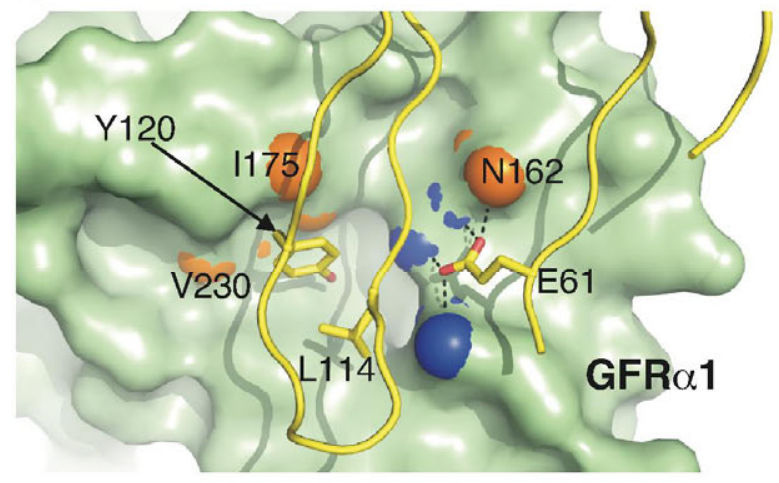

B

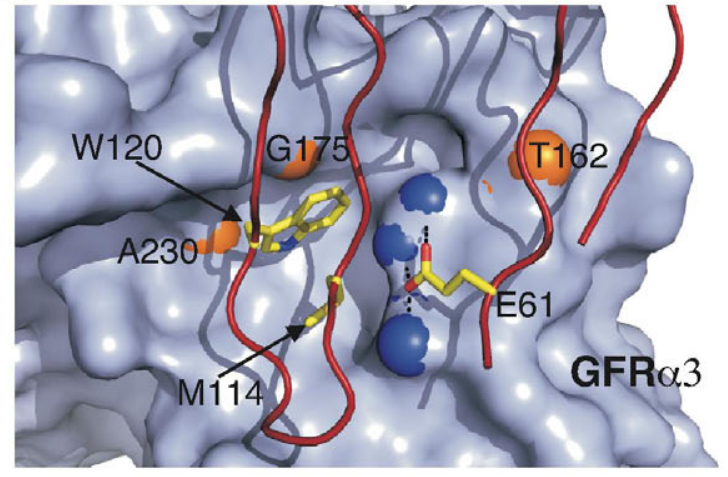

C

\section{Domain 2}

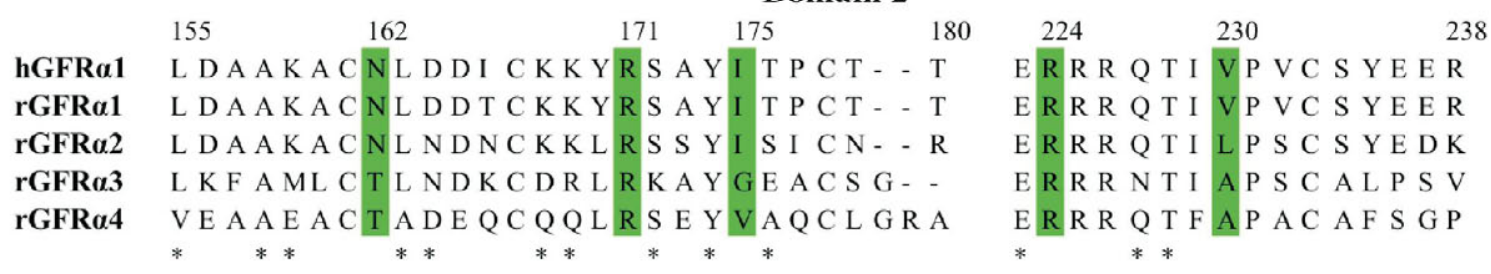

\begin{tabular}{|c|c|c|}
\hline & Finger 1 & Finger 2 \\
\hline & 57 & 105 \\
\hline hGDNF & YE T K E E L I F R Y C S G & I A F D D D L F L D D N V Y H I L R K \\
\hline rGDNF & YE T K E E L I F R Y S G & VAFDDDLSF L D S L V Y H I L K \\
\hline rNRTN & Y T S D E T V L F R Y C A G & T A Y E D E V S F L D V H S R Y T L Q E \\
\hline rARTN & HS S DE L I R F R C S G & TR Y EA - VSF MDVNST WR T VDH \\
\hline rPSPN & 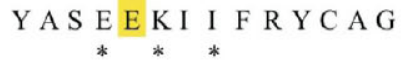 & 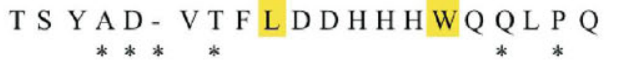 \\
\hline
\end{tabular}

Figure 4.5 The GFL-GFR $\alpha$ binding interface and the sequence alignment. A) GFR $\alpha 1$ in a surface representation (pale green) is positioned under GDNF in yellow loop. B) GFR $\alpha 3$ (in light blue) is shown similarly under ARTN in dark red loop. The key differences between GFR $\alpha 1$ and GFR $\alpha 3$ are shown in orange and the two arginines of the ion-triple are blue. The key GDNF and ARTN residues are shown as sticks: carbon, yellow, oxygen, red and nitrogen, blue. C) Alignments of segments from the binding interface region of the rat GFR $\alpha$ and GFL sequences along with human GFR $\alpha 1$ and human GDNF, respectively. The interface residues within GFR $\alpha 1$ shown in Figure A have a green background, and those GDNF, a yellow background. Other interface residues are marked with asterisks.

On the other hand, the buttressing interaction contributed by N162 to the ion triple in GFR $\alpha 1$ (see section 4.1.1) is not present in the ARTN-GFR $\alpha 3$ interface, because $\mathrm{T} 170^{\mathrm{GFR} \alpha 3}$ (analogous to N162) is too far to interact with the ion triple (Figure 4.5A \& 
4.5B). The $\mathrm{N} 162^{\mathrm{GFR} \alpha 1}$ to Ala mutation showed a significant loss of RET phosphorylation (Figure 4.4A). This variation of residues $\left(\mathrm{L} 114^{\mathrm{GDNF}} \rightarrow \mathrm{M}^{\mathrm{ARTN}}, \quad \mathrm{Y} 120^{\mathrm{GDNF}} \rightarrow \mathrm{W}^{\mathrm{ARTN}}\right.$,

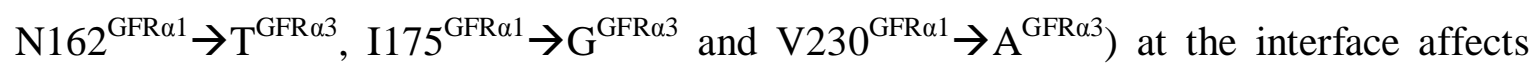
the approach of the ligand fingers: in comparison to GDNF, the finger loops of ARTN twist $\left(\sim 20^{\circ}\right)$ about their longitudinal axis and turn $\left(\sim 20^{\circ}\right)$ around a vertical axis in relation to the triangular helix spiral of GFR $\alpha$ (Study I, Figure 4).

Thus the non-conserved core residues at position 114 and 120 in the ligand, and 162, 175 and 230 in the coreceptor form complementary surfaces at the binding interface (Figure 4.5C). The variation of these residues forms the basis of specificity among different GFLGFR $\alpha$ complexes. In addition, it explains the promiscuity, as the ion triple is conserved and forms the primary interaction between GFL and GFR $\alpha$. The binding is weaker in the cross-talk complexes (GDNF binding GFR $\alpha 3$ and vice versa), because mismatch in the complementary residues at the interface leads to a weaker ion triple. This is why the binding affinity of the cross-talk complexes is much lower than that of the specific complexes (Cik et al., 2000; Carmillo et al., 2005).

As discussed before (see section 1.3.3), GFR $\alpha 1$ does not show any cross talk signalling with PSPN. Baloh and co-workers (2000) by making chimeric GFLs, identified three critical regions in GDNF, NRTN and ARTN, which are essential to activate GFR $\alpha 1-$ RET receptor complex: regions I (residues 73-80), II (residues 103-110), and III (residues 120127) (Figure 4.6A). Regions I and II do not belong to the coreceptor-binding site, as they are not in the fingertips and so these must have a more direct effect on RET activation. Regions I and II from GDNF, NRTN and ARTN may either be involved in binding RET, or may affect the homodimeric structural conformation of the GFLs. As regions I and II are less conserved in GFLs, they probably do not interact with RET. Thus, these regions are more likely to influence the structure of the homodimer. I found only two residues D80 (region I) and R103 (region II), which are conserved in GDNF, NRTN and ARTN - but not in PSPN (Figure 4.6). The structures of $\mathrm{GDNF}_{2}$ and $\mathrm{ARTN}_{2}$ showed that these two residues form a unique inter-monomer ion pair (Figure 4.6). This interaction seems to prevent the movement of the heel, as one side of the heel is buried but the other side is exposed to solvent and forms the D80-R103 ion pair. 


\begin{tabular}{|c|c|c|c|c|c|}
\hline & $\beta 1$ & 310 & L2 & & heel \\
\hline & 45 & 53 & 73 & & 82 \\
\hline hGDNF & A I HL N & VT D L & $D A-A E T$ & T Y D & K I L K N L S R N \\
\hline hNRTN & E LEV R & V S E L & E A A A R & $-\mathrm{YD}$ & L GLR R L RQR \\
\hline hARTN & S QL V P & VR A L & RR - A R S & P H D & L S LAS L LGA \\
\hline hPSPN & S L T L S & VAEL & P R GAR T & Q H G & L A L A R L Q Q Q \\
\hline mGDNF & A I HL N & VT DL & $E S-A E T$ & MYD & K I L K NL SR S \\
\hline mARTN & S QL V P & V S A L & RR - A R S & Q H D & L S L A S L LGA \\
\hline mNRTN & E LEV R & VSE L & E A A I R I & $-\mathrm{YD}$ & L GLR R L RQR \\
\hline mPSPN & S L T L P & VAEL & P Q E A R T & QH S & L VL A R L RGR \\
\hline
\end{tabular}

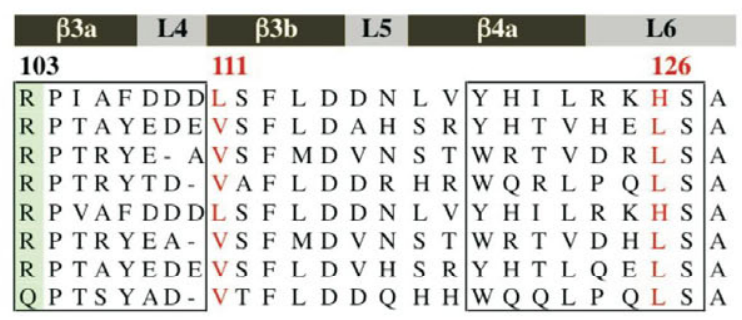

B

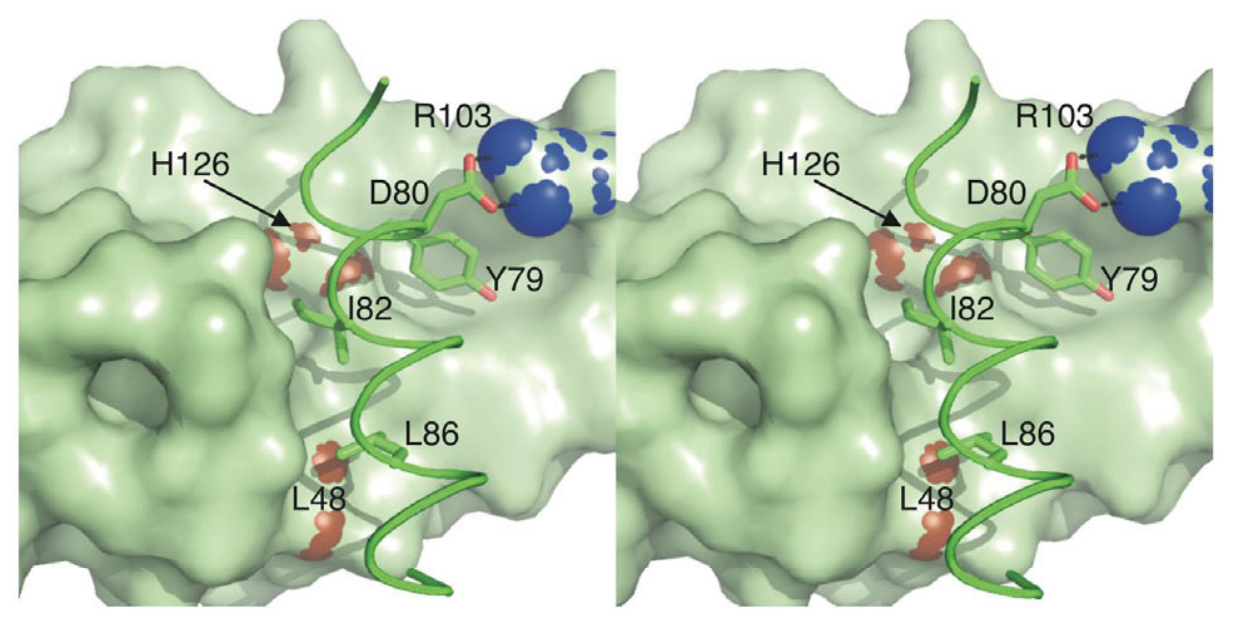

C

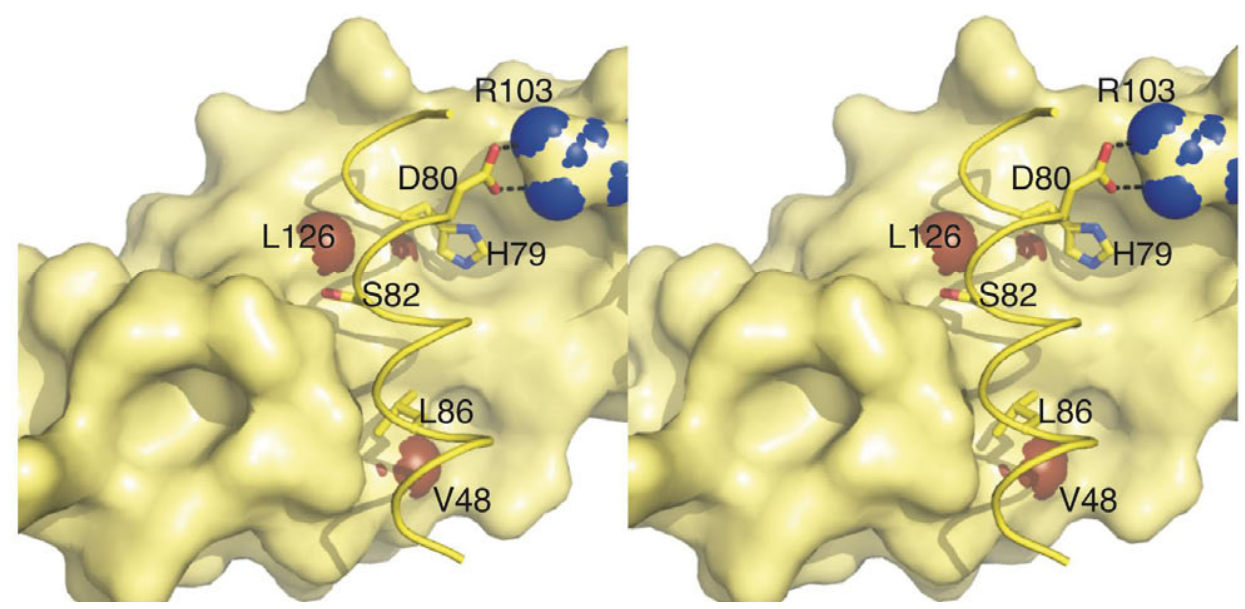

Figure 4.6 Interaction of the ligand heel with the finger domain, and sequence alignment between GFLs. A) Sequence alignment between GFLs (human and mouse sequences) around the buried region. The secondary structure is shown at the top and the numbering according to human GDNF. D80 and R103 forming ion pair (see Figure B and C) in the GDNF and ARTN structures are in light green background. Important differing residues discussed in text are in red. B) GDNF homodimer interface. One monomer is in surface representation (in pale green), while other monomer, showing heel only, is in cartoon loop in green. The important interface residues, not conserved among GFLs, are shown in sticks and brown surface. The inter-monomer ion pair between D80 and R103 is also shown. C) The ARTN homodimer as in Figure B. The finger domain is in pale yellow surface and heel is in yellow loop. Residue numbering is according to the GDNF sequence. Modified and reprinted with permission from Acta Cryst. sect. F (Study III) copyrights 2009. 
Since regions I and II from GDNF/NRTN/ARTN are required to allow mouse PSPN chimeras to signal through GFR $\alpha 1$, the intermonomer ion pair between D80 and R103 may be essential for signalling through the GFR $\alpha 1-$ RET receptor complex (Study III). This ion pair interaction appears to be required for the structural integrity of $\mathrm{GDNF}_{2}$, $\mathrm{NRTN}_{2}$ and $\mathrm{ARTN}_{2}$ - but not PSPN${ }_{2}$. The lack of this ion pair in $\mathrm{PSPN}_{2}$ may influence its signalling through RET-GFR $\alpha 4$ complex, which explains inability of PSPN to signal through RET-GFR $\alpha 1$ (Enokido et al., 1998).

\subsubsection{Structural difference between GFLs indicates novel ways of signalling}

The monomer structures of GDNF and ARTN differ with respect to the hinge angle between the finger and the heel (see section 1.2). This difference in the monomer structures is imparted to the GDNF and ARTN homodimers, which thus have different bend angles. As can be seen (Figure 4.7), the bend angle difference of $46^{\circ}$ in the GDNFand ARTN-coreceptor complexes provide significant dissimilarity in their quarternary structures (Figure 4.7C), which is preserved in another crystal structure of the $\mathrm{GDNF}_{2}-$ GFR $\alpha 1_{2}$ complex (see section 4.1.4).

The bend angle of the GFLs may cause differential signalling through RET, since the MAPK-luciferase assay showed a faster activation via GDNF than ARTN (Study I, Figure 4). This may also explain different effects exerted by GDNF and NRTN on GFR $\alpha 1$ expressing cells as shown by Lee et al. (2006b): GDNF promoted cell survival, while NRTN induced neurite outgrowth. The different bend angles could change the presentation of the RET tyrosine kinase domains on the inside of the cell. These changes in the intracellular region of RET could lead to its interaction with different targets, and affect downstream signalling. 

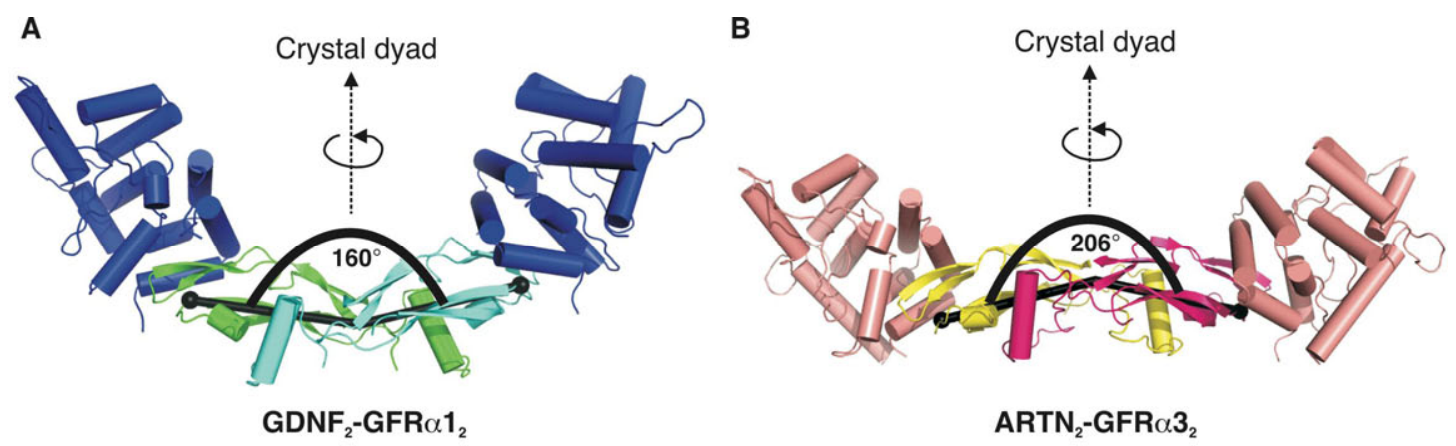

C

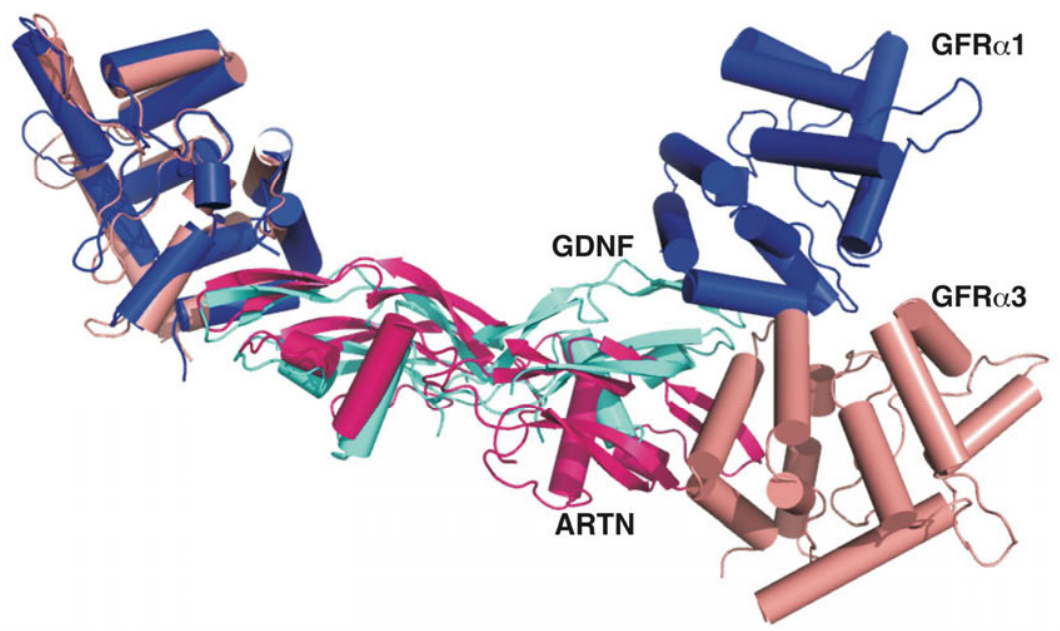

Figure 4.7 GFL bend angle and comparison of $\mathrm{GDNF}_{2}-\mathrm{GFR} \alpha 1_{2}$ and $\mathrm{ARTN}_{2}-\mathrm{GFR} \alpha 3_{2}$ structures. A) Bend angle for the GDNF complex structure (2V5E). Using Pymol (DeLano, 2002), the bend angle is measured between the two finger domains of the monomers (in black spheres) from the intermonomer disulphide bridge (Figure 1.2). The monomers in the GDNF homodimer are cyan and green, and the GFR $\alpha 1$ s are blue. B) The bend angle for the ARTN complex structure. ARTN homodimer is in magenta and yellow, and GFR $\alpha 3 \mathrm{~s}$ in salmon. C) Heterotetramer superposition of $\mathrm{ARTN}_{2}-\mathrm{GFR}_{2} 3_{2}$ (code 2GH0) and $\mathrm{GDNF}_{2^{-}}$GFR $\alpha 1_{2}$ (code 2V5E) structures. The GFR $\alpha 3$ structure on the left side in the ARTN-GFR $\alpha 3$ complex (2GH0) was superimposed on GFR $\alpha 1$ in 2V5E. The GDNF homodimer is in cyan and ARTN in magenta. GFR $\alpha 1$ and GFR $\alpha 3$ s are as in Figure A \& B. Modified and reprinted with permission from Acta Cryst. sect. F (Study III) copyrights 2009 .

\subsubsection{Analysis of GFL structural variation (Study III)}

To analyze whether the differences between GDNF and ARTN are due to crystallographic artefacts, I crystallized another $\mathrm{GDNF}_{2}-\mathrm{GFR} \alpha 1_{2}$ complex. There were three differences in purification and crystallization: first, the new GDNF-complex was purified and crystallized in the absence of SOS. Second, I did not treat the purified complex with peptide: $N$-glycosidase $\mathrm{F}$, so that the complex remains glycosylated. Third, the crystals were grown at room temperature. The crystals were obtained in a well solution containing 
15\% PEG 4000, $0.15 \mathrm{M}\left(\mathrm{NH}_{4}\right)_{2} \mathrm{SO}_{4}, 0.1 \mathrm{M}$ MES buffer $\mathrm{pH}$ 6. A dataset at $2.35 \AA$ was collected which was processed in space group C2 using XDS (Study III, Table 1).

The complex structure was solved by molecular replacement using the previous GDNFGFR $\alpha 1$ structure (2V5E) as a search model. The asymmetric unit contains two GDNFGFR $\alpha 1$ heterodimers (chains $\mathrm{A} \& \mathrm{~B}, \mathrm{C} \& \mathrm{D}$ ), each forming an independent symmetric heterotetramer around the two unique crystallographic two-fold axes. The two new $\mathrm{GDNF}_{2}-\mathrm{GFR} \alpha 1_{2}$ complexes are almost identical (Study III), and have almost the same bend angle of $158^{\circ}$.

The new GDNF complex (3FUB) is very similar to the previous complex structure (heterodimer RMSD of $1.9 \AA$ for $280 \mathrm{C}_{\alpha}$ ). The important difference between the two $\mathrm{GDNF}_{2}-\mathrm{GFR} \alpha 1_{2}$ complexes (2V5E \& 3FUB) is in the GDNF. The GDNF heel is rotated by about $20^{\circ}$ in the heterodimer superposition (Study III, Figure 4), which is accompanied by a rotation of $20^{\circ}$ of the right hand heterodimer, viewed down the two-fold axis (Figure 4.8). Nonetheless, the bend angle in the GDNFs and the separation between the two putative RET binding surfaces is almost identical to that in the previous structure (2V5E). The GDNF structural changes thus do not considerably affect the positioning of the RETs with respect to each other on the inside of the membrane. On the other hand, superposition of the $\mathrm{ARTN}_{2}-\mathrm{GFR} \alpha 3_{2}$ complex with the new $\mathrm{GDNF}_{2}-\mathrm{GFR} \alpha 1_{2}$ complex (code $3 \mathrm{FUB}$ ) results in similar differences in the GFL bend angle as with 2V5E.

So far five GDNF crystal structures have been determined both unbound and with coreceptor bound. Each $\mathrm{GDNF}_{2}$ has a different bend angle varying from $146^{\circ}$ to $168^{\circ}$ (Figure 1.2B). On the other hand, the six ARTN structures are more rigid; the bend angle in the homodimeric structures varies from $201^{\circ}-206^{\circ}$. Therefore it appears that $\mathrm{GDNF}_{2}$ has more bend angle flexibility than $\mathrm{ARTN}_{2}$. However, comparison of the two $\mathrm{GDNF}_{2}-$ GFR $\alpha 1_{2}$ complexes suggests that the structural variation in $\mathrm{GDNF}_{2}$ (Study III, Figure 6) do not affect the heterotetrameric arrangement of the complex, but the larger difference between $\mathrm{GDNF}_{2}$ and $\mathrm{ARTN}_{2}$ do (Figure 4.7C). In addition, the structural differences between the GDNF- and ARTN-coreceptor complexes do not appear to be due to crystallization artefacts. Thus comparison of previous $\mathrm{GFL}_{2}-\mathrm{GFR} \alpha_{2}$ complexes (2V5E and $2 \mathrm{GH} 0$ ) with the new $\mathrm{GDNF}_{2}-\mathrm{GFR} \alpha 1_{2}$ complex (3FUB) supports our proposal about the 
role of bend angle in GDNF signalling (see section 4.1.3.2). What causes bend angle differences among GFLs and what makes $\mathrm{GDNF}_{2}$ more flexible?

A

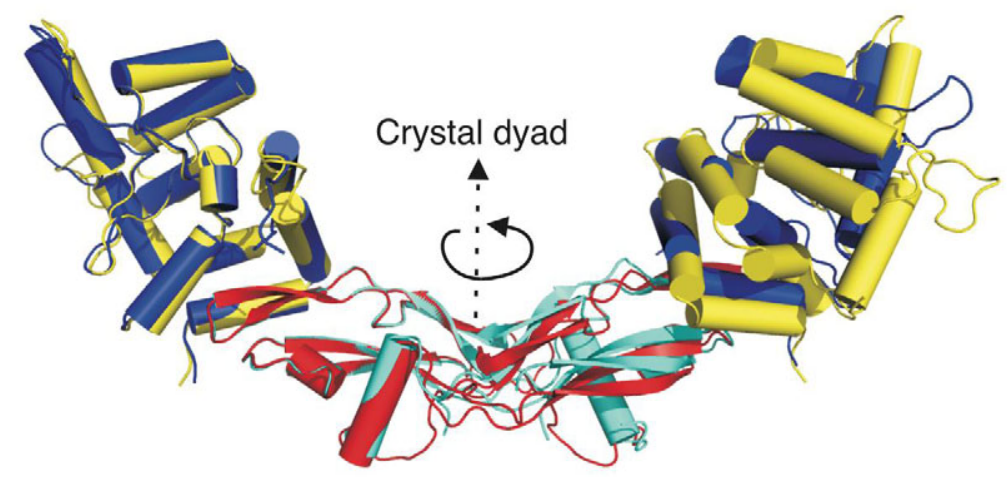

B
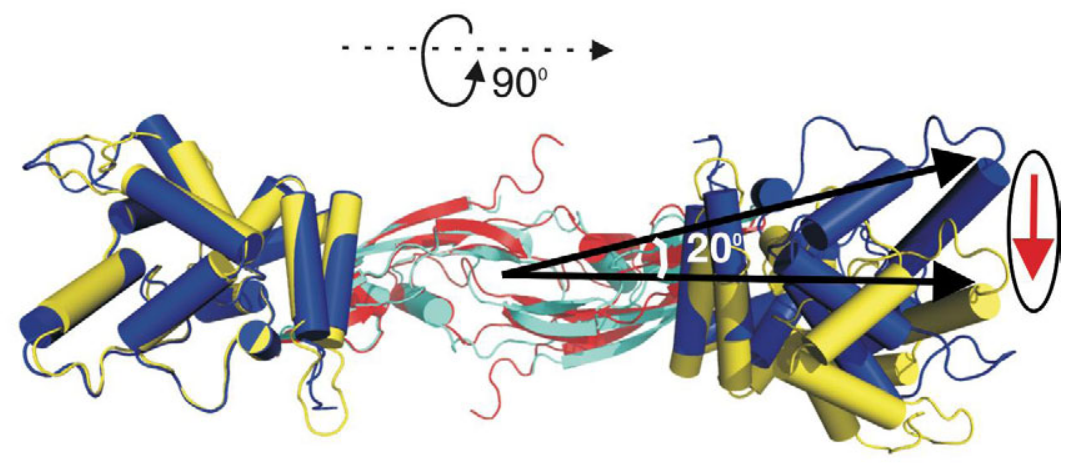

Figure 4.8 Comparison between the two $\mathrm{GDNF}_{2}-\mathrm{GFR} \alpha 1_{2}$ complexes. A) \& B) Superposition of the $\mathrm{GDNF}_{2}-\mathrm{GFR} \alpha 1_{2}$ complexes (2V5E \& 3FUB). The left-hand heterodimer was superimposed to show the differences in the right-hand heterodimer. The two-fold axis in the two heterotetramers is thus in a slightly different position in each structure; the one shown is for 3FUB. The bend in the quaternary structure of the $\mathrm{GDNF}_{2}-\mathrm{GFR} \alpha 1_{2}$ complex is the same in both structures. Figure $\mathrm{B}$ is rotated $90^{\circ}$ from Figure A about the horizontal axis. The red arrow represents the direction of motion between the two right-hand GFR $\alpha 1$ s. Reprinted with permission from Acta Cryst. sect. F (Study III) copyrights 2009.

\section{Molecular basis for GFL variation}

The head-to-tail homodimer structure of the GFLs is formed by the packing of the heel against the finger domain of the other monomer. In the 11 unique ARTN and GDNF structures known so far, $\mathrm{ARTN}_{2}$ buries approximately $800 \AA^{2}$ more surface area at the homodimer interface. As can be seen (Figure 1.2), ARTN fingers are more curved, which allow $\mathrm{ARTN}_{2}$ to bury more surface area at the homodimer interface. In addition, the curvature affects the hinge angle, which subsequently influences the bend angle. Thus, both the observed GDNF flexibility and the variation in the ligand bend angle are because the GDNF fingers are less curved. 
The residues at the homodimer interface form the molecular basis for ligand bend angle and its flexibility. At the homodimer interface, the substantial change of I82 ${ }^{\mathrm{GDNF}} \rightarrow \mathrm{S}^{\mathrm{ARTN}}$ in the heel is accompanied by a complementary change of $\mathrm{H} 126^{\mathrm{GDNF}} \rightarrow \mathrm{L}^{\mathrm{ARTN}}$ in the finger domain of the other monomer. The bulkier Ile82 in $\mathrm{GDNF}_{2}$ pushes His126 backwards, which in turn pushes Leu111 of strand $\beta 3$ b (Study III, Figure 7). On the other hand, the analogous residues S82, V111 and L126 (GDNF numbering) at the $\mathrm{ARTN}_{2}$ interface are less bulky (Figure 4.6C); their interactions bring the fingers closer to the heel (Study III, Figure 7). The same applies to $\mathrm{L} 48^{\mathrm{GDNF}} \rightarrow \mathrm{V}^{\mathrm{ARTN}}$ change at finger 1 . These changes bring curvature in the ARTN fingers, bringing the fingers closer to the heel than in GDNF (Figure 4.6). It thus increases the bend angle between the ARTN monomer fingers.

NRTN should have an ARTN-like structure, as three (V48, V111, L126) of the four residues mentioned above are similar to ARTN (Figure 4.6C). The only significant difference between NRTN and ARTN is the residue at position 82, which is Ser in ARTN and Gly in NRTN; this should increase, not decrease, the level of curvature. Therefore, NRTN appears to be rigid and essentially flat, so it probably shows ARTN-like, not GDNF-like, MAPK activation.

Since loop 'L3' in GDNF (Figure 1.2A) is disordered or has high B-factors in all of the GDNF-containing crystal structures (Study III, Table 3), it may provide flexibility to the $\mathrm{GDNF}_{2}$ structure. On the other hand, the post-helix loop L3 of ARTN (Study III, Figure 1 and 8) is more ordered in all the six ARTN structures (Silvian et al., 2006; Wang et al., 2006). The pre-helix L2 region in ARTN is positively charged ${ }^{73} \operatorname{RRARS}^{77}$ and forms a $3_{10}$ helix, while the GDNF ${ }^{73} \mathrm{DAAET}^{77}$ does not (Study III, Figure 1). This change in the prehelix region appears to provide a different relative orientation of finger 1 with respect to the heel, which affects the hinge angle. Thus, in addition to the heel region, the pre-helix and the post-helix loops of the GFLs also seem to influence the bend angle. 


\subsection{Structural studies of MANF and CDNF}

MANF and CDNF are two newly discovered neurotrophic factors. There are no structures for these proteins. In an attempt to unravel the molecular basis of MANF/CDNF signalling, I solved the crystal structures of MANF and CDNF. The results described in this section are based on Study II.

\subsubsection{The crystal structure of MANF and CDNF}

Mature human MANF (amino acids 1-158) was expressed in Escherichia coli Origami (DE3) cells as a His-tagged fusion protein (Peränen et al., 1996). It was purified by $\mathrm{Ni}^{2+}$ affinity, ion exchange and size-exclusion chromatography. MANF crystals grew over a reservoir solution of $100 \mathrm{mM}$ Na-cacodylate buffer, $\mathrm{pH} 6.5,0.2 \mathrm{M} \mathrm{MgAc}_{2}$ and 12-18\% PEG 8000. Three datasets were collected; native data diffracted to $3.0 \AA$, sulphur-SAD to $2.8 \AA$, and Hg-derivative to $4.0 \AA$ (Study II, Table 1). The crystals belong to space group $\mathrm{P}_{1}$.

Recombinant human CDNF (amino-acids 1-167) was expressed in Sf9 insect cells and purified as described (Lindholm et al., 2007). A proteolytic N-terminal fragment that copurified with the full-length CDNF was, after tag-removal, purified to high homogeneity by gel filtration using a Superdex 200 (GE Healthcare) column. The fragment was assigned as CDNF- $\Delta \mathrm{C}$, which crystallized over a reservoir solution of $100 \mathrm{mM} \mathrm{NaAc}, \mathrm{pH}$ 4.6, 0.2 $\mathrm{M} \mathrm{NH}_{4} \mathrm{Ac}$ and 25-30\% (w/v) MME-PEG 2000. A native dataset, which diffracted to $1.6 \AA$, was collected. The crystals belong to space group $\mathrm{P} 2_{1}$ with two molecules per asymmetric unit. For selenomethionine (SeMet) labelling in insect cells, the CDNF- $\Delta C$ expression protocol was modified according to Leppänen et al. (2004). MAD data were collected from a SeMet-substituted CDNF- $\Delta$ C crystal. Using SHELX (Schneider and Sheldrick, 2002), six selenium sites were identified and refined to calculate phases for the MAD data. The final model contained two identical molecules of CDNF- $\Delta \mathrm{C}^{9-105}$ in the asymmetric unit (RMSD $0.25 \AA$ for all $\mathrm{C}_{\alpha}$ ). The structure was refined using native data to a final R-factor of $20.9 \%\left(\mathrm{R}_{\text {free }} 24 \%\right)$.

For MANF structure solution, position of three $\mathrm{Hg}$ atoms were determined and refined by using the SHELX C/D/E programs in HKL2MAP (Schneider and Sheldrick, 2002). After improving and extending the phases using DM (Collaborative Computational Project, 
Number 4, 1994), a partial model was built from Hg-phased electron density map. Finally, the CDNF- $\Delta \mathrm{C}$ structure was used as a search model to solve the structure of MANF. The anomalous map from $\mathrm{Hg}$-phases and S-SAD structure factors identified four disulphide bridges, three in the N-terminus and the fourth one in the C-terminus. The final MANF structure was refined at $2.8 \AA$ resolution using S-SAD data to a crystallographic R-factor of $28.0 \%\left(\mathrm{R}_{\text {free }} 30.5 \%\right)$.

\subsubsection{The closed saposin fold of N-termini of MANF and CDNF}

The N-termini of MANF (MANF-N ${ }^{1-95}$ ) and CDNF $\left(\mathrm{CDNF}-\Delta \mathrm{C}^{9-105}\right)$ are essentially the same (RMSD $0.89 \AA$ for $86 \mathrm{C}_{\alpha}$ ), consisting of five $\alpha$-helices $(\alpha 1-\alpha 5)$ followed by a turn of $3_{10}$ helix (Figure 4.9A, 4.9B and 4.9C). The structural fold of MANF-N and CDNF- $\Delta \mathrm{C}$ is identical to the 'closed' saposin-like fold (Figure 4.9B-E), and the spacing between the six cysteines in their sequences is identical to that in the 80 residues long SAPLIP domain (Figure 4.9A). The closest structural homologs of MANF-N and CDNF- $\Delta \mathrm{C}$ are granulysin (Anderson et al., 2003) and NK-lysin (Liepinsh et al., 1997), which are membrane-lytic SAPLIPs. The RMSDs of superposition for CDNF- $\Delta \mathrm{C}$ and MANF-N upon granulysin are $3.5 \AA$ and $3.0 \AA$ for 69 and $70 \mathrm{C}_{\alpha}$-atoms, respectively, out of a total of $74 \mathrm{C}_{\alpha}$-atoms. Compared to other SAPLIPs, granulysin sequence has five cysteines, which can form only two disulphide bridges. The SAPLIP domain in most proteins has low sequence identity $(\leq 17 \%)$ to saposins, and so do MANF and CDNF. Thus MANF and CDNF are distantly related to saposins (Figure 4.10). 
A

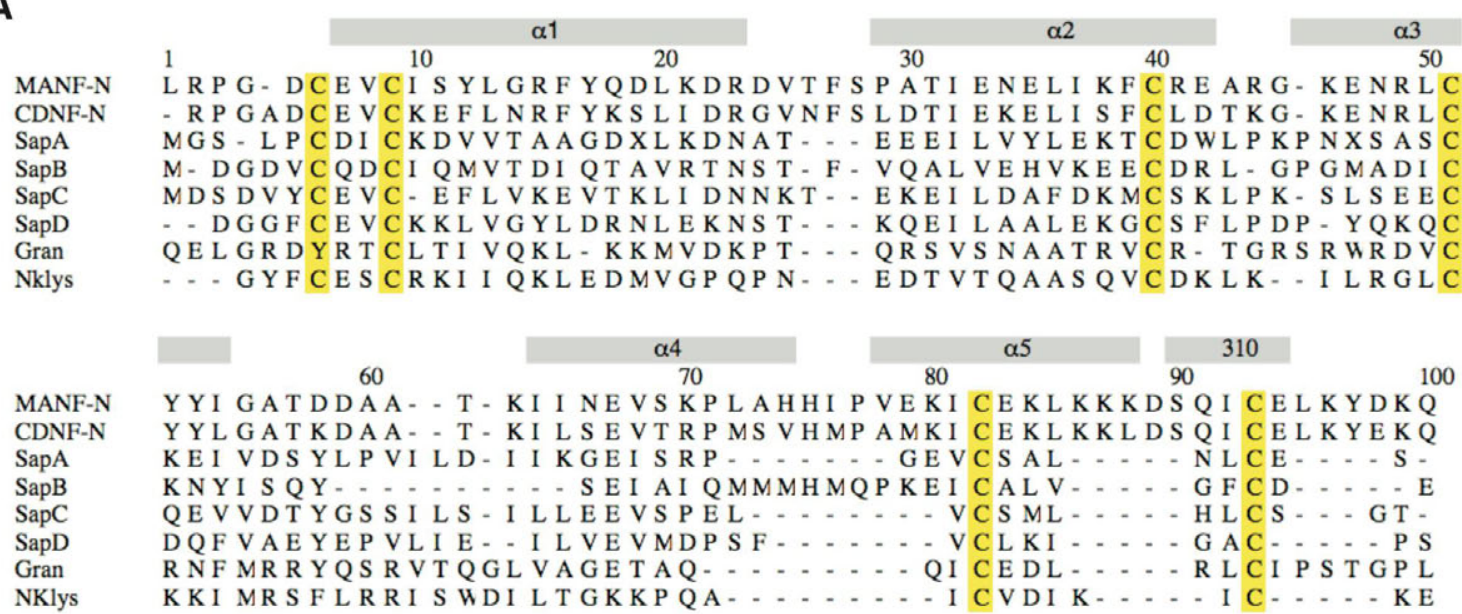

B

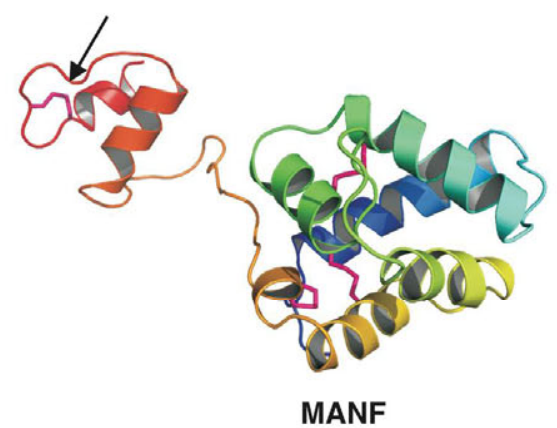

C

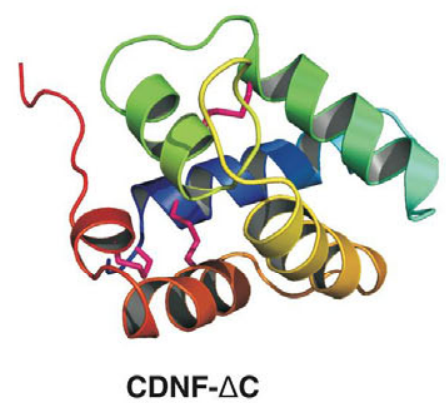

D

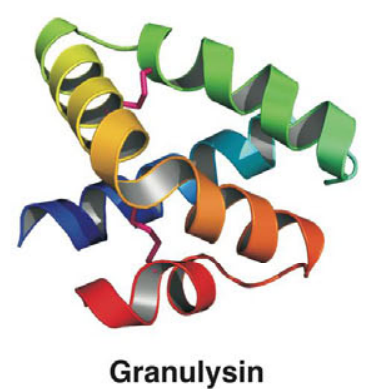

E

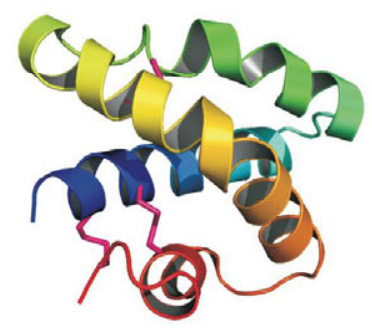

Saposin C - monomer
$\mathbf{F}$

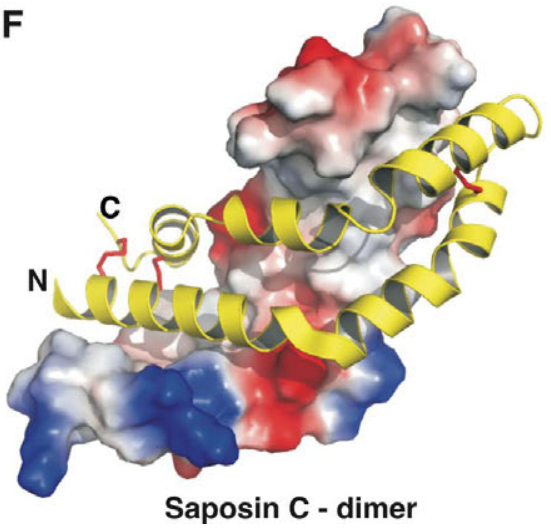

Figure 4.9 Aligned sequences of MANF, CDNF and related SAPLIPs, and their structures in 'open' and 'closed' conformations. A) Structure based sequence alignment of the N-termini of MANF and CDNF with saposin A, B, C, D, and granulysin and NK-lysin. B) Cartoon representation of MANF colour coded from blue to red. Disulphide bridges are shown in sticks with carbon in magenta and sulphur in yellow. The flexible C-terminus is composed of a connecting loop and two helices. An arrow marks the position of the fourth disulphide bridge. C) CDNF- $\Delta$ C in the same orientation, colour and cartoon scheme as Figure B. D) \& E) Granulysin and saposin $\mathrm{C}$ showing the "closed' saposin fold as a rainbow. F) The "domain swapped" saposin $\mathrm{C}$ homodimer. One monomer is in cartoon (yellow), and the other one is shown in electrostatic surface representation. Colour scheme in surface representation: blue, positive; red, negative and white, hydrophobic residues. 


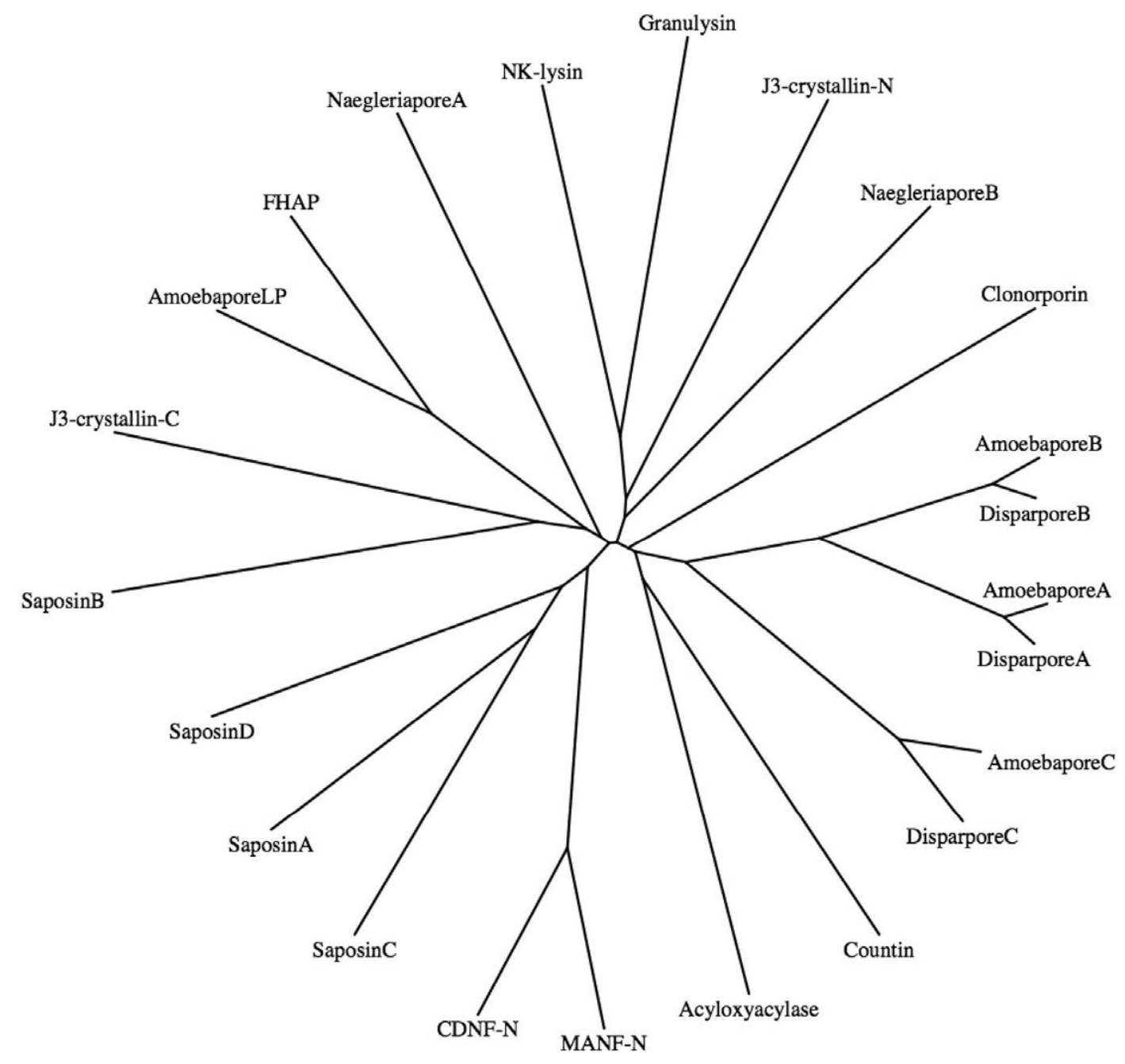

Figure 4.10 Phylogenetic tree for SAPLIP family including MANF and CDNF.

\subsubsection{The C-terminus of MANF and CDNF}

The C-terminus of MANF was disordered in the crystal structure, and I could only build polyalanine model for residues 95-137 (Figure 4.9B). Residues 138-158 are not visible at all. It is consistent with the unstructured regions indicated by DisEMBL (Linding et al., 2003). The MANF C-terminus consists of a loop from 95 to 111 followed by two parallel helices ( $\alpha 6$ and $\alpha 7$ ) connected by a loop from residues 123 to 130. The C-terminus, therefore, can adopt different conformations, and in the structure in the crystal is stabilized by crystal contacts.

Recent studies have shown cytoprotective role of MANF and presumably CDNF using a variety of ER stress models (see section 1.4.3). ER stress results in accumulation of 
unfolded proteins, which induces UPR. UPR reduces ER stress by enhancing the protein folding capacity and degradation of misfolded proteins. Thiol/disulphide oxidoreductases, the CXXC motif containing proteins, increase protein folding by catalyzing the formation of intramolecular disulphide bonds. These proteins include thioredoxins, like protein disulphide isomerases (PDIs), which function in the ER (Ellgaard and Ruddock, 2005). The CXXC motif containing proteins are usually involved in reduction, oxidation and isomerisation reactions that are necessary for proper disulphide bond formation of target proteins in the ER (Horibe et al., 2004). The CXXC motif may also bind metal ions in metal-binding proteins, including PDI (Narindrasorasak et al., 2003).

MANF and CDNF contain two CXXC motifs in the N- and C-termini (Figure 1.5). The cysteines C9 and C6 in the N-terminus motif form disulphide bridges with the cysteines on helices $\alpha 5$ and $3_{10}$, respectively, as in other SAPLIPs. The second ${ }^{127} \mathrm{CXXC}^{130}$ motif (MANF numbering) forms an internal disulphide bridge in the MANF structure (Figure 4.9B). Like oxidoreductases, the C-terminal CXXC motif of MANF may also be involved in protein folding, which may explain its cytoprotective role in the ER.

\subsubsection{Functional implications from MANF and CDNF structures}

\subsubsection{Interaction with lipid or membrane}

Interestingly, SAPLIPs have a characteristic ability to interact with membranes or lipids (Bruhn, 2005). Saposin C was shown to interact with lipids through the positively charged residues, which are thought to interact with negatively charged lipid headgroups to initiate membrane binding (Liu et al., 2005). Furthermore other SAPLIPs, such as NK-lysin and granulysin, also have positively charged residues on the surface, which are also indicated to interact with the negatively charged lipid headgroups in the membrane (Miteva et al., 1999; Sánchez-Barrena et al., 2003). In a similar way, the SAPLIP domain of MANF and CDNF has conserved positively charged residues on the surface that are located in two adjacent regions. These include R44, K46, R49 and K96 (MANF numbering), which lie on $\alpha 3$ and $\alpha 5$ within one region. Other region oriented approximately $90^{\circ}$ to the first contain K70, K80, K84, K86 and K87 (Figure 4.11A \& 4.11B). This suggests that, like 
saposins and SAPLIPs, the conserved positively charged residues of MANF and CDNF might bind lipids.

A

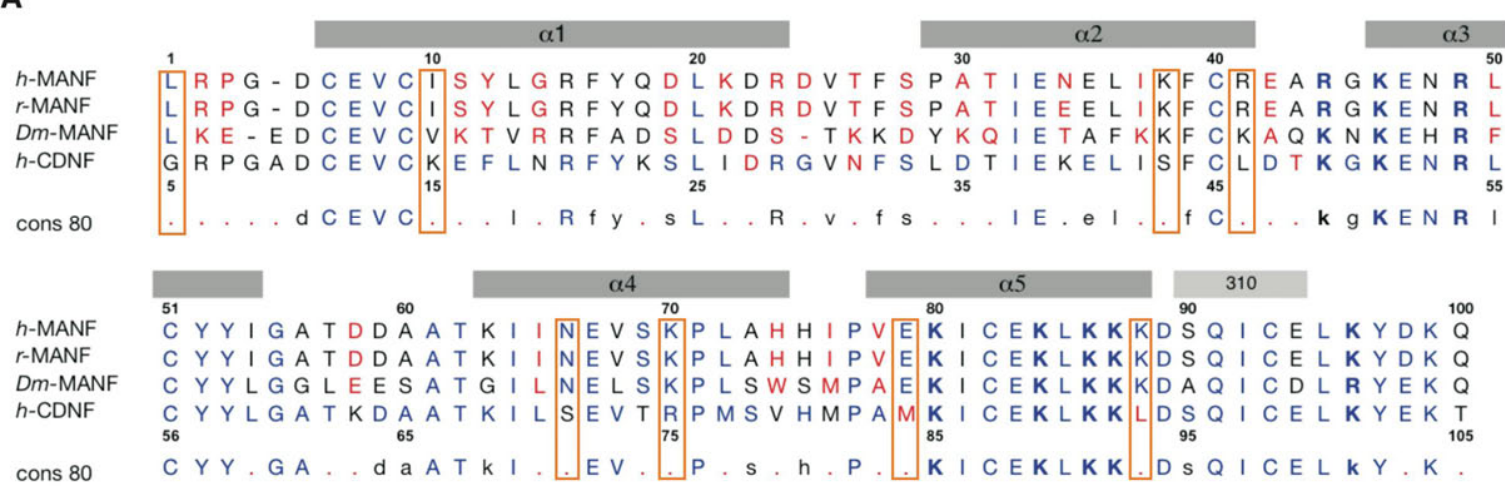

B

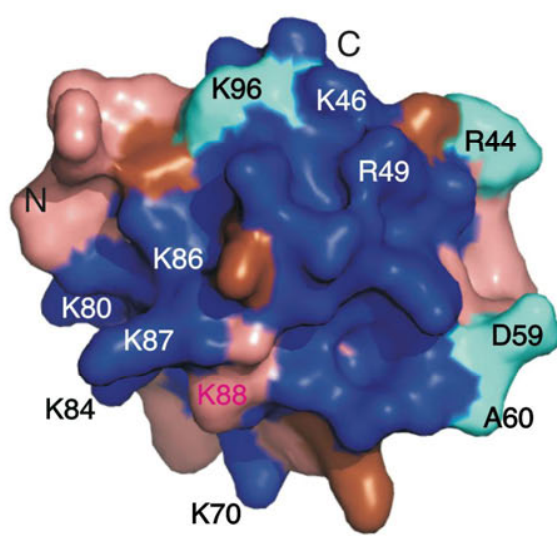

MANF-N

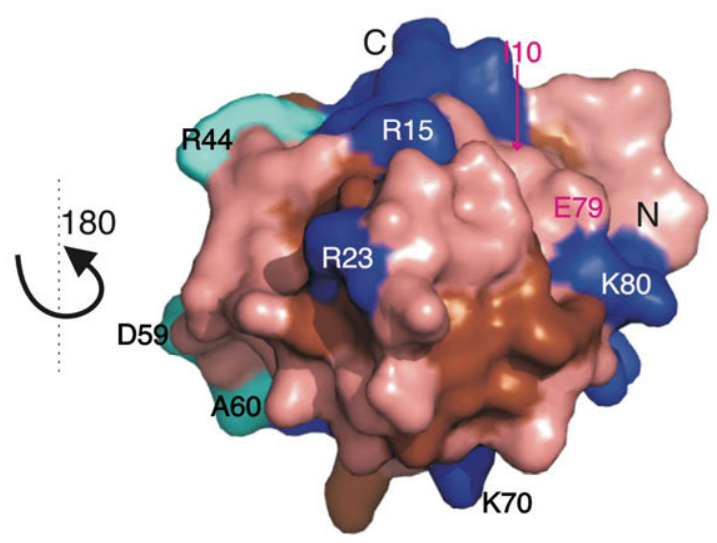

MANF-N

Figure 4.11 Sequence alignment and conserved surfaces of the N-terminal domain. A) Structurebased sequence alignment between the N-terminus of human-, rat- and Dm-MANF, and human CDNF, with secondary structure elements indicated above the alignment. Blue: completely conserved in the individual families (>80\% identity); semi-conserved (60-80\% identity), black; non-conserved $(<60 \%$ identity), red. MANF sequence numbering is shown above and CDNF numbering below. Last line: consensus alignment for the entire MANF/CDNF family: conserved in blue (uppercase), semi-conserved in black (lowercase); non-conserved as red dots. The most non-conserved residues between Dm-MANF and human-CDNF are boxed in orange. Residue 70 is strictly conserved as Lys in MANF, while it is conserved as Arg in CDNFs (Figure 1.5). It is also boxed in orange, as this change may also contribute to functional differences between MANF and CDNF. Conserved positively charged residues are bolded. Dm, Drosophila melanogaster. B) MANF-N surface coloured by conservation: Blue, conserved; brown, semi-conserved; salmon, non-conserved. The similar residues R44/K, D59/E, A60/S and K96/R are shown in cyan. Left: the most conserved surface of MANF-N. Right: the most non-conserved surface. It is related to the left image by a rotation of $180^{\circ}$ about the vertical axis in the picture. Conserved positively charged surface residues are labelled in black and white, while the positions of the three biggest differences between MANF and CDNF (I10K, E79M and K88L) are labelled in magenta. Reprinted with permission from PEDS (Study II) copyrights 2009. 
Initial experiments indicated that MANF and CDNF also interact with lipids, which may be crucial for the activity of CDNF and MANF (Hongxia Zhao and Mart Saarma personal communication). However, unlike granulysin and NK-lysin, MANF and CDNF do not seem to disrupt the target membranes, as they do not induce cell death (Lindholm and Saarma, unpublished).

\subsubsection{Oligomerisation}

Oligomerisation is common to saposins and SAPLIPs, which can be induced by its interaction with lipids or in response to $\mathrm{pH}$ changes. Interaction of lipids with saposin $\mathrm{B}$ opens its folded leaf structure to form a dimer (Figure 1.6B). The solution structure of saposin $\mathrm{C}$ also opens its hydrophobic core in the presence of sodium dodecyl sulphate (Hawkins et al., 2005). At low pH (4.8) or in the presence of detergent, saposins A and C form dimers and trimers in solution (Ahn et al., 2003). The crystal structure of saposin C at $\mathrm{pH} 4$ revealed another open conformation where it formed a domain-swapped homodimer (Figure 4.9F), but saposin D at pH 6 crystallized as a dimer in the closed conformation (Rossmann et al., 2008). Interestingly, the crystal structure of CDNF- $\Delta \mathrm{C}$, in the closed conformation, contained a dimer in the asymmetric unit at $\mathrm{pH} 4.6$, while MANF crystallized as a monomer at neutral $\mathrm{pH}$. Lipid binding or $\mathrm{pH}$ changes may also induce dimerization of CDNF and MANF.

\subsubsection{Comparison between MANF and CDNF}

MANF and CDNF have shown similar expression in mouse tissues (Lindholm et al., 2007; 2008). Like GDNF (Lin et al., 1993), both MANF (Voutilainen et al., 2009) and CDNF (Lindholm et al., 2007) protect and repair midbrain dopaminergic neurons in vivo in a rat 6-OHDA model of PD. Recently, MANF was shown to be neuroprotective against cerebral ischemia (Airavaara et al., 2009). Though sharing similar biological functions, MANF and CDNF show no sequence or structural homology to other neurotrophic factors such as GDNF and BDNF.

The only ortholog in invertebrates, which is more related to vertebrate MANF than CDNF (Palgi et al., 2009), suggests that the two paralogs MANF and CDNF in vertebrates might be the result of gene duplication event during evolution. In gene knockout experiments, only human MANF, not CDNF, rescues the Drosophila MANF gene knockout lethality, 
suggesting different functions governed by both the proteins, although both shared high sequence and structural similarity (Palgi et al., 2009). This functional difference between human-MANF and CDNF might be due to surface residues that are similar or identical in human- and Dm-MANF but different in human-CDNF. There are three such regions: K38, R41 on helix $\alpha 2$ (S, L in CDNF); L1, I10, E79 on helix $\alpha 1$ and $\alpha 5$ (G, K, M in CDNF); and N66, K70 and K88 on helix $\alpha 4$ and $\alpha 5$ (S, R and L) (Figure 4.11). Of these, the strictly conserved residues L1, N66, K70, E79 and K88 in MANFs appear to be more important than the less well conserved I10, K38 and R41 (Figure 4.11A). Therefore, the changes ${ }^{\mathrm{MANF}} \mathrm{L} 1 \rightarrow \mathrm{G}^{\mathrm{CDNF}}, \quad{ }^{\mathrm{MANF}} \mathrm{N} 66 \rightarrow \mathrm{S}^{\mathrm{CDNF}}, \quad{ }^{\mathrm{MANF}} \mathrm{K} 70 \rightarrow \mathrm{R}^{\mathrm{CDNF}}, \quad{ }^{\mathrm{MANF}} \mathrm{E} 79 \rightarrow \mathrm{M}^{\mathrm{CDNF}}$ and ${ }^{\mathrm{MANF}} \mathrm{K} 88 \rightarrow \mathrm{L}^{\mathrm{CDNF}}$ probably cause the functional differences between CDNF and MANF. Most significant of these are the $\mathrm{E} 79 \rightarrow \mathrm{M}$ and $\mathrm{K} 88 \rightarrow \mathrm{L}$ changes, which are nonconservative changes next to the conserved positive region that is indicated to be involved in membrane binding.

\subsubsection{Bifunctional role of MANF and CDNF}

Recent studies on MANF and CDNF suggest that they have dual role: as extracellular neurotrophic factors and as ER resident cytoprotective proteins. MANF (Petrova et al., 2003; Voutilainen et al., 2009) and CDNF (Lindholm et al., 2007) promote the survival of midbrain dopaminergic neurons, and MANF is also cytoprotective against ER stress induced cell death (Apostolou et al., 2008; Tadimalla et al., 2008). The structures of MANF and CDNF reveal a saposin fold, and these proteins are the first SAPLIPs with neuroprotective and neurorestorative activities, along with a role in the ER stress response. Since the characteristic feature of saposins and SAPLIPs is to bind lipids or membranes via positively charged residues on their surface (Bruhn, 2005), it is possible that the conserved Lys and Arg residues on the MANF/CDNF surface bind negatively charged lipid headgroups in the membrane. In addition, saposin $\mathrm{C}$ and prosaposin have been indicated to have neurotrophic activities (Kotani et al., 1996; Liu et al., 2001). Secreted MANF and CDNF may thus interact with membrane lipids or with a transmembrane (lipo) receptor through its N-terminus SAPLIP domain but their mode of action is unclear. Initial experiments have shown that MANF and CDNF indeed interact with lipids. Oxidoreductases, like PDIs, contain CXXC motifs and function in the ER (Collet et al., 2003; Horibe et al., 2004). The crystal structure of MANF C-terminus, which also contain CXXC motif, supports the idea of MANF (and CDNF) as an anti ER stress protein. 
MANF and CDNF may facilitate protein folding in the ER by proper disulphide bond formation, thus reducing the ER stress caused by unfolded or incorrectly folded proteins.

On the other hand, cytoprotection and neurotrophic effects may be related. In vitro studies suggest that 6-OHDA toxicity results in ER stress (Silva et al., 2005). It is possible that neurotrophic activity of CDNF (Lindholm et al., 2007) or MANF (Voutilainen et al., 2009) on adult rat 6-OHDA model of PD is due to reduction in ER stress. Although initial experiments have failed to detect oxidoreductase activity (Mizobuchi et al., 2007), further characterization of these proteins is needed to demonstrate their oxidoreductase or metal binding activities and their cellular targets. 


\section{CONCLUSIONS}

Here I solved the crystal structure of the $\mathrm{GDNF}_{2}-\mathrm{GFR} \alpha 1_{2}$ complex, which is the first step in $\mathrm{GDNF}_{2}-\mathrm{GFR} \alpha 1_{2}-\mathrm{RET}_{2}$ signalling. The complex structure is formed by the interaction of GDNF fingers with the triangular helix spiral within D2 of GFR $\alpha 1$. The key interaction at the interface is the ion triple $\mathrm{Arg}^{\mathrm{GFR} \alpha}{ }_{-\mathrm{Glu}}{ }^{\mathrm{GFL}}-\mathrm{Arg}^{\mathrm{GFR} \alpha}$. The mutations $\mathrm{N} 162 \mathrm{~A}^{\mathrm{GFR} \alpha 1}$ and I175G $\mathrm{G}^{\mathrm{GFR} \alpha 1}$ at the ligand-binding interface abolish RET phosphorylation. These residues, and the previously identified $\mathrm{Y} 120^{\mathrm{GDNF}}$ and $\mathrm{L} 114^{\mathrm{GDNF}}$, are non-conserved and determine the specificity between GFL-GFR $\alpha$ complexes (Study I).

The bend angle difference between GDNF and ARTN induces a large structural change in the $\mathrm{GDNF}_{2}-\mathrm{GFR} \alpha 1_{2}$ and $\mathrm{ARTN}_{2}-\mathrm{GFR} \alpha 3_{2}$ complexes. It appears to form the basis of varied signalling between different GFLs (Study I). The second crystal structure of the $\mathrm{GDNF}_{2}-\mathrm{GFR} \alpha 1_{2}$ complex has a similar bend angle to the first one, which suggests that the difference between the $\mathrm{GDNF}_{2}-\mathrm{GFR} \alpha 1_{2}$ and ARTN-GFR $\alpha 3_{2}$ complexes are not due to crystallographic artefacts (Study III).

The binding of GFR $\alpha 1$ to the heparin column suggests that GFR $\alpha 1$ has a heparin-binding site. In the $\mathrm{GDNF}_{2}-\mathrm{GFR} \alpha 1_{2}$ complex structure (Study I), D2 of GFR $\alpha 1$ binds the heparin mimic SOS. Modelling of pentasaccharide on SOS in the structure of the complex suggests how heparin binds GFR $\alpha 1$. In addition, mutagenesis data suggest that the heparin binding surface of GFR $\alpha 1$ is involved in RET binding too. These new insights into the heparin and RET binding can explain how exogenous heparin could inhibit RET phosphorylation. Furthermore, the arrangement in the crystal structure suggests that cell surface heparan sulphate chains may link $\mathrm{GDNF}_{2}-\mathrm{GFR} \alpha 1_{2}$ complexes in trans, which induces synapses (Study I).

In addition, I solved the crystal structures of two new evolutionarily conserved neurotrophic factors, MANF and CDNF, which support the survival of dopaminergic neurons (Study II). The structures provide a beginning towards the identification of their signalling mechanism. Both structures have a completely different fold from any of the previously known growth factor superfamilies. However, the N-terminal domains of MANF and CDNF are SAPLIPs. Like lipid-binding SAPLIPs, the conserved Lys and Args on the MANF and CDNF surface in the N-terminal domain may interact with 
phospholipids. The MANF structure suggests that the CXXC motif in the natively unfolded C-terminus forms a disulphide bridge. As CXXC motifs are common in protein disulphide isomerases or reductases, the C-terminus of MANF may thus be involved in oxidative protein folding, which explains its function in the ER. Thus structural studies of MANF and CDNF indicate an explanation for this bifunctional role: the N-terminal domain may be responsible for its neurotrophic activity and the C-terminal domain may function in the ER. Finally, the highly similar MANF and CDNF surfaces of the Nterminal domain indicates three positions in the sequence (10, 79 and 88), which are conserved in human and Drosophila MANF but non-conserved in human-CDNF. Here these residues are proposed to account for the functional difference between MANF and CDNF in rescue experiments in Drosophila MANF gene knockouts. 


\section{Acknowledgements}

This research work was carried out at the macromolecular X-ray crystallography group in the Institute of Biotechnology, University of Helsinki, during the years 2005-2009. Financial support was from the Academy of Finland, the Sigrid Juselius foundation and a fellowship from the Viikki Graduate School of Biosciences (VGSB).

I am deeply indebted to my supervisor Prof. Adrian Goldman, director of research, for providing me with the opportunity to work in the field of neurotrophic factors. His support and guidance was very important for the successful completion of my thesis work. His stimulating suggestions and encouragement played a significant role in my Ph.D. I have learned many things from him. I learned that discipline and hard work are the key to success. Playing table tennis with him was quite relaxing. His kind and gentle nature has always impressed me. I give him my sincere thanks, respects, and salutations. I am grateful to Prof. Mart Saarma, director of the institute, for providing world-class facilities and a cordial dynamic working atmosphere. I am also thankful to him for collaborating with us. In addition, I thank him and Prof. Arto Annila for being members of my follow-up thesis committee meeting. I am grateful to both of you for giving constructive criticism and positive directions to my Ph.D. project.

I thank Prof. Carl G. Gahmberg, head of the Division of Biochemistry, for his positive attitude towards my studies. I thank Prof. Dennis Bamford, director of VGSB, for allowing me to be a part of the graduate school and to enjoy the studies and privileges offered by the school. I am also thankful to coordinators Sandra Falck and Eeva Sievi of the graduate school for their kind patience, help and guidance. I am very thankful to my previous supervisor Prof. Veli-Pekka Lehto for allowing me to take a crystallography course from Birkbeck College, London. I can never forget his kindness. I thank Docent Tuomo Glumoff and Prof. Kari Keinänen for kindly reviewing and giving constructive comments on my thesis.

I owe my deepest thank to Veli-Matti Leppänen whose guidance and help allowed me to complete my doctoral studies in time. It was a great experience working with him. I am thankful to Jack Leo for helping me to learn biochemistry in the beginning stage of my Ph.D. I thank Jaana M. Jurvansuu for her help in the project, reading this thesis and her constructive criticism. I thank Seija Mäki and Andrzej Lyskowski for help in all my 
crystallisation experiments. I thank Veli-Pekka Jaakola, Esko Oksanen and Lari Lehtiö for their helpful discussions on crystallography. They have helped me learning practical aspects of macromolecular crystallography. Also, I thank Pirkko Heikinheimo for her kind suggestions.

I thank my co-authors (Heidi, Pia, Maxim, Päivi, Mart, Esko, Veli-Matti, Youlia, Jaana, Nisse and Johan) for collaboration. My thanks to the other people in the lab - Igor, Saurabh, Heli, Lari, Ansko, Mika, Chiara, Sanjay, Tommi, Sirpa, Maria, Katja, Juho, Wez, Arnabh, Heidi, Danielle and Elina - for making my stay in the lab a memorable one, and for all your help sometimes or the other. Also, I wish to mention here a few more names Ari Ora and Jari Meriläinen - who motivated me for research in macromolecular crystallography.

I sincerely thank all the people of the Indian community in Finland who have always helped me feel at home, and have made my stay in Helsinki a bright and colourful one. I cannot forget to thank my school, college and university friends. Their love and encouraging words have motivated me to reach here. I am thankful to Shukla family (from Norway) for their love and considering us as their family. We spent a quality time with you in Norway and Finland.

My sincere thanks and regards to my relatives and in-laws. I am deeply obliged to my parents for what I am today. Your love, praying and support have always motivated me towards a bright career. I thank my brothers and sister for their love and emotional support in difficult moments of life. I thank my wife from deepest corner of my heart. You have enlightened my life with your gorgeous smile. I thank you for being always there, and sharing and fighting with me the ups and downs of life.

Finally, my sincerest regards and gratitude go to holy Sherawali Mata and all Hindu Gods, and RadhaSoami Satsang, Dayalbagh, Agra. Prayers to Mata and RadhaSoami guru have always brought me out of tensions and troubles. The satang practice has given me a calm attitude, which has helped me not to give-up during the difficult moments of my life.

Vimal Parkash

Helsinki, $16^{\text {th }}$ Oct 2009 


\section{References}

Åkerud, P, Holm, PC, Castelo-Branco, G, Sousa, K, Rodriguez, FJ, Arenas, E (2002) Persephin-overexpressing neural stem cells regulate the function of nigral dopaminergic neurons and prevent their degeneration in a model of Parkinson's disease. Mol. Cell. Neurosci., 21: 205-222.

Alexi, T, Hefti, F (1993) Trophic actions of transforming growth factor $\alpha$ on mesencephalic dopaminergic neurons developing in culture. Neuroscience, 55: 903-918.

Ahn, VE, Faull, KF, Whitelegge, JP, Fluharty, AL, Privé, GG (2003) Crystal structure of saposin B reveals a dimeric shell for lipid binding. Proc. Natl. Acad. Sci. USA, 100: 3843.

Ahn, VE, Leyko, P, Alattia, J-R, Chen, L, Privé, GG (2006) Crystal structures of saposins A and C. Protein. Sci., 15: 1849-1857.

Airaksinen, MS, Saarma, M (2002) The GDNF family: signalling, biological functions and therapeutic value. Nat. Rev. Neurosci., 3: 383-394.

Airaksinen, MS, Titievsky, A, Saarma, M (1999) GDNF family neurotrophic factor signalling: four masters, one servant? Mol. Cell Neurosci., 13: 313-325.

Airavaara, M, Shen, H, Kuo, C-C, Peränen, J, Saarma, M, Hoffer, B, Wang, Y (2009) Mesencephalic astrocyte-derived neurotrophic factor (MANF) reduces ischemic brain injury and promotes behavioral recovery in rats. J. Comp. Neurol., 515: 116-124.

Alfano, I, Vora, P, Mummery, RS, Mulloy, B, Rider, CC (2007) The major determinant of the heparin binding of glial cell-line-derived neurotrophic factor is near the $\mathrm{N}$-terminus and is dispensable for receptor binding. Biochem. J., 404: 131-140.

Amoresano, A, Incoronato, M, Monti, G, Pucci, P, de Franciscis, V, Cerchia, L (2005) Direct interactions among RET, GDNF and GFR $\alpha 1$ molecules reveal new insights into the assembly of a functional three-protein complex. Cell. Signal., 17: 717-727.

Anders, J, Kjær, S, Ibáñez, CF (2001) Molecular modeling of the extracellular domain of the RET receptor tyrosine kinase reveals multiple cadherin-like domains and a calciumbinding site. J. Biol. Chem., 276: 35808-35817.

Anderson, DH, Sawaya, MR, Cascio, D, Ernst, W, Modlin, R, Krensky, A, Eisenberg, D (2003) Granulysin crystal structure and a structure-derived lytic mechanism. J. Mol. Biol., 325: 355-365.

Apostolou, A, Shen, Y, Liang, Y, Luo, J, Fang, S (2008) ARMET, a UPR-upregulated protein, inhibits cell proliferation and ER stress-induced cell death. Exp. Cell. Res., 314: 2454-2467.

Arenas, E, Trupp, M, Åkerud, P, Ibáñez, CF (1995) GDNF prevents degeneration and promotes the phenotype of brain noradrenergic neurons in vivo. Neuron, 15: 1465-1473.

Arighi, E, Borrello, MG, Sariola, H (2005) RET tyrosine kinase signaling in development and cancer. Cytokine Growth Factor Rev., 16: 441-467.

Baloh, RH, Tansey, MG, Lampe, PA, Fahrner, TJ, Enomoto, H, Simburger, KS, Leitner, ML, Araki, T, Johnson, EM, Jr., Milbrandt, J (1998) Artemin, a novel member of the 
GDNF ligand family, supports peripheral and central neurons and signals through the GFR $\alpha 3-R E T$ receptor complex. Neuron, 21: 1291-1302.

Baloh, RH, Tansey, MG, Golden, JP, Creedon, DJ, Heuckeroth, RO, Keck, CL, Zimonjic, DB, Popescu, NC, Johnson, EMJ, Milbrandt, J (1997) TrnR2, a novel receptor that mediates neurturin and GDNF signaling through RET. Neuron, 18: 793-802.

Baloh, RH, Tansey, MG, Johnson Jr, EM, Milbrandt, J (2000) Functional mapping of receptor specificity domains of glial cell line-derived neurotrophic factor (GDNF) family ligands and production of GFR $\alpha 1$ RET-specific agonists. J. Biol. Chem., 275: 3412-3420.

Barnett, MW, Fisher, CE, Perona-Wright, G, Davies, JA (2002) Signalling by glial cell line-derived neurotrophic factor (GDNF) requires heparan sulphate glycosaminoglycan. $J$. Cell Sci., 115: 4495-4503.

Benati, D, Baldari, CT (2008) SRC family kinases as potential therapeutic targets for malignancies and immunological disorders. Curr. Med. Chem., 15: 1154-1165.

Besset, V, Scott, RP, Ibáñez, CF (2000) Signaling complexes and protein-protein interactions involved in the activation of the Ras and phosphatidylinositol 3-kinase pathways by the c-RET receptor tyrosine kinase. J. Biol. Chem., 275: 39159-39166.

Bjorklund, A, Kirik, D, Rosenblad, C, Georgievska, B, Lundberg, C, Mandel, RJ (2000) Towards a neuroprotective gene therapy for Parkinson's disease: use of adenovirus, AAV and lentivirus vectors for gene transfer of GDNF to the nigrostriatal system in the rat Parkinson model. Brain Res., 886: 82-98.

Bjorklund, A, Rosenblad, C, Winkler, C, Kirik, D (1997) Studies on neuroprotective and regenerative effects of GDNF in a partial lesion model of Parkinson's disease. Neurobiol. Dis., 4: 186-200.

Borrello, MG, Alberti, L, Arighi, E, Bongarzone, I, Battistini, C, Bardelli, A, Pasini, B, Piutti, C, Rizzetti, MG, Mondellini, P, Radice, MT, Pierotti, MA (1996) The full oncogenic activity of RET/PTC2 depends on tyrosine 539, a docking site for phospholipase C $\gamma$. Mol. Cell. Biol., 16: 2151-2163.

Bourque, MJ, Trudeau, LE (2000) GDNF enhances the synaptic efficacy of dopaminergic neurons in culture. Eur. J. Neurosci., 12: 3172-3180.

Bruhn, H (2005) A short guided tour through functional and structural features of saposinlike proteins. Biochem. J., 389: 249-257.

Buj-Bello, A, Adu, J, Pinon, LG, Horton, A, Thompson, J, Rosenthal, A, Chinchetru, M, Buchman, VL, Davies, AM (1997) Neurturin responsiveness requires a GPI-linked receptor and the RET receptor tyrosine kinase. Nature, 387: 721-724.

Bullock, SL, Fletcher, JM, Beddington, RS, Wilson, VA (1998) Renal agenesis in mice homozygous for a gene trap mutation in the gene encoding heparan sulfate 2sulfotransferase. Genes Dev., 12: 1894-1906.

Butte, MJ (2001) Neurotrophic factor structures reveal clues to evolution, binding, specificity, and receptor activation. Cell. Mol. Life Sci., 58: 1003-1013.

Cacalano, G, Farinas, I, Wang, LC, Hagler, K, Forgie, A, Moore, M, Armanini, M, Phillips, H, Ryan, AM, Reichardt, LF, Hynes, M, Davies, A, Rosenthal, A (1998) GFR $\alpha 1$ is an essential receptor component for GDNF in the developing nervous system and kidney. Neuron, 21: 53-62. 
Calne, DB (1984) Progress in Parkinson's disease. N. Engl. J. Med., 310: 523-524.

Carlomagno, F, De Vita, G, Berlingieri, MT, de Franciscis, V, Melillo, RM, Colantuoni, V, Kraus, MH, Di Fiore, PP, Fusco, A, Santoro, M (1996) Molecular heterogeneity of RET loss of function in Hirschsprung's disease. EMBO J., 15: 2717-2725.

Carmillo, P, Dago, L, Day, ES, Worley, DS, Rossomando, A, Walus, L, Orozco, O, Buckley, C, Miller, S, Tse, A, Cate, RL, Rosenblad, C, Sah, DW, Gronborg, M, Whitty, A (2005) Glial cell line-derived neurotrophic factor (GDNF) receptor $\alpha-1$ (GFR $\alpha 1$ ) is highly selective for GDNF versus artemin. Biochemistry, 44: 2545-2554.

Cass, WA (1996) GDNF selectively protects dopamine neurons over serotonin neurons against the neurotoxic effects of methamphetamine. J. Neurosci., 16: 8132-8139.

Cheetham, GM (2004) Novel protein kinases and molecular mechanisms of autoinhibition. Curr. Opin. Struct. Biol., 14: 700-705.

Choi-Lundberg, DL, Lin, Q, Chang, YN, Chiang, YL, Hay, CM, Mohajeri, H, Davidson, BL, Bohn, MC (1997) Dopaminergic neurons protected from degeneration by GDNF gene therapy. Science, 275: 838-841.

Cik, M, Masure, S, Lesage, AS, Van Der Linden, I, Van Gompel, P, Pangalos, MN, Gordon, RD, Leysen, JE (2000) Binding of GDNF and neurturin to human GDNF family receptor $\alpha 1$ and 2. Influence of cRET and cooperative interactions. J. Biol. Chem., 275: 27505-27512.

Collaborative Computational Project, Number 4 (1994) The CCP4 suite: programs for protein crystallography. Acta Crystallogr. D Biol. Crystallogr., 50: 760-763.

Collet, J-F, D'Souza, JC, Jakob, U, Bardwell, JCA (2003) Thioredoxin 2, an oxidative stress-induced protein, contains a high affinity zinc binding site. J. Biol. Chem., 278: 45325-45332.

Costantini, F, Shakya, R (2006) GDNF/RET signaling and the development of the kidney. Bioessays, 28: 117-127.

Coulpier, M, Anders, J, Ibáñez, CF (2002) Coordinated activation of autophosphorylation sites in the RET receptor tyrosine kinase: importance of tyrosine 1062 for GDNF mediated neuronal differentiation and survival. J. Biol. Chem., 277: 1991-1999.

Creedon, DJ, Tansey, MG, Baloh, RH, Osborne, PA, Lampe, PA, Fahrner, TJ, Heuckeroth, RO, Milbrandt, J, Johnson, EMJ (1997) Neurturin shares receptors and signal transduction pathways with glial cell line-derived neurotrophic factor in sympathetic neurons. Proc. Natl. Acad. Sci. USA, 94: 7018-7023.

Davies, JA, Millar, CB, Johnson, EMJ, Milbrandt, J (1999) Neurturin: an autocrine regulator of renal collecting duct development. Dev. Genet., 24: 284-292.

Davies, JA, Yates, EA, Turnbull, JE (2003) Structural determinants of heparan sulphate modulation of GDNF signalling. Growth Factors, 21: 109-119.

Davis, S, Aldrich, TH, Ip, NY, Stahl, N, Scherer, S, Farruggella, T, DiStefano, PS, Curtis, R, Panayotatos, N, Gascan, H (1993) Released form of CNTF receptor $\alpha$ component as a soluble mediator of CNTF responses. Science, 259: 1736-1739.

DeLano, WL (2002) The PyMOL Molecular Graphics System. 
Durbec, P, Marcos-Gutierrez, CV, Kilkenny, C, Grigoriou, M, Wartiowaara, K, Suvanto, P, Smith, D, Ponder, B, Costantini, F, Saarma, M (1996) GDNF signalling through the RET receptor tyrosine kinase. Nature, 381: 789-793.

Ebert, AD, Beres, AJ, Barber, AE, Svendsen, CN (2008) Human neural progenitor cells over-expressing IGF-1 protect dopamine neurons and restore function in a rat model of Parkinson's disease. Exp. Neurol., 209: 213-223.

Eigenbrot, C, Gerber, N (1997) X-ray structure of glial cell-derived neurotrophic factor at $1.9 \AA$ A resolution and implications for receptor binding. Nat. Struct. Biol., 4: 435-438.

Eketjäll, S, Fainzilber, M, Murray-Rust, J, Ibáñez, CF (1999) Distinct structural elements in GDNF mediate binding to GFR $\alpha 1$ and activation of the GFR $\alpha 1-c-R E T$ receptor complex. EMBO J., 18: 5901-5910.

Ellgaard, L, Ruddock, LW (2005) The human protein disulphide isomerase family: substrate interactions and functional properties. EMBO Rep., 6: 28-32.

Encinas, M, Crowder, RJ, Milbrandt, J, Johnson, EMJ (2004) Tyrosine 981, a novel RET autophosphorylation site, binds c-Src to mediate neuronal survival. J. Biol. Chem., 279: $18262-18269$.

Encinas, M, Tansey, MG, Tsui-Pierchala, BA, Comella, JX, Milbrandt, J, Johnson, EMJ (2001) c-Src is required for glial cell line-derived neurotrophic factor (GDNF) family ligand-mediated neuronal survival via a phosphatidylinositol-3 kinase (PI-3K)-dependent pathway. J. Neurosci., 21: 1464-1472.

Eng, C, Mulligan, LM (1997) Mutations of the RET proto-oncogene in the multiple endocrine neoplasia type 2 syndromes, related sporadic tumours, and hirschsprung disease. Hum. Mutat., 9: 97-109.

Engele, J, Bohn, MC (1991) The neurotrophic effects of fibroblast growth factors on dopaminergic neurons in vitro are mediated by mesencephalic glia. J. Neurosci., 11: 3070-3078.

Enokido, Y, de Sauvage, F, Hongo, JA, Ninkina, N, Rosenthal, A, Buchman, VL, Davies, AM (1998) GFR $\alpha 4$ and the tyrosine kinase RET form a functional receptor complex for persephin. Curr. Biol., 8: 1019-1022.

Enomoto, H, Araki, T, Jackman, A, Heuckeroth, RO, Snider, WD, Johnson, EMJ, Milbrandt, J (1998) GFR $\alpha$-deficient mice have deficits in the enteric nervous system and kidneys. Neuron, 21: 317-324.

Enomoto, H, Crawford, PA, Gorodinsky, A, Heuckeroth, RO, Johnson, EMJ, Milbrandt, J (2001) RET signaling is essential for migration, axonal growth and axon guidance of developing sympathetic neurons. Development, 128: 3963-3974.

Fallon, J, Reid, S, Kinyamu, R, Opole, I, Opole, R, Baratta, J, Korc, M, Endo, TL, Duong, A, Nguyen, G, Karkehabadhi, M, Twardzik, D, Patel, S, Loughlin, S (2000) In vivo induction of massive proliferation, directed migration, and differentiation of neural cells in the adult mammalian brain. Proc. Natl. Acad. Sci. USA, 97: 14686-14691.

Fontan, A, Rojo, A, Sanchez Pernaute, R, Hernandez, I, Lopez, I, Castilla, C, Sanchez Albisua, J, Perez Higueras, A, Al-Rashid, I, Rabano, A, Gonzalo, I, Angeles Mena, M, Cools, A, Eshuis, S, Maguire, P, Pruim, J, Leenders, K, Garcia de Yebenes, J (2002) Effects of fibroblast growth factor and glial-derived neurotrophic factor on akinesia, F- 
DOPA uptake and dopamine cells in parkinsonian primates. Parkinsonism Relat Disord, 8: $311-323$.

Fujita, N, Suzuki, K, Vanier, MT, Popko, B, Maeda, N, Klein, A, Henseler, M, Sandhoff, K, Nakayasu, H, Suzuki, K (1996) Targeted disruption of the mouse sphingolipid activator protein gene: a complex phenotype, including severe leukodystrophy and wide-spread storage of multiple sphingolipids. Hum. Mol. Genet., 5: 711-725.

Garces, A, Haase, G, Airaksinen, MS, Livet, J, Filippi, P, deLapeyriere, O (2000) GFR $\alpha 1$ is required for development of distinct subpopulations of motoneuron. J. Neurosci., 20: 4992-5000.

Gash, DM, Gerhardt, GA, Hoffer, BJ (1998) Effects of glial cell line-derived neurotrophic factor on the nigrostriatal dopamine system in rodents and nonhuman primates. Adv. Pharmacol., 42: 911-915.

Gash, DM, Zhang, Z, Ovadia, A, Cass, WA, Yi, A, Simmerman, L, Russell, D, Martin, D, Lapchak, PA, Collins, F, Hoffer, BJ, Gerhardt, GA (1996) Functional recovery in parkinsonian monkeys treated with GDNF. Nature, 380: 252-255.

Genc, S, Kuralay, F, Genc, K, Akhisaroglu, M, Fadiloglu, S, Yorukoglu, K, Fadiloglu, M, Gure, A (2001) Erythropoietin exerts neuroprotection in 1-methyl-4-phenyl-1,2,3,6tetrahydropyridine-treated C57/BL mice via increasing nitric oxide production. Neurosci. Lett., 298: 139-141.

Geneste, O, Bidaud, C, De Vita, G, Hofstra, RM, Tartare-Deckert, S, Buys, CH, Lenoir, GM, Santoro, M, Billaud, M (1999) Two distinct mutations of the RET receptor causing Hirschsprung's disease impair the binding of signalling effectors to a multifunctional docking site. Hum. Mol. Genet., 8: 1989-1999.

Gianino, S, Grider, JR, Cresswell, J, Enomoto, H, Heuckeroth, RO (2003) GDNF availability determines enteric neuron number by controlling precursor proliferation. Development, 130: 2187-2198.

Gill, SS, Patel, NK, Hotton, GR, O'Sullivan, K, McCarter, R, Bunnage, M, Brooks, DJ, Svendsen, CN, Heywood, P (2003) Direct brain infusion of glial cell line-derived neurotrophic factor in Parkinson's disease. Nat. Med., 9: 589-595.

Golden, JP, Milbrandt, J, Johnson, EMJ (2003) Neurturin and persephin promote the survival of embryonic basal forebrain cholinergic neurons in vitro. Exp. Neurol., 184: 447-455.

Granholm, AC, Reyland, M, Albeck, D, Sanders, L, Gerhardt, G, Hoernig, G, Shen, L, Westphal, H, Hoffer, B (2000) Glial cell line-derived neurotrophic factor is essential for postnatal survival of midbrain dopamine neurons. J. Neurosci., 20: 3182-3190.

Hamilton, JF, Morrison, PF, Chen, MY, Harvey-White, J, Pernaute, RS, Phillips, H, Oldfield, E, Bankiewicz, KS (2001) Heparin coinfusion during convection-enhanced delivery (CED) increases the distribution of the glial-derived neurotrophic factor (GDNF) ligand family in rat striatum and enhances the pharmacological activity of neurturin. Exp. Neurol., 168: 155-161.

Hansen, SM, Berezin, V, Bock, E (2008) Signaling mechanisms of neurite outgrowth induced by the cell adhesion molecules NCAM and N-cadherin. Cell. Mol. Life Sci., 65: 3809-3821. 
Harvey, BK, Hoffer, BJ, Wang, Y (2005) Stroke and TGF- $\beta$ proteins: glial cell linederived neurotrophic factor and bone morphogenetic protein. Pharmacol. Ther., 105: 113125.

Hawkins, CA, de Alba, E, Tjandra, N (2005) Solution structure of human saposin C in a detergent environment. J. Mol. Biol., 346: 1381-1392.

Hayashi, H, Ichihara, M, Iwashita, T, Murakami, H, Shimono, Y, Kawai, K, Kurokawa, K, Murakumo, Y, Imai, T, Funahashi, H, Nakao, A, Takahashi, M (2000) Characterization of intracellular signals via tyrosine 1062 in RET activated by glial cell line-derived neurotrophic factor. Oncogene, 19: 4469-4475.

Hecht, O, Van Nuland, NA, Schleinkofer, K, Dingley, AJ, Bruhn, H, Leippe, M, Grotzinger, J (2004) Solution structure of the pore-forming protein of Entamoeba histolytica. J. Biol. Chem., 279: 17834-17841.

Heikkila, RE, Hess, A, Duvoisin, RC (1984) Dopaminergic neurotoxicity of 1-methyl-4phenyl-1,2,5,6-tetrahydropyridine in mice. Science, 224: 1451-1453.

Heinrich, PC, Behrmann, I, Haan, S, Hermanns, HM, Müller-Newen, G, Schaper, F (2003) Principles of interleukin (IL)-6-type cytokine signalling and its regulation. Biochem. J., 374: 1-20.

Helms, JB, Zurzolo, C (2004) Lipids as targeting signals: lipid rafts and intracellular trafficking. Traffic., 5: 247-254.

Henderson, CE, Phillips, HS, Pollock, RA, Davies, AM, Lemeulle, C, Armanini, M, Simmons, L, Moffet, B, Vandlen, RA, Simmons, L (1994) GDNF: a potent survival factor for motoneurons present in peripheral nerve and muscle. Science, 266: 1062-1064.

Heuckeroth, RO, Lampe, PA, Johnson, EM, Milbrandt, J (1998) Neurturin and GDNF promote proliferation and survival of enteric neuron and glial progenitors in vitro. Dev. Biol., 200: 116-129.

Hileman, RE, Fromm, JR, Weiler, JM, Linhardt, RJ (1998) Glycosaminoglycan-protein interactions: definition of consensus sites in glycosaminoglycan binding proteins. Bioessays, 20: 156-167.

Hofmann, MC (2008) GDNF signaling pathways within the mammalian spermatogonial stem cell niche. Mol. Cell. Endocrinol., 288: 95-103.

Hofstra, RM, Wu, Y, Stulp, RP, Elfferich, P, Osinga, J, Maas, SM, Siderius, L, Brooks, AS, vd Ende, JJ, Heydendael, VM, Severijnen, RS, Bax, KM, Meijers, C, Buys, CH (2000) RET and GDNF gene scanning in Hirschsprung patients using two dual denaturing gel systems. Hum. Mutat., 15: 418-429.

Holland, DR, Cousens, LS, Meng, W, Matthews, BW (1994) Nerve growth factor in different crystal forms displays structural flexibility and reveals zinc binding sites. J. Mol. Biol., 239: 385-400.

Honma, Y, Araki, T, Gianino, S, Bruce, A, Heuckeroth, R, Johnson, E, Milbrandt, J (2002) Artemin is a vascular-derived neurotropic factor for developing sympathetic neurons. Neuron, 35: 267-282.

Horger, BA, Nishimura, MC, Armanini, MP, Wang, LC, Poulsen, KT, Rosenblad, C, Kirik, D, Moffat, B, Simmons, L, Johnson, EJ, Milbrandt, J, Rosenthal, A, Bjorklund, A, 
Vandlen, RA, Hynes, MA, Phillips, HS (1998) Neurturin exerts potent actions on survival and function of midbrain dopaminergic neurons. J. Neurosci., 18: 4929-4937.

Horibe, T, Gomi, M, Iguchi, D, Ito, H, Kitamura, Y, Masuoka, T, Tsujimoto, I, Kimura, T, Kikuchi, M (2004) Different contributions of the three CXXC motifs of human proteindisulphide isomerase-related protein to isomerase activity and oxidative refolding. J. Biol. Chem., 279: 4604-4611.

Huang, EJ, Reichardt, LF (2001) Neurotrophins: roles in neuronal development and function. Annu. Rev. Neurosci., 24: 677-736.

Hubbard, SR, Wei, L, Ellis, L, Hendrickson, WA (1994) Crystal structure of the tyrosine kinase domain of the human insulin receptor. Nature, 372: 746-754.

Hyman, C, Hofer, M, Barde, YA, Juhasz, M, Yancopoulos, GD, Squinto, SP, Lindsay, RM (1991) BDNF is a neurotrophic factor for dopaminergic neurons of the substantia nigra. Nature, 350: 230-232.

Ichihara, M, Murakumo, Y, Takahashi, M (2004) RET and neuroendocrine tumors. Cancer Lett., 204: 197-211.

Iwashita, T, Murakami, H, Asai, N, Takahashi, M (1996) Mechanism of RET dysfunction by Hirschsprung mutations affecting its extracellular domain. Hum. Mol. Genet., 5: 15771580 .

Jaaro, H, Beck, G, Conticello, SG, Fainzilber, M (2001) Evolving better brains: a need for neurotrophins? Trends Neurosci., 24: 79-85.

Jain, S, Encinas, M, Johnson, EMJ, Milbrandt, J (2006) Critical and distinct roles for key RET tyrosine docking sites in renal development. Genes Dev., 20: 321-333.

Jijiwa, M, Fukuda, T, Kawai, K, Nakamura, A, Kurokawa, K, Murakumo, Y, Ichihara, M, Takahashi, M (2004) A targeting mutation of tyrosine 1062 in RET causes a marked decrease of enteric neurons and renal hypoplasia. Mol. Cell. Biol., 24: 8026-8036.

Jing, S, Wen, D, Yu, Y, Holst, PL, Luo, Y, Fang, M, Tamir, R, Antonio, L, Hu, Z, Cupples, R, Louis, J-C, Hu, S, Altrock, BW, Fox, GM (1996) GDNF-induced activation of the RET protein tyrosine kinase is mediated by GDNFR- $\alpha$, a novel receptor for GDNF. Cell, 85: 1113-1124.

Jing, S, Yu, Y, Fang, M, Hu, Z, Holst, PL, Boone, T, Delaney, J, Schultz, H, Zhou, R, Fox, GM (1997) GFR $\boldsymbol{\alpha}-2$ and GFR $\boldsymbol{\alpha}-3$ are two new receptors for ligands of the GDNF family. J. Biol. Chem., 272: 33111-33117.

Johansson, J, Curstedt, T, Jornvall, H (1991) Surfactant protein B: disulfide bridges, structural properties, and kringle similarities. Biochemistry, 30: 6917-6921.

Jordan, J, Bottner, M, Schluesener, HJ, Unsicker, K, Krieglstein, K (1997) Bone morphogenetic proteins: neurotrophic roles for midbrain dopaminergic neurons and implications of astroglial cells. Eur. J. Neurosci., 9: 1699-1709.

Kawamoto, Y, Takeda, K, Okuno, Y, Yamakawa, Y, Ito, Y, Taguchi, R, Kato, M, Suzuki, H, Takahashi, M, Nakashima, I (2004) Identification of RET autophosphorylation sites by mass spectrometry. J. Biol. Chem., 279: 14213-14224. 
Kervinen, J, Tobin, GJ, Costa, J, Waugh, DS, Wlodawer, A, Zdanov, A (1999) Crystal structure of plant aspartic proteinase prophytepsin: inactivation and vacuolar targeting. EMBO J., 18: 3947-3955.

Kishimoto, Y, Hiraiwa, M, O'Brien, JS (1992) Saposins: structure, function, distribution, and molecular genetics. J. Lipid Res., 33: 1255-1267.

Kjær, S, Ibáñez, CF (2003a) Identification of a surface for binding to the GDNF-GFR $\alpha 1$ complex in the first cadherin-like domain of RET. J. Biol. Chem., 278: 47898-47904.

Kjær, S, Ibáñez, CF (2003b) Intrinsic susceptibility to misfolding of a hot-spot for Hirschsprung disease mutations in the ectodomain of RET. Hum. Mol. Genet., 12: 21332144.

Klein, RD, Sherman, D, Ho, WH, Stone, D, Bennett, GL, Moffat, B, Vandlen, R, Simmons, L, Gu, Q, Hongo, JA, Devaux, B, Poulsen, K, Armanini, M, Nozaki, C, Asai, N, Goddard, A, Phillips, H, Henderson, CE, Takahashi, M, Rosenthal, A (1997) A GPIlinked protein that interacts with RET to form a candidate neurturin receptor. Nature, 387: 717-721.

Knowles, PP, Murray-Rust, J, Kjær, S, Scott, RP, Hanrahan, S, Santoro, M, Ibáñez, CF, McDonald, NQ (2006) Structure and chemical inhibition of the RET tyrosine kinase domain. J. Biol. Chem., 281: 33577-33587.

Knusel, B, Michel, PP, Schwaber, JS, Hefti, F (1990) Selective and nonselective stimulation of central cholinergic and dopaminergic development in vitro by nerve growth factor, basic fibroblast growth factor, epidermal growth factor, insulin and the insulin-like growth factors I and II. J. Neurosci., 10: 558-570.

Kodama, Y, Asai, N, Kawai, K, Jijiwa, M, Murakumo, Y, Ichihara, M, Takahashi, M (2005) The RET proto-oncogene: a molecular therapeutic target in thyroid cancer. Cancer Sci., 96: 143-148.

Kokaia, Z, Airaksinen, MS, Nanobashvili, A, Larsson, E, Kujamaki, E, Lindvall, O, Saarma, M (1999) GDNF family ligands and receptors are differentially regulated after brain insults in the rat. Eur. J. Neurosci., 11: 1202-1216.

Kordower, JH, Emborg, ME, Bloch, J, Ma, SY, Chu, Y, Leventhal, L, McBride, J, Chen, EY, Palfi, S, Roitberg, BZ, Brown, WD, Holden, JE, Pyzalski, R, Taylor, MD, Carvey, P, Ling, Z, Trono, D, Hantraye, P, Deglon, N, Aebischer, P (2000) Neurodegeneration prevented by lentiviral vector delivery of GDNF in primate models of Parkinson's disease. Science, 290: 767-773.

Kotani, Y, Matsuda, S, Wen, TC, Sakanaka, M, Tanaka, J, Maeda, N, Kondoh, K, Ueno, S, Sano, A (1996) A hydrophilic peptide comprising 18 amino acid residues of the prosaposin sequence has neurotrophic activity in vitro and in vivo. J. Neurochem., 66: 2197-2200.

Kotzbauer, PT, Lampe, PA, Heuckeroth, RO, Golden, JP, Creedon, DJ, Johnson Jr, EM, Milbrandt, J (1996) Neurturin, a relative of glial-cell-line-derived neurotrophic factor. Nature, 384: 467-470.

Kramer, ER, Aron, L, Ramakers, GM, Seitz, S, Zhuang, X, Beyer, K, Smidt, MP, Klein, R (2007) Absence of RET signaling in mice causes progressive and late degeneration of the nigrostriatal system. PLoS Biol., 5: e39. 
Krieglstein, K, Unsicker, K (1994) Transforming growth factor- $\beta$ promotes survival of midbrain dopaminergic neurons and protects them against $\mathrm{N}$-methyl-4-phenylpyridinium ion toxicity. Neuroscience, 63: 1189-1196.

Kubota, H, Avarbock, MR, Brinster, RL (2004) Growth factors essential for self-renewal and expansion of mouse spermatogonial stem cells. Proc. Natl. Acad. Sci. USA, 101: 16489-16494.

Lang, AE, Gill, S, Patel, NK, Lozano, A, Nutt, JG, Penn, R, Brooks, DJ, Hotton, G, Moro, E, Heywood, P, Brodsky, MA, Burchiel, K, Kelly, P, Dalvi, A, Scott, B, Stacy, M, Turner, D, Wooten, VG, Elias, WJ, Laws, ER, Dhawan, V, Stoessl, AJ, Matcham, J, Coffey, RJ, Traub, M (2006) Randomized controlled trial of intraputamenal glial cell line-derived neurotrophic factor infusion in Parkinson disease. Ann. Neurol., 59: 459-466.

Lantieri, F, Griseri, P, Ceccherini, I (2006) Molecular mechanisms of RET-induced Hirschsprung pathogenesis. Ann. Med., 38: 11-19.

Lawlor, PA, During, MJ (2004) Gene therapy for Parkinson's disease. Expert. Rev. Mol. Med., 6: 1-18.

Ledda, F, Paratcha, G, Sandoval-Guzmán, T, Ibáñez, CF (2007) GDNF and GFRa1 promote formation of neuronal synapses by ligand-induced cell adhesion. Nat. Neurosci., 10: $293-300$.

Lee, AH, Iwakoshi, NN, Glimcher, LH (2003) XBP-1 regulates a subset of endoplasmic reticulum resident chaperone genes in the unfolded protein response. Mol. Cell. Biol., 23: 7448-7459.

Lee, JH, Yang, ST, Rho, SH, Im, YJ, Kim, SY, Kim, YR, Kim, MK, Kang, GB, Kim, JI, Rhee, JH, Eom, SH (2006a) Crystal structure and functional studies reveal that PAS factor from Vibrio vulnificus is a novel member of the saposin-fold family. J. Mol. Biol., 355: 491-500.

Lee, RHK, Wong, WL, Chan, CH, Chan, SY (2006b) Differential effects of glial cell linederived neurotrophic factor and neurturin in RET/GFRa1-expressing cells. J. Neurosci. Res., 83: 80-90.

Leppänen, V-M, Bespalov, MM, Runeberg-Roos, P, Puurand, Ü, Merits, A, Saarma, M, Goldman, A (2004) The structure of GFR $\alpha 1$ domain 3 reveals new insights into GDNF binding and RET activation. EMBO J., 23: 1452-1462.

Levi-montalcini, R, Hamburger, V (1951) Selective growth stimulating effects of mouse sarcoma on the sensory and sympathetic nervous system of the chick embryo. J. Exp. Zool., 116: 321-361.

Liepinsh, E, Andersson, M, Ruysschaert, J-M, Otting, G (1997) Saposin fold revealed by the NMR structure of NK-lysin. Nat. Struct. Biol., 4: 793-795.

Lin, L-F, Doherty, DH, Lile, JD, Bektesh, S, Collins, F (1993) GDNF: a glial cell linederived neurotrophic factor for midbrain dopaminergic neurons. Science, 260: 1130-1132.

Lindahl, M, Poteryaev, D, Yu, L, Arumäe, U, Timmusk, T, Bongarzone, I, Aiello, A, Pierotti, MA, Airaksinen, MS, Saarma, M (2001) Human glial cell line-derived neurotrophic factor receptor $\alpha 4$ is the receptor for persephin and is predominantly expressed in normal and malignant thyroid medullary cells. J. Biol. Chem., 276: $9344-$ 9351. 
Lindahl, U (1994) [The great Scandinavian Jahre Prize 1993. What is the function of heparan sulfate?]. Nord. Med., 109: 4-8.

Lindholm, P, Peränen, J, Andressoo, JO, Kalkkinen, N, Kokaia, Z, Lindvall, O, Timmusk, T, Saarma, M (2008) MANF is widely expressed in mammalian tissues and differently regulated after ischemic and epileptic insults in rodent brain. Mol. Cell. Neurosci., 39: 356-371.

Lindholm, P, Voutilainen, MH, Laurén, J, Peränen, J, Leppänen, V-M, Andressoo, J-O, Lindahl, M, Janhunen, S, Kalkkinen, N, Timmusk, T, Tuominen, RK, Saarma, M (2007) Novel neurotrophic factor CDNF protects and rescues midbrain dopamine neurons in vivo. Nature, 448: 73-77.

Liu, J, Wang, CY, O'Brien, JS (2001) Prosaptide D5, a retro-inverso 11-mer peptidomimetic, rescued dopaminergic neurons in a model of Parkinson's disease. FASEB J., 15: 1080-1082.

Liu, A, Wenzel, N, Qi, X (2005) Role of lysine residues in membrane anchoring of saposin C. Arch. Biochem. Biophys., 443: 101-112.

Lücking, CB, Lichtner, P, Kramer, ER, Gieger, C, Illig, T, Dichgans, M, Berg, D, Gasser, $T$ (2008) Polymorphisms in the receptor for GDNF (RET) are not associated with Parkinson's disease in Southern Germany. Neurobiol. Aging,

Mangina, CA, Sokolov, EN (2006) Neuronal plasticity in memory and learning abilities: theoretical position and selective review. Int. J. Psychophysiol., 60: 203-214.

Marciniak, SJ, Ron, D (2006) Endoplasmic reticulum stress signaling in disease. Physiol. Rev., 86: 1133-1149.

Mason, I (2000) The RET receptor tyrosine kinase: activation, signalling and significance in neural development and disease. Pharm. Acta Helv., 74: 261-264.

Massague, J, Weis-Garcia, F (1996) Serine/threonine kinase receptors: mediators of transforming growth factor $\beta$ family signals. Cancer Surv., 27: 41-64.

McDonald, NQ, Lapatto, R, Murray-Rust, J, Gunning, J, Wlodawer, A, Blundell, TL (1991) New protein fold revealed by a $2.3 \AA$ resolution crystal structure of nerve growth factor. Nature, 354: 411-414.

Meng, X, de Rooij, DG, Westerdahl, K, Saarma, M, Sariola, H (2001) Promotion of seminomatous tumors by targeted overexpression of glial cell line-derived neurotrophic factor in mouse testis. Cancer Res., 61: 3267-3271.

Meng, X, Lindahl, M, Hyvonen, ME, Parvinen, M, de Rooij, DG, Hess, MW, Raatikainen-Ahokas, A, Sainio, K, Rauvala, H, Lakso, M, Pichel, JG, Westphal, H, Saarma, M, Sariola, H (2000) Regulation of cell fate decision of undifferentiated spermatogonia by GDNF. Science, 287: 1489-1493.

Milbrandt, J, de Sauvage, FJ, Fahrner, TJ, Baloh, RH, Leitner, ML, Tansey, MG, Lampe, PA, Heuckeroth, RO, Kotzbauer, PT, Simburger, KS, Golden, JP, Davies, JA, Vejsada, R, Kato, AC, Hynes, M, Sherman, D, Nishimura, M, Wang, L-C, Vandlen, R, Moffat, B, Klein, RD, Poulsen, K, Gray, C, Garces, A, Henderson, CE, Phillips, HS, Johnson Jr, EM (1998) Persephin, a novel neurotrophic factor related to GDNF and neurturin. Neuron, 20: 245-253. 
Miteva, M, Andersson, M, Karshikoff, A, Otting, G (1999) Molecular electroporation: a unifying concept for the description of membrane pore formation by antibacterial peptides, exemplified with NK-lysin. FEBS Lett., 462: 155-158.

Mizobuchi, N, Hoseki, J, Kubota, H, Toyokuni, S, Nozaki, J-I, Naitoh, M, Koizumi, A, Nagata, K (2007) ARMET is a soluble ER protein induced by the unfolded protein response via ERSE-II element. Cell Struct. Funct., 32: 41-50.

Mohapel, P, Frielingsdorf, H, Haggblad, J, Zachrisson, O, Brundin, P (2005) Plateletderived growth factor (PDGF-BB) and brain-derived neurotrophic factor (BDNF) induce striatal neurogenesis in adult rats with 6-hydroxydopamine lesions. Neuroscience, 132: 767-776.

Moore, MW, Klein, RD, Farinas, I, Sauer, H, Armanini, M, Phillips, H, Reichardt, LF, Ryan, AM, Carver-Moore, K, Rosenthal, A (1996) Renal and neuronal abnormalities in mice lacking GDNF. Nature, 382: 76-79.

Mulligan, LM, Marsh, DJ, Robinson, BG, Schuffenecker, I, Zedenius, J, Lips, CJ, Gagel, RF, Takai, SI, Noll, WW, Fink, M (1995) Genotype-phenotype correlation in multiple endocrine neoplasia type 2: report of the International RET Mutation Consortium. $J$. Intern. Med., 238: 343-346.

Murzin, AG, Brenner, SE, Hubbard, T, Chothia, C (1995) SCOP: a structural classification of proteins database for the investigation of sequences and structures. J. Mol. Biol., 247: 536-540.

Narindrasorasak, S, Yao, P, Sarkar, B (2003) Protein disulfide isomerase, a multifunctional protein chaperone, shows copper-binding activity. Biochem. Biophys. Res. Commun., 311: 405-414.

Natarajan, D, Marcos-Gutierrez, C, Pachnis, V, de Graaff, E (2002) Requirement of signalling by receptor tyrosine kinase RET for the directed migration of enteric nervous system progenitor cells during mammalian embryogenesis. Development, 129: 51515160 .

Nikiforov, YE (2002) RET/PTC rearrangement in thyroid tumors. Endocr. Pathol., 13: 316.

Nikkhah, G, Odin, P, Smits, A, Tingstrom, A, Othberg, A, Brundin, P, Funa, K, Lindvall, O (1993) Platelet-derived growth factor promotes survival of rat and human mesencephalic dopaminergic neurons in culture. Exp. Brain Res., 92: 516-523.

Nozaki, C, Asai, N, Murakami, H, Iwashita, T, Iwata, Y, Horibe, K, Klein, RD, Rosenthal, A, Takahashi, M (1998) Calcium-dependent RET activation by GDNF and neurturin. Oncogene, 16: 293-299.

Nutt, JG, Burchiel, KJ, Comella, CL, Jankovic, J, Lang, AE, Laws, ERJ, Lozano, AM, Penn, RD, Simpson, RKJ, Stacy, M, Wooten, GF (2003) Randomized, double-blind trial of glial cell line-derived neurotrophic factor (GDNF) in PD. Neurology, 60: 69-73.

Oatley, JM, Avarbock, MR, Brinster, RL (2007) Glial cell line-derived neurotrophic factor regulation of genes essential for self-renewal of mouse spermatogonial stem cells is dependent on Src family kinase signaling. J. Biol. Chem., 282: 25842-25851.

O'Brien, JS, Carson, GS, Seo, HC, Hiraiwa, M, Kishimoto, Y (1994) Identification of prosaposin as a neurotrophic factor. Proc. Natl. Acad. Sci. USA, 91: 9593-9596. 
Palgi, M, Lindstrom, R, Peränen, J, Piepponen, TP, Saarma, M, Heino, TI (2009) Evidence that DmMANF is an invertebrate neurotrophic factor supporting dopaminergic neurons. Proc. Natl. Acad. Sci. USA, 106: 2429-2434.

Pandey, A, Duan, H, Di Fiore, PP, Dixit, VM (1995) The RET receptor protein tyrosine kinase associates with the SH2-containing adapter protein Grb10. J. Biol. Chem., 270: 21461-21463.

Paratcha, G, Ibáñez, CF (2002) Lipid rafts and the control of neurotrophic factor signaling in the nervous system: variations on a theme. Curr. Opin. Neurobiol., 12: 542-549.

Paratcha, G, Ledda, F, Baars, L, Coulpier, M, Besset, V, Anders, J, Scott, R, Ibáñez, CF (2001) Released GFR $\alpha 1$ potentiates downstream signaling, neuronal survival, and differentiation via a novel mechanism of recruitment of c-RET to lipid rafts. Neuron, 29: $171-184$

Paratcha, G, Ledda, F, Ibáñez, CF (2003) The neural cell adhesion molecule NCAM is an alternative signaling receptor for GDNF family ligands. Cell, 113: 867-879.

Peränen, J, Rikkonen, M, Hyvönen, M, Kääriäinen, L (1996) T7 vectors with modified T7lac promoter for expression of proteins in Escherichia coli. Anal. Biochem, 236: 371373.

Peterson, AL, Nutt, JG (2008) Treatment of Parkinson's disease with trophic factors. Neurotherapeutics, 5: 270-280.

Petrova, PS, Raibekas, A, Pevsner, J, Vigo, N, Anafi, M, Moore, MK, Peaire, AE, Shridhar, V, Smith, DI, Kelly, J, Durocher, Y, Commissiong, JW (2003) MANF: a new mesencephalic, astrocyte-derived neurotrophic factor with selectivity for dopaminergic neurons. J. Mol. Neurosci., 20: 173-188.

Pichel, JG, Shen, L, Sheng, HZ, Granholm, AC, Drago, J, Grinberg, A, Lee, EJ, Huang, SP, Saarma, M, Hoffer, BJ, Sariola, H, Westphal, H (1996) Defects in enteric innervation and kidney development in mice lacking GDNF. Nature, 382: 73-76.

Plaza-Menacho, I, Burzynski, GM, de Groot, JW, Eggen, BJ, Hofstra, RM (2006) Current concepts in RET-related genetics, signaling and therapeutics. Trends Genet., 22: 627-636.

Poteryaev, D, Titievsky, A, Sun, YF, Thomas-Crusells, J, Lindahl, M, Billaud, M, Arumae, U, Saarma, M (1999) GDNF triggers a novel RET-independent Src kinase family-coupled signaling via a GPI-linked GDNF receptor $\alpha 1$. FEBS Lett., 463: 63-66.

Popsueva, A, Poteryaev, D, Arighi, E, Meng, X, Angers-Loustau, A, Kaplan, D, Saarma, M, Sariola, H (2003) GDNF promotes tubulogenesis of GFR $\alpha 1$-expressing MDCK cells by Src-mediated phosphorylation of MET receptor tyrosine kinase. J. Cell. Biol., 161: $119-129$.

Puskovic, V, Wolfe, D, Wechuck, J, Krisky, D, Collins, J, Glorioso, JC, Fink, DJ, Mata, M (2006) HSV-mediated delivery of erythropoietin restores dopaminergic function in MPTP-treated mice. Mol. Ther., 14: 710-715.

Pützer, BM, Drosten, M (2004) The RET proto-oncogene: a potential target for molecular cancer therapy. Trends Mol Med, 10: 351-357.

Quesada, A, Micevych, PE (2004) Estrogen interacts with the IGF-1 system to protect nigrostriatal dopamine and maintain motoric behavior after 6-hydroxdopamine lesions. $J$. Neurosci. Res., 75: 107-116. 
Rapraeger, AC, Krufka, A, Olwin, BB (1991) Requirement of heparan sulfate for bFGFmediated fibroblast growth and myoblast differentiation. Science, 252: 1705-1708.

Reichardt, LF (2006) Neurotrophin-regulated signalling pathways. Philos. Trans. R. Soc. Lond. B. Biol. Sci., 361: 1545-1564.

Rickard, SM, Mummery, RS, Mulloy, B, Rider, CC (2003) The binding of human glial cell line-derived neurotrophic factor to heparin and heparan sulfate: importance of 2-Osulfate groups and effect on its interaction with its receptor, GFR $\alpha 1$. Glycobiology, 13: 419-426.

Rosenblad, C, Gronborg, M, Hansen, C, Blom, N, Meyer, M, Johansen, J, Dago, L, Kirik, D, Patel, UA, Lundberg, C, Trono, D, Bjorklund, A, Johansen, TE (2000) In vivo protection of nigral dopamine neurons by lentiviral gene transfer of the novel GDNFfamily member neublastin/artemin. Mol. Cell. Neurosci., 15: 199-214.

Rosenblad, C, Kirik, D, Bjorklund, A (1999) Neurturin enhances the survival of intrastriatal fetal dopaminergic transplants. Neuroreport, 10: 1783-1787.

Rossi, J, Luukko, K, Poteryaev, D, Laurikainen, A, Sun, YF, Laakso, T, Eerikainen, S, Tuominen, R, Lakso, M, Rauvala, H, Arumae, U, Pasternack, M, Saarma, M, Airaksinen, MS (1999) Retarded growth and deficits in the enteric and parasympathetic nervous system in mice lacking GFR $\alpha 2$, a functional neurturin receptor. Neuron, 22: 243-252.

Rossmann, M, Schultz-Heienbrok, R, Behlke, J, Remmel, N, Alings, C, Sandhoff, K, Saenger, W, Maier, T (2008) Crystal structures of human saposins C and D: implications for lipid recognition and membrane interactions. Structure, 16: 809-817.

Salvatore, D, Barone, MV, Salvatore, G, Melillo, RM, Chiappetta, G, Mineo, A, Fenzi, G, Vecchio, G, Fusco, A, Santoro, M (2000) Tyrosines 1015 and 1062 are in vivo autophosphorylation sites in RET and RET-derived oncoproteins. J. Clin. Endocrinol. Metab., 85: 3898-3907.

Sánchez-Barrena, MJ, Martínez-Ripoll, M, Gálvez, A, Valdivia, E, Maqueda, M, Cruz, V, Albert, A (2003) Structure of bacteriocin AS-48: from soluble state to membrane bound state. J. Mol. Biol., 334: 541-549.

Sánchez, MP, Silos-Santiago, I, Frisén, J, He, B, Lira, SA, Barbacid, M (1996) Renal agenesis and the absence of enteric neurons in mice lacking GDNF. Nature, 382: 70-73.

Sanicola, M, Hession, C, Worley, D, Carmillo, P, Ehrenfels, C, Walus, L, Robinson, S, Jaworski, G, Wei, H, Tizard, R, Whitty, A, Pepinsky, RB, Cate, RL (1997) Glial cell linederived neurotrophic factor-dependent RET activation can be mediated by two different cell-surface accessory proteins. Proc. Natl. Acad. Sci. USA, 94: 6238-6243.

Santoro, M, Carlomagno, F, Romano, A, Bottaro, DP, Dathan, NA, Grieco, M, Fusco, A, Vecchio, G, Matoskova, B, Kraus, MH, et, a (1995) Activation of RET as a dominant transforming gene by germline mutations of MEN2A and MEN2B. Science, 267: 381383.

Sariola, H, Saarma, M (2003) Novel functions and signalling pathways for GDNF. J. Cell Sci., 116: 3855-3862.

Schinder, AF, Poo, M (2000) The neurotrophin hypothesis for synaptic plasticity. Trends Neurosci., 23: 639-645. 
Schlee, S, Carmillo, P, Whitty, A (2006) Quantitative analysis of the activation mechanism of the multicomponent growth-factor receptor RET. Nat. Chem. Biol., 2: 636644.

Schlessinger, J (2003) Signal transduction. Autoinhibition control. Science, 300: 750-752.

Schneider, TR, Sheldrick, GM (2002) Substructure solution with SHELXD. Acta Crystallogr. D Biol. Crystallogr., 58: 1772-1779.

Schober, A (2004) Classic toxin-induced animal models of Parkinson's disease: 6-OHDA and MPTP. Cell. Tissue Res., 318: 215-224.

Schober, A, Peterziel, H, von Bartheld, CS, Simon, H, Krieglstein, K, Unsicker, K (2007) GDNF applied to the MPTP-lesioned nigrostriatal system requires TGF- $\beta$ for its neuroprotective action. Neurobiol. Dis., 25: 378-391.

Schuchardt, A, D'Agati, V, Larsson-Blomberg, L, Costantini, F, Pachnis, V (1994) Defects in the kidney and enteric nervous system of mice lacking the tyrosine kinase receptor RET. Nature, 367: 380-383.

Scott, RP, Ibáñez, CF (2001) Determinants of ligand binding specificity in the glial cell line-derived neurotrophic factor family receptor $\alpha$. J. Biol. Chem., 276: 1450-1458.

Shridhar, V, Rivard, S, Shridhar, R, Mullins, C, Bostick, L, Sakr, W, Grignon, D, Miller, OJ, Smith, DI (1996) A gene from human chromosomal band 3p21.1 encodes a highly conserved arginine-rich protein and is mutated in renal cell carcinomas. Oncogene, 12: 1931-1939.

Shults, CW, Ray, J, Tsuboi, K, Gage, FH (2000) Fibroblast growth factor-2-producing fibroblasts protect the nigrostriatal dopaminergic system from 6-hydroxydopamine. Brain Res., 883: 192-204.

Shults, CW (2004) Neurotrophic factors. In: Movement disorders: neurologic principles and practice (2nd ed.) (Watts, RL, Koller, WC, eds), pp 131-142. New York: McGrawHill.

Shults, CW, Kimber, T, Martin, D (1996) Intrastriatal injection of GDNF attenuates the effects of 6-hydroxydopamine. Neuroreport, 7: 627-631.

Silva, RM, Ries, V, Oo, TF, Yarygina, O, Jackson-Lewis, V, Ryu, EJ, Lu, PD, Marciniak, SJ, Ron, D, Przedborski, S, Kholodilov, N, Greene, LA, Burke, RE (2005) CHOP/GADD153 is a mediator of apoptotic death in substantia nigra dopamine neurons in an in vivo neurotoxin model of parkinsonism. J. Neurochem., 95: 974-986.

Silverman, WF, Krum, JM, Mani, N, Rosenstein, JM (1999) Vascular, glial and neuronal effects of vascular endothelial growth factor in mesencephalic explant cultures. Neuroscience, 90: 1529-1541.

Silvian, L, Jin, P, Carmillo, P, Boriack-Sjodin, PA, Pelletier, C, Rushe, M, Gong, B, Sah, D, Pepinsky, B, Rossomando, A (2006) Artemin crystal structure reveals insights into heparan sulfate binding. Biochemistry, 45: 6801-6812.

Simon, H, LeMoal, M, Galey, D, Cardo, B (1974) Selective degeneration of central dopaminergic systems after injection of 6-hydroxydopamine in the ventral mesencephalic tegmentum of the rat. Demonstration by the Fink-Heimer strain. Exp. Brain Res., 20: 375384. 
Sjöstrand, D, Carlsson, J, Paratcha, G, Persson, B, Ibáñez, CF (2007) Disruption of the GDNF Binding Site in NCAM Dissociates Ligand Binding and Homophilic Cell Adhesion. J. Biol. Chem., 282: 12734-12740.

Sjöstrand, D, Ibáñez, CF (2008) Insights into GFR $\alpha 1$ regulation of neural cell adhesion molecule (NCAM) function from structure-function analysis of the NCAM/GFR 1 receptor complex. J. Biol. Chem., 283: 13792-13798.

Sleeman, MW, Anderson, KD, Lambert, PD, Yancopoulos, GD, Wiegand, SJ (2000) The ciliary neurotrophic factor and its receptor, CNTFR $\alpha$. Pharm. Acta Helv., 74: 265-272.

Slevin, JT, Gerhardt, GA, Smith, CD, Gash, DM, Kryscio, R, Young, B (2005) Improvement of bilateral motor functions in patients with Parkinson disease through the unilateral intraputaminal infusion of glial cell line-derived neurotrophic factor. $J$. Neurosurg., 102: 216-222.

Smith, MP, Cass, WA (2007) GDNF reduces oxidative stress in a 6-hydroxydopamine model of Parkinson's disease. Neurosci. Lett., 412: 259-263.

Sorice, M, Molinari, S, Di Marzio, L, Mattei, V, Tasciotti, V, Ciarlo, L, Hiraiwa, M, Garofalo, T, Misasi, R (2008) Neurotrophic signalling pathway triggered by prosaposin in PC12 cells occurs through lipid rafts. FEBS J., 275: 4903-4912.

Spina, MB, Hyman, C, Squinto, S, Lindsay, RM (1992) Brain-derived neurotrophic factor protects dopaminergic cells from 6-hydroxydopamine toxicity. Ann. NY Acad. Sci., 648: 348-350.

Srinivasan, S, Anitha, M, Mwangi, S, Heuckeroth, RO (2005) Enteric neuroblasts require the phosphatidylinositol 3-kinase/AKT/Forkhead pathway for GDNF-stimulated survival. Mol. Cell. Neurosci., 29: 107-119.

Studer, L, Csete, M, Lee, SH, Kabbani, N, Walikonis, J, Wold, B, McKay, R (2000) Enhanced proliferation, survival, and dopaminergic differentiation of CNS precursors in lowered oxygen. J. Neurosci., 20: 7377-7383.

Sun, PD, Davies, DR (1995) The cystine-knot growth-factor superfamily. Annu. Rev. Biophys. Biomol. Struct., 24: 269-291.

Tadimalla, A, Belmont, PJ, Thuerauf, DJ, Glassy, MS, Martindale, JJ, Gude, N, Sussman, MA, Glembotski, CC (2008) Mesencephalic astrocyte-derived neurotrophic factor is an ischemia-inducible secreted endoplasmic reticulum stress response protein in the heart. Circ. Res., 103: 1249-1258.

Takahashi, M, Ritz, J, Cooper, GM (1985) Activation of a novel human transforming gene, RET, by DNA rearrangement. Cell, 42: 581-588.

Tanaka, M, Xiao, H, Kiuchi, K (2002) Heparin facilitates glial cell line-derived neurotrophic factor signal transduction. Neuroreport, 13: 1913-1916.

Tansey, MG, Baloh, RH, Milbrandt, J, Johnson Jr, EM (2000) GFR $\alpha$-mediated localization of RET to lipid rafts is required for effective downstream signaling, differentiation, and neuronal survival. Neuron, 25: 611-623.

Taraviras, S, Marcos-Gutierrez, CV, Durbec, P, Jani, H, Grigoriou, M, Sukumaran, M, Wang, LC, Hynes, M, Raisman, G, Pachnis, V (1999) Signalling by the RET receptor tyrosine kinase and its role in the development of the mammalian enteric nervous system. Development, 126: 2785-2797. 
Tomac, A, Widenfalk, J, Lin, LF, Kohno, T, Ebendal, T, Hoffer, BJ, Olson, L (1995) Retrograde axonal transport of glial cell line-derived neurotrophic factor in the adult nigrostriatal system suggests a trophic role in the adult. Proc. Natl. Acad. Sci. USA, 92: 8274-8278.

Treanor, JJ, Goodman, L, de Sauvage, F, Stone, DM, Poulsen, KT, Beck, CD, Gray, C, Armanini, MP, Pollock, RA, Hefti, F, Phillips, HS, Goddard, A, Moore, MW, Buj-Bello, A, Davies, AM, Asai, N, Takahashi, M, Vandlen, R, Henderson, CE, Rosenthal, A (1996) Characterization of a multicomponent receptor for GDNF. Nature, 382: 80-83.

Trupp, M, Arenas, E, Fainzilber, M, Nilsson, AS, Sieber, BA, Grigoriou, M, Kilkenny, C, Salazar-Grueso, E, Pachnis, V, Arumae, U (1996) Functional receptor for GDNF encoded by the c-RET proto-oncogene. Nature, 381: 785-789.

Trupp, M, Belluardo, N, Funakoshi, H, Ibáñez, CF (1997) Complementary and overlapping expression of glial cell line-derived neurotrophic factor (GDNF), c-RET proto-oncogene, and GDNF receptor- $\alpha$ indicates multiple mechanisms of trophic actions in the adult rat CNS. J. Neurosci., 17: 3554-3567.

Trupp, M, Scott, R, Whittemore, SR, Ibáñez, CF (1999) RET-dependent and -independent mechanisms of glial cell line-derived neurotrophic factor signaling in neuronal cells. $J$. Biol. Chem., 274: 20885-20894.

Vaccaro, AM, Salvioli, R, Tatti, M, Ciaffoni, F (1999) Saposins and their interaction with lipids. Neurochem. Res., 24: 307-314.

Vaidya, VA, Duman, RS (2001) Depresssion--emerging insights from neurobiology. $\mathrm{Br}$ Med Bull, 57: 61-79.

Virtanen, H, Yang, J, Bespalov, MM, Hiltunen, JO, Leppänen, V-M, Kalkkinen, N, Goldman, A, Saarma, M, Runeberg-Roos, P (2005) The first cysteine-rich domain of the receptor GFR $\alpha 1$ stabilizes the binding of GDNF. Biochem. J., 387: 817-824.

Voutilainen, MH, Back, S, Porsti, E, Toppinen, L, Lindgren, L, Lindholm, P, Peranen, J, Saarma, M, Tuominen, RK (2009) Mesencephalic astrocyte-derived neurotrophic factor is neurorestorative in rat model of Parkinson's disease. J. Neurosci., 29: 9651-9659.

Wang, CY, Yang, F, He, XP, Je, HS, Zhou, JZ, Eckermann, K, Kawamura, D, Feng, L, Shen, L, Lu, B (2002) Regulation of neuromuscular synapse development by glial cell line-derived neurotrophic factor and neurturin. J. Biol. Chem., 277: 10614-10625.

Wang, S, Elitt, CM, Malin, SA, Albers, KM (2008) Effects of the neurotrophic factor artemin on sensory afferent development and sensitivity. Sheng Li Xие Bao, 60: 565-570.

Wang, X, Baloh, RH, Milbrandt, J, Garcia, KC (2006) Structure of artemin complexed with its receptor GFR $\alpha 3$ : convergent recognition of glial cell line-derived neurotrophic factors. Structure, 14: 1083-1092.

Worley, DS, Pisano, JM, Choi, ED, Walus, L, Hession, CA, Cate, RL, Sanicola, M, Birren, SJ (2000) Developmental regulation of GDNF response and receptor expression in the enteric nervous system. Development, 127: 4383-4393.

Xue, YQ, Zhao, LR, Guo, WP, Duan, WM (2007) Intrastriatal administration of erythropoietin protects dopaminergic neurons and improves neurobehavioral outcome in a rat model of Parkinson's disease. Neuroscience, 146: 1245-1258. 
Yamagata, M, Sanes, JR, Weiner, JA (2003) Synaptic adhesion molecules. Curr. Opin. Cell. Biol., 15: 621-632.

Yasuhara, T, Shingo, T, Kobayashi, K, Takeuchi, A, Yano, A, Muraoka, K, Matsui, T, Miyoshi, Y, Hamada, H, Date, I (2004) Neuroprotective effects of vascular endothelial growth factor (VEGF) upon dopaminergic neurons in a rat model of Parkinson's disease. Eur. J. Neurosci., 19: 1494-1504.

Yasuhara, T, Shingo, T, Muraoka, K, Kameda, M, Agari, T, Wen Ji, Y, Hayase, H, Hamada, H, Borlongan, CV, Date, I (2005) Neurorescue effects of VEGF on a rat model of Parkinson's disease. Brain Res., 1053: 10-18.

Yayon, A, Klagsbrun, M, Esko, JD, Leder, P, Ornitz, DM (1991) Cell surface, heparinlike molecules are required for binding of basic fibroblast growth factor to its high affinity receptor. Cell, 64: 841-848.

Ylikoski, J, Pirvola, U, Virkkala, J, Suvanto, P, Liang, XQ, Magal, E, Altschuler, R, Miller, JM, Saarma, M (1998) Guinea pig auditory neurons are protected by glial cell linederived growth factor from degeneration after noise trauma. Hear. Res., 124: 17-26.

Young, HM, Hearn, CJ, Farlie, PG, Canty, AJ, Thomas, PQ, Newgreen, DF (2001) GDNF is a chemoattractant for enteric neural cells. Dev Biol, 229: 503-516.

Yu, T, Scully, S, Yu, Y, Fox, GM, Jing, S, Zhou, R (1998) Expression of GDNF family receptor components during development: implications in the mechanisms of interaction. $J$ Neurosci, 18: 4684-4696.

Zaltash, S, Johansson, J (1998) Secondary structure and limited proteolysis give experimental evidence that the precursor of pulmonary surfactant protein B contains three saposin-like domains. FEBS Lett., 423: 1-4.

Zhai, Y, Saier, MHJ (2000) The amoebapore superfamily. Biochim. Biophys. Acta, 1469: 87-99.

Zhang, Z, Miyoshi, Y, Lapchak, PA, Collins, F, Hilt, D, Lebel, C, Kryscio, R, Gash, DM (1997) Dose response to intraventricular glial cell line-derived neurotrophic factor administration in parkinsonian monkeys. J. Pharmacol. Exp. Ther., 282: 1396-1401. 